
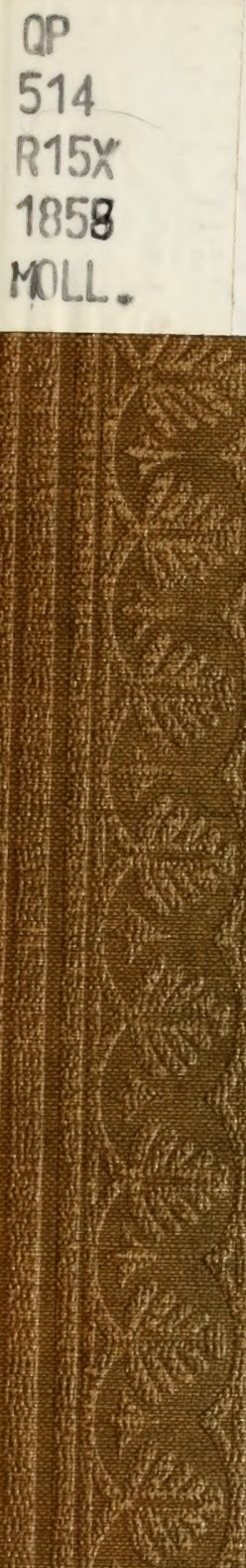

3.7. 3.7. 5.t. 5.m.

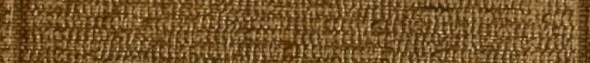
Th:

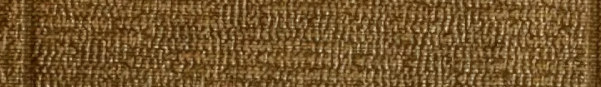
4)

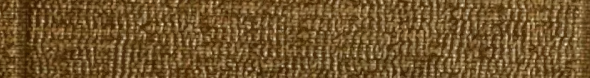

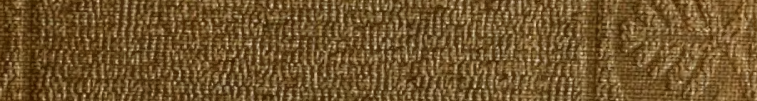
3.7. H. W

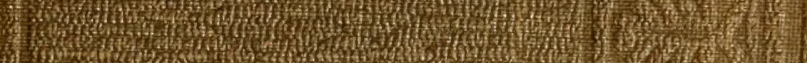

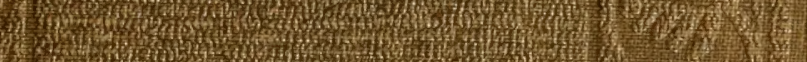
W.1. H.

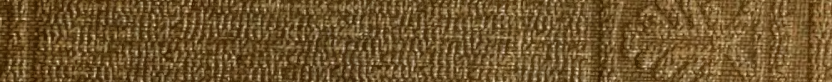
TH:

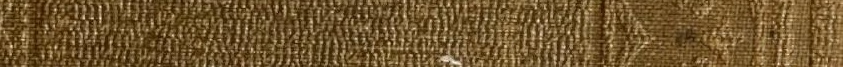
3 r. 4.7. 3. (n)

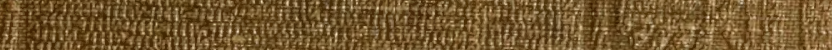

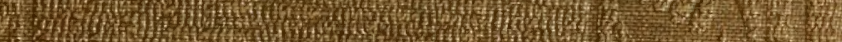
Inth

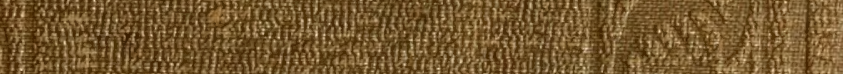

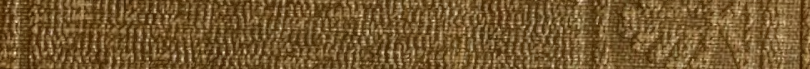
thom

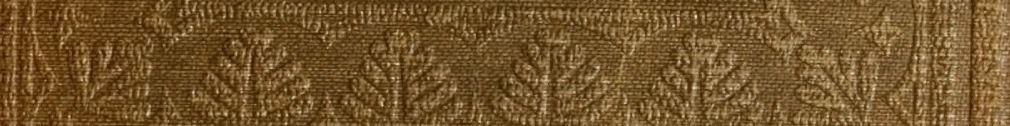

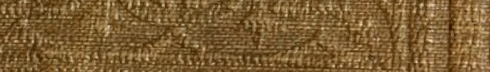

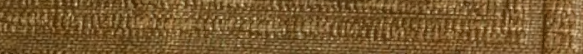




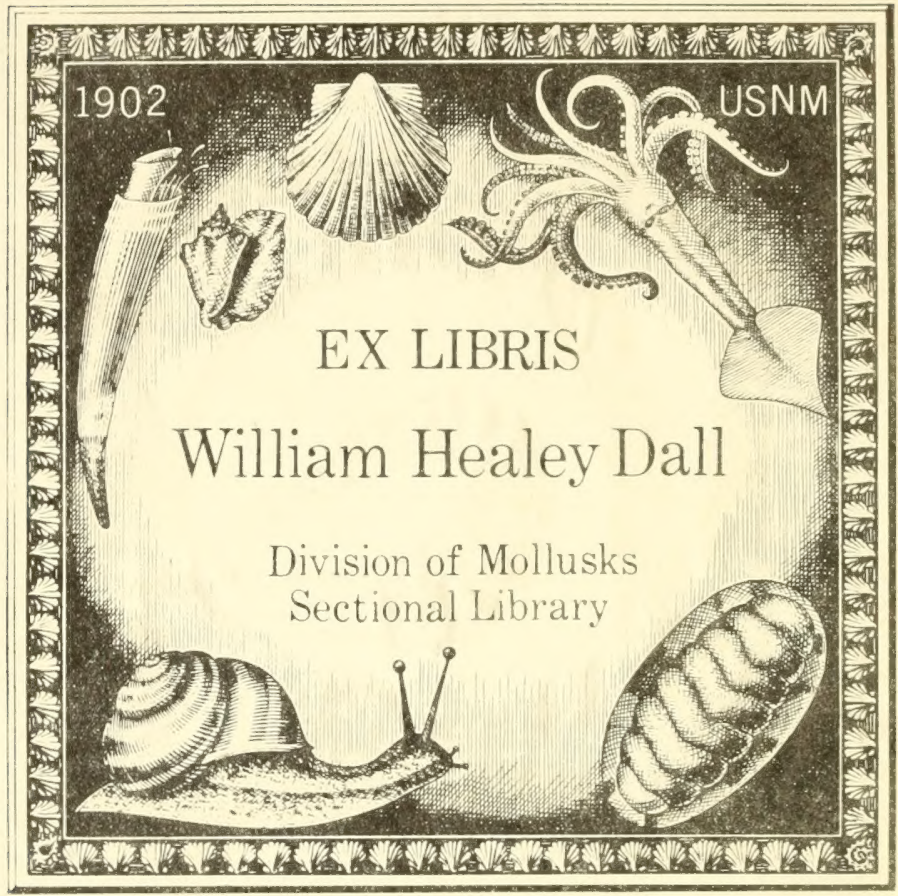




THE

\section{MODE OF FORMATION}

SHELLS OF ANIMALS, \&c. 

PRINTED BY J. E. ADLARD, BARTHOLOMEW CLOSE, 
PREF A CE.

A GREAT variety of subjects being treated of in the following pages, it must follow that some of the facts and views therein mentioned have been previously described or suggested by others; but as the facts and views to which I allude are for the most part of a general character, and of dubious authority, I have thought it better to refrain from mentioning names in connexion with them, than to attribute their origin to wrong authors, especially as the mention of them here will not in any way interfere with the claim to priority of those with whom they originated. I may observe that a portion of the matter comprised in the following treatise has already appeared in the 'British and Foreign Medico-Chirurgical Review' for October, 1857, and a portion in the 'Quarterly Journal 
of Microscopical Science,' for January, 1858; but that many fresh facts, both physical and anatomical, are here introduced for the first time. What in this treatise I consider to have entirely originated with myself, are-Firstly, a process by which carbonate of lime can be made to assume a globular form, and the explanation of the nature of the process, "molecular coalescence," by which that form is produced. Secondly, the explanation of the probable cause of crystallization, and the manner in which the rectilinear form of crystals is effected. Thirdly, the discovery of a process of "molecular disintegration" of the globules of carbonate of lime by inverting the mechanical conditions upon which their previous globular form had depended. Fourthly, the recognition, in animal tissues, of forms of earthy matter analogous to those produced artificially. And fifthly, the deduction from the above fact, and considerations of the dependence of the rounded forms of organized bodies on physical and not on vital agencies. Being anxious to present the results of my experiments and observations to the public in as demonstrable a form as possible, I have, for the convenience of those who wish to repeat and to extend them, given in detail all 
my processes and formula ; and in the Physiological Section of this work I have indicated the animals and parts best fitted for displaying the facts here described, with the best way of preparing them for microscopical examination. And in conclusion I may add, that I shall be glad to show, to such as are interested in the subject, those preparations in my possession which have been frequently referred to in the body of this work.

G. R.

9, Church Road, Honerton;

October, 1858. 



\section{CONTENTS.}

Introductory observations

Process for making Artificial Calculi . . . 5

Mode of mounting Artificial Calculi . $\quad$. $\quad$. 7

Explanation of the process of Coalescence . . . S

Attraction of Gravitation the cause of Coalescence . 14

$\begin{array}{lllllll}\text { Molecular agitation } & \text {. } & \text {. } & & 16\end{array}$

Molecular disintegration . . . . . 15

Dumb-bell-shaped Calculi . $\quad$ - $\quad$. $\quad 19$

Elliptical Calculi becoming spherical and laminated . $\quad 20$

Density of Calculi varies as the distance from the centre . 22

Another cause of Lamination . . . . 24

Flat appearance of Calculi under the microscope $\quad 25$

Calculi formed by the coalescence of several small ones . 25

Inertia the cause of Lamination a d . $\quad 27$

Coalescence of Large Calculi similarly laminated . . 25

Radiating lines in Calculi . . . . $\quad 30$

Nature and cause of Crystallization . . . 30

Rectilinear arrangement to the effect of a separating force . $3 \mathrm{I}$

Tenacity or attraction of tenacity $\quad$ - $\quad 32$

Calculi composed of carbonate of lime and triple phosphate 34

Change of the crystalline into the globular form . . 36

Effect of globular carbonate on glass . . 35

Attraction of tenacity neutralized . . $\quad 40$

Change from the globular to the crystalline form by heat . 41 
Sudden productions of Crystals by heat

Crystallization the effect of an impulsive force

The impulsive force causing Crystallization inferred to be Electricity

Explanation of the mamner in which rectilineal forms are produced

Explanation of the mode of production of radiating lines in Calculi

Complete molecular disintegration

Experiment showing complete molecular disintegration produced by keeping Calculi in a denser solution.

Experiments showing complete molecular disintegration in Calculi composed partly of vegetable matter

Experiment showing complete molecular disintegration by depositing carbonate of lime upon Caleuli perfectly performed

Time an element in the operation both of coalescence and disintegration

The form of ultimate Molecules or Atoms

Physiological Part.-Introductory observations . . 72

Formation of Calculi found in the Urine of the Horse . 72

These Calculi considered as organic formations . . 72

Viervs of the Cell-germ theory . . . it

Mode of formation of Calculi occurring in the Urine of the Horse $\quad 75$

Vitality not connected with the formation of these Calculi . $\quad 76$

"Aninal basis" exists in Artificial Calculi-Experiment showing the fact . . . . . . 77

Structure of the Shell-tissue in Crustaceans. . . 78

Vertical section of the Crab-shell-Precautions in grinding them 82

Crav-fish well suited for the examination of Shell-tissue o $\quad 83$

The radiating lines explained, not tubules . . $\quad 94$

The structure of Crab-shell compared with Trory . $\quad 86$

The Dentinal Canals not regular Tubules a d $\quad 87$

Regular tubes in Shells not analogous with so-called Dentinal Tubes . . . . . . SS

The part of Crab-shell called Apodemata well adapted for showing molecular coalescence 
Comparison of Natural and Artificial Products.

Alkaline C:ubonate formed on surface of Crustaceans covered with Shell . . . .

Chemical conditions for the formation and coalescence of Carbonate of Lime in Crustaceans . .

The part which vitality takes in the formation of Organic Structures . . .

Formation and coalescence of Carbonate on the Apodemata of Crab. . . . .

Chemical conditions necessary for the formation of Carbonate of Lime on the Apodemata . . . $\quad 97$

Blastema, its signification, according to both views _ $\quad 97$

On the Shells of Molluses . . . . 98

Part of the Shell of Oyster best for examination . $\quad 101$

Lime composing the Carbonate comes directly from the water . 102

The Nacreous Lustre not due to the plications of Membrane 103

Chemical conditions for the formation of Carbonate in Oyster . 104

The formation of Interlaminar Cavities in Oyster . 105

The ultimate of the Carbonate of Lime in the Shells of Molluses 106

Amorphous state of Carbonate in Oyster-shell . . 107

Confervæ in Oyster-shell . . . 107

Arguments against the view of Cells being formed first, and the

Carbonate deposited in them . . I0S

Formation of Carbonate of Lime on Membranes have marking $\quad 110$

Rhombohedral masses resembling Crystals . . 111

"Prismatic Cellular Substance" in shell of Pima . . . 111

Structure and formation of Bone . . . . 114

Use of Carbonate of Lime in Bone . . . . 116

Formation of Lacunæ and Canaliculi . . . . 118

The Nucleus in Lacunæ . . . . 121

The use of Lacunie, Canaliculi, \&c. . . . $\quad 124$

The chemical conditions under which the earthy matter is deposited . . . . . 127

Sclerous vegetable tissue . $\quad$. $\quad$. $\quad 130$

Formation of less dense tissues by coalescence . . 131

The physical explanation applies to the formation of tissues not to their function

Cartilage compared with artificial products . . 135

Pigment-cells, development of . . . 136 

of the cysticereus cellulosx.

Crystalline lens of Fish . . . . . . 138

The way to examine the Crystalline Tsens . 139

$\begin{array}{ll}\text { Structure of the Crystalline Lens of Stickleback } & 140\end{array}$

Development of Crystalline Lens . . . 144

Concluding observations on the Analogy of Nature $\quad 152$ 


\section{FORMATION OF SIIELLS OF ANIMALS,}

$$
\S c .
$$

Tne observations about to be made upon the mode of formation of organic structures, rest upon the fact, that, by a proper cmployment of chemical and mechanical means, and by an exact adjustment of the conditions under which they act, caleareous bodies, identical in structure and similar in composition to the elementary forms of the structures above mentioned, can be artificially produced. It will therefore be neessary, first, to describe minutely the artificial process for obtaining these bodies, and to explain the mamner in which the physical and rhemical agencies thereiu engaged act in producing them: and, sccondly, to show that, wherever natural products are found identical in strueture with the artificial ones, the existence of plysical and ehemical conditions, similar to those associated in the artifieial process, can be demonstrated.

Hence the subjects amomed in the title fall naturally under two heads: onc, embracing all such considerations as are strictly physical, and admitting of experimental demonstration, without any possible interference from 
vitality, belongs to physies. The other, though commeted with structures cxhibiting the same class of appearinees, and being of a similar composition, but oceurring in living parts, and therefore variously interfered with in their development by vitality, belongs to physiologry.

I shall discuss the plysical part of this paper as hricty as the extent and importance of the subject will permit, and introduce into it nothing which is not cither directly or indirectly connected with physiology ; lout it may not be amiss to obscrve, that the commexion of the two parts is so intimate, that the latter will not be intelligible without an adequate acquaintance with the former.

The chemical substances to be employed in the production of the artificial calculi are, a soluble compound of line, aud carbouate (sub-carbonate of the old phamacopocias) of potash or sola, dissolved in separate portions of water; and some riscid regetable or animal substance, such as gum or allumen, to be mixed with each of these solutions. And the mechanical conditions required to act in conjunction with the chemical means, are the presence of such a quantity of the viscid matcrial in cach solution as will be sufficient to make the two solutions, when mixed together, of about the same density as that of the nascent rarbonate of lime, and a state of perfect rest of the fluid in which the decomposition is going on; so that the newly-formed compound may be initerfered with as little at: poxilble in its subsidence to the sides and bottom of the rescel. 'Tllis will require two or three weeks, or binerer, according to the size and completeness of the salcoli. But I lave not found that they increase at all after sir weeks.

Xnw, fiom this process there result- the simple though r.ry intportant daet. that when the carbonate of line thus 
formed is in a solution of a viscid material, its form, in the place of being erystalline as when produced in the same manner in pure or common water, is globular, and that in this state it possesses, in a remarkable manner, the property of coalescing with contiguous particles of the same compound, as well as of intimately blending with such substances as, in its molecular state, it may happen to be brought into contact with; so that the minute spherules in which it first appears, if allowed to remain sufficiently long within the spliere of their mutual attractions, coalesce into large, spherical, transparent calculi, which, if suffered to remain a suficient time on the surface of a glass slide, will leare permanently impressed upon it the form of the part of the calculis which was in contact with the glass. On reflecting npon these properties of this form of carbonate of lime, and contrastius the conditions under which it is formed in the experimental process, with those which I considered would most probably be found to be present in animal calcifying tissues-the earbonate being in these formed and deposited in contact with a certain amount of riscid anmal matter-I expected to find the same form of carbouate existing in the carlicst states of calcification of animal tissues, and possessed of the same property of coalescing and intimately blendine with contignous structures, as that produced artificially. Tinder this impression I commeneed the cxamination of shell-structures; but, though espertines to find some analogy, I had no thomele of necting with :0 perfect at

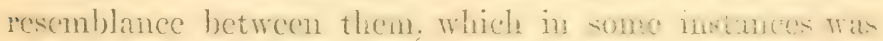
o complete, that, in sume!l portions of the two proulurts

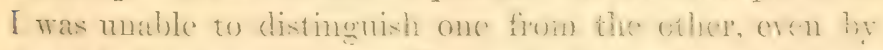

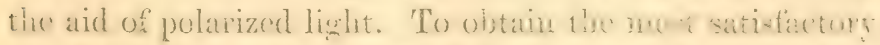

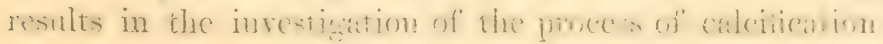


of animal tissues, it is indispensably necessary that the parts examined slould be in the earliest stages of the process, and before the caleifying membrane is entirely covered with the globular coalescing deposit. The usual plan of examining shells in thin vertical sections is entirely useless, unless it be simply to see the number and arrangement of their layers; the part of the section in such specimens, in which the calcifying process ought to be best seen, being entirely ground off. This part, being the softest, can only be preserved in the process of grinding by extreme eare, and by keeping the lower edge of the section always thicker than the upper.

Now, as the perfect resemblance of the globular form of the carbonate of lime, as prepared artificially, and as occurring in uature, indicates a corresponding similarity in the nature of the process by which they are formed, and an identity of the forees concerned in their formation, the careful experimental investigation of the precise mode of formation of the artificial products cannot fail to throw great light upou the genesis of the natural ones, and thus tend to emancipate this department of histology from the obscurity in which it now lies, and bring it under the domain of experimental physical science. Besides, I may add that the artificial calculi, when carefully and properly prepared, present the microscopist with a new class of polariscope oljects not exceeded in beanty or brilliansy by any others. But even these optical phenomena, and the physical facts comected with them, mar, when more minutely investipated, be found to possess ofler points of interest besides their mere appearance; for, occurring as they do in bodies whose molecular constitution and mode of formation can be demonstrated, they ought to open new avcunes to a more complete mulerstanding of the 
nature of polarized light, and to a more accurate knowledge of the cause of crystallization. Upon the former of these topies I shall not be able to touch in this paper, but I shall offer some observations upon the latter. This globular form of carbonate of lime was first observed by me in 1819, and was shown at that time to sereral of my fricuds; but I did not discover its gencral properties, and its existence in organic products, until the year 1856 . I may observe, howerer, that in the interval between these dates I had carefully examined a variety of morbid products, especially a form of corpuscle called by pathologists "glomerulus," whose globular form I felt convinced was due to a mechanical cause; and that from this conviction I was led to the further examination of the bodies I had discovered in 1849.

After numberless experiments made with a view to determine the process best adapted for furnishing these calculi of the largest size, and in the shortest space of time, I found the following to answer best, which, if strictly followed, will nerer fail to ensure satisfactory results. This process is giren in the "Transactions of the Microscopical Socicty,' published in the 'Quarterly Journal of Microscopical Science' for January, 1858. It consist. in introducing into a two-cunce phial, about three inches in licight, with a mouth about one inch and a quarter in width, half an ounce by measure of a solution of gum arabic saturated with carbouate of potash (the sub-carbonate of the old pharmacopocias). The specific gravity of the compound solution should be 1.4068, when one ounce will weigh $6 \% 2$ grains. This solution must be perfectly clear; all the carbonate of lime which had been formed by the decomposition of the malate of lime contained in the gum, and also all the triple phosphate set 
free by the alkali, must have been allowed completely to subside. Next, two clean microscopic slicles of glass, of the ordinary dimensions, are to be introdueed, witli the upper end of one slide resting against that of the other, and with their lower cnds separated as far as the width of the phial will permit; and lastly, the bottle is to be filled up with a solution of gum arabic in common water, of $1 \cdot 08+1$ specific gravity, one ounce of which will weigh 5:20 grains. This solution must also be perfectly clear, having been first strained through cloth, and then left to stand for some days to allow of the subsidence of all the floating vegetable matter, It must also be added carefully to the alkaline solution, that the two solutions may be mixed as little as possible in this part of the process. The bottle must now be kept perfectly still, corered with a picee of paper to prevent the admission of dust, for three weeks or a month. Time would be saved by having a dozen bottles thus charged, and examining their contents at stated intervals, according to the chief object sought for in the experiment. The soluble salts of lime to be decomposed by the sub-carbonate of potash are contained in the gum, in combination with malic acid, and also in the common water; ammoniaco-magnesian, or triple phospliate, is also contained in the gum, and is set free by the alkali. Muriate of lime, dissolved in a solution of gum from which all the lime had been previously separated, would answer a similar purpose, provided the muriate were not in too great excess for the gum, in which case crystals of carbonate would be formed together with the globules, and the surface of the slide would become covered with coalescing patches of the latter. Also muriate of barytes, and muriate of strontia, when treated in the same manner as the muriate of lime, furnish each a globular carbonate, 
the splicrieal form of the latter being particularly perfect and benutiful. But muriate of magnesia, when decomposed in the same manner, and under precisely the same conditions, does not furnish globules, but crystals of carbonate of magnesia, evincing no tentency to become globular.

After the slides have been withdrawn from the bottle, all the globules deposited on their upper surface may be rubbed off with the finger, or, if very closely adherent, washed off with muriatic acid, care being taken that it does not touch the elge of the slide, and so reach the opposite surface. Afterwards, the lower surface, which has the clearest and most perfect globules upon it, must be well washed for sereral minutes, or half an hour, by a stream of water ruming from a tap, so that all the gum may be removed. It will then be necessary to wash it well in distilled water, in order that no deposit from the impure water may be left on the glass when it is dried. The specimen, especially if it is to be put up in Canada balsam, should now be further dried, on a plate placed over boiling water, and afterwards washed with oil of turpentine. In mounting these calculi in Camada balsam, the balsam must not be boiled on the same slide as the calculi, as, in this case, the heat employed being too intense, would cause the calculi, containing triple phosphate in combination with the carbonate, to become filled with rhomboidal erystals; but the balsam, inspissated on another slide, may be poured hot upon the one having on it the globules. Lastly, a thin glass corer of the width of the slide may be placed upon it, resting at each end upon a ledge of thin glass. The deposit which remains in the bottle may be next examined, and put up in any way that may be thought proper. The large calculi contained 
therein are not quite so clear as those adherent to the lower surface of the slide, but in many respects they are more like natural calculi.

The smaller ones are more accurately elliptical than those on the slide, the mechanical conditions under which they are formed being less interfered with by the attraction of the glass.

Among the facts deducible from a careful examination of the results of these experiments, the most remarkable and inportant is the perfect conlescence into one of two or more globules of caibonate of lime, as much as $\frac{1}{12} 5$ of an inch in diameter, perfectly transparent, of a hardness nearly equal to that of glass, and giving the sensation, when rubbed forcibly by the finger on a smooth, hard surface, of small glass beads; the incorporation of these globules being so coniplete, that the resulting one has the same spherical form, the same degree of transpareney, and the same hardness and structure as the component ones. Let it be observed, moreover, that this is effected without any possible assistance from the application of external force or messure, and that therefore it can only be produced by the mutual attraction of the two globules.

Now, in order thoroughly to molerstand the cause of this singular fact, and the manner in which the physical forces, upon whose operation it depends, act in producing it, every step of the process will require to be carefully and minutely considered. For this purpose, small portions of the two solutions before mentioned may be introduced under a piece of thin glass fixed to a microsecpic slide, and examined by the microscope with different magnifying powers while the solutions are blending together and the carbonate of lime is in progress of formation. The appearance which is first risible is a faint 
nebulosity, at the line of union of the two solutions, showing that the particles of earbonate of lime, when they first come into existence, are too minute to arlmit of being distinguished individually by the highest power's of the microscope. (This examination was made with one of Ross's best lenses of $\frac{1}{8}$ of an inch focus. See Fig. 1, a.)
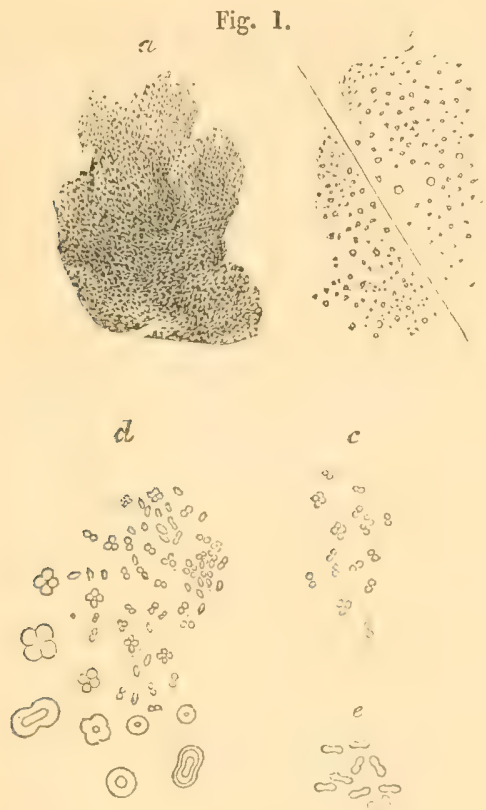

In a few hours exquisitely minute spherules, too small to allow of accurate measurement, can be seen in the nebulous part, a portion of which has disappeared, and is replaced by these spherical particles. (See Fig. 1, b.) Examined at a later period, dumb-bell-like bodies will have made their appearance, and with them elliptical par- 
ticles of diflerent degrees of excentricity, some containing within them one or more ellipses, nore or less complete, and parallel with the onter one. (Soc Fig. 1, $c$, e, and d.) For the further examination of the globular carbonate, it will be necessary to have recourse to those formed on the slides, and to the deposit contained in the bottles above mentioned. I may ohserve, that mixed with these calculi, there are all those forms, with the exception of the nebulous one, which I have just deseribed. Fig. : ( $"$ and $b$ ) represents the forms of some of those contained

Fig. 2.

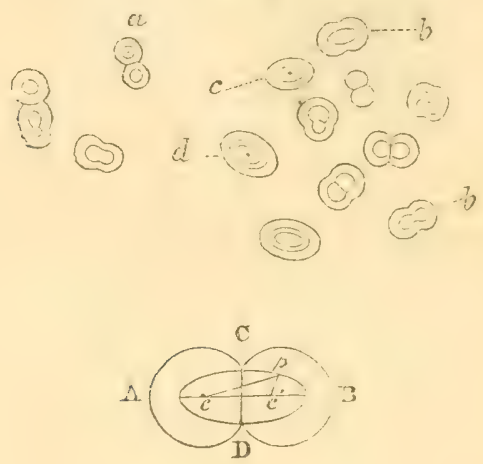

in that deposit, and Fig. 3 represents calculi as they are found on the under surface of the slides. Fig. 4 represents one form of globule sometimes found both in the deposit and on the slicles, as well as the most perfect forms of the laminated calculi with radii. As these figures, being correct delincations of the artificial products, will be minutely referred to when treating of the subject of molccular coalescence, it will not be necessary to gire a written description of the forms of calculi of 
which they are the aceurate representations, and therefore I may at once proeced to consider the cause of these several appearances, and the manner in which this cause acts in producing them. Besides, these ealeuli being easily prepared by following earefully the directions already given for their preparation, the various appear-

Fig. 3.

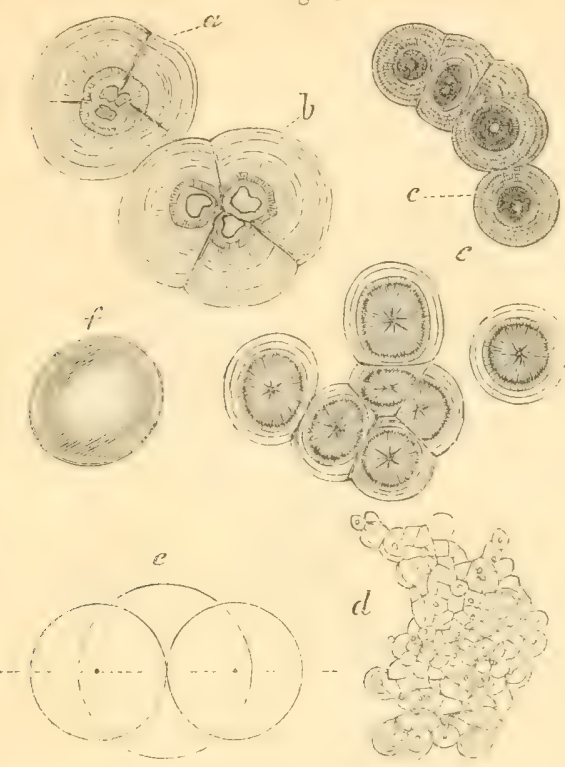

ances which they present in their several stages of formation can be observed by any one who likes to prepare them on specimens of his own making.

To show that the appearances presented by the carbonate of lime, as they are seen in the first experiment, fully justify the inference which has been deduced from 
them, namely, the existence of a physical process of coalesecnee of hard, solid, globular bodics, by means of their mutual attraction, it may be observed, that the presence of these globular and oval particles, as there noticed, can only be accounted for in one or other of two ways: either these must have been the forms and dimensions which they first assumed at the instant of their coming into existence as solid bodies, or these forms and dimensions must have resulted from the aggregation of preexisting smaller particles. Now, as in the earliest stage

Fig. 4 .
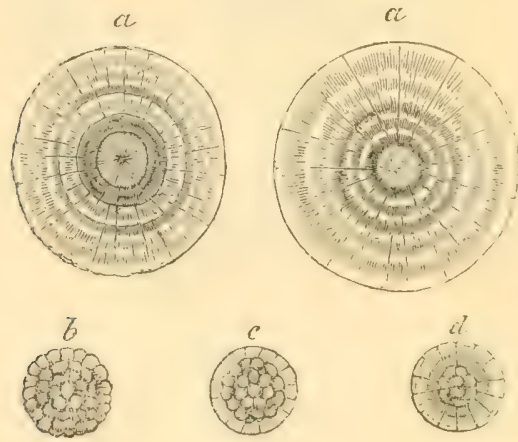

of this experiment none of the larger globular and oval particles are visible, whilst the minutest ones ahound, producing the nebulosity before mentioned-it being only at a subsequent period, and after much of the nebulosity has vanished, that the larger globules make their appearance-it is certain, as far as ocular proof can make it, that the larger globular and oval particles are not the first or elementary forms of the carbonate of lime occurring in this experiment; and henee it must follow that the sceond 
is the only way of accounting for them-that is, that they result from the union and intimate blending together of pre-existing minuter particles. The same train of reasoning applies equally to the larger and more complex forms of these calculi, as represented in Figs. 3 and 4 , with this additional fact, that the secondary forms, which by their urion form the largest calculi, possess characters sufficiently marked to render them individually recognisable, both when grouped together into spherieal masses to form compound calculi, and when passing through their various changes of form, even almost up to their complete coalesence into one perfectly spherieal body. For the satisfactory examination of these changes of form jolarized light is indispensably necessary. Now, as in such a group as that represented at fig. $3, c$, there is no mechanical reason deducille alone from its gencral figure which can account for the fact of its contour being made up of ares of rery difierent lengths, though of circles of nearly the same radius, and for the ares of the two extreme pieces being each of thein so much longer than that of the middle piece, the explanation must be sought for in some cause v:hich had acted upon the individual fragments; but as there is no conceivable combination of mechanical forces which could have produced one part of any one of these fragments of spheres without at the same time producing its counterpart, these pieces must have had, when separate, a form difierent to that which they have when combined, and that form, from the figure of the different fragments, may be inferred to have becu spherieal. Ilence it remains now to demonstrate in what mamer the spherical figure is first given to the component globules, and, after that, to slow how these become incorporated in these of the larger size, so as to resilt in the production 
of ealculi of the same globular form and of the same structure as those of which they are marle up.

As every particle of matter, whatever may be its form or dimensions, is admitted by philosophers to be under the influence of gravity, to mhich law, if universal, the molecules of carbonate of lime, as produced in the manncr alrearly described, can form no exception, it must follow that, the instant they are brought into existence, they will commence arranging themselres in splicrical figures, unless there should be some other forec of an opposite kind acting upon them, adequate either entirely to orercome that of gravity, or sufficient only imperfectly to resist its influcnce; in which ease results of an intermediate lind would be produced, depending upon the relative powers and modes of opcration of the opposing ancucies. Now, as it is an undoubted fact, and one anmitting of ocular demonstration, that the particles of carbonate of lime formed by the double decomposition of a salt of lime and carbonate of potash previously dissolved in a solution of veretable snm, or of albunen of about the samo density as the resulting earbonate, do assume, as their first appreciable form, that of minute spherules, and as this is exactly the figure which the molecules composing these particles would assume under the mechanical conditions in which they are placed, if they were simultancously subjected to the effective influence of gravitation, that is, if they attracted one another with a force varying inrepely as the squares of the distanees between them, and direetly as the quantity of matter in each molecule; the shlunicity of these particles may be inferred to be the diecet of pravity. And, besides, as there is no other

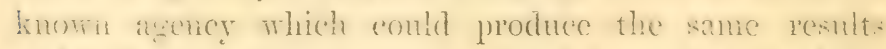

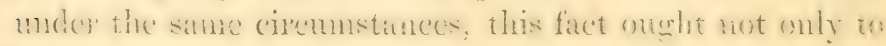


be looked upon as the effect of gravity, but also as a proof of it. There is no question but these molecules or atoms are of inconceivable minuteness, and the spaces betrecn them, when they first come into existence, incomprehensibly small; yet, as they are material existences, and the distances between them real spaces, they necessarily come within the scope of a power which is admitted to be of universal operation. If this conchusion is inaduissible, then the operation of gravity is not universal. The mode of formation of the first set of spherical particles of carbonate of lime being considered, it remains to offer a few remarks on the mamner in which these coalesce to produce the larger calculi. Now, as it has been demonstrated br Newton, that, in a splicre the total attraction resulting from the particular attractions of all its component atoms is the same with respect to any body drawn towards it, as if all the attracting particles had been conecutrated at the centre, these minute spherical particles, as so many gravitating points, will be drawn towards each other with a force varying inverscly as the squares of the distances between their respectire centres; hence, beines contaneci in a fiud medium of an equal density, or nearly so, in which all external sources of attraction will be countrracted, it is evident that they will, by their mutual attraction alone, form themselves into spherical collections or masses. Now, as every one of the spherieal particles entering into the composition of each of these masses is built mp of molecules, so disposed aromel its centre that erery molecule is balaneed and kept in its place ly the attraction of some other molecule on the opluscite side of the centre, no one of these particles can manintain its

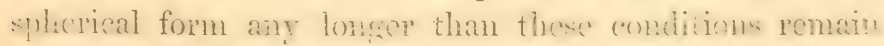

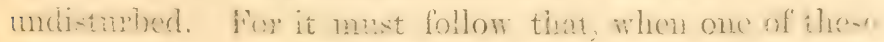


spherules is brought into apposition with another of the same lind, as must take place in the supposed conglomerations, the molecules of their adjacent sides will be differently attracted from those of the remote ones, and the balaneal condition of the molecules in both will be destroyed. Hence, the molecules which were before contact at perfect rest, being then between cqual and opposite attracting forces, will now he thrown into a state of molecular agitation, which must continue until all the molecules of the two spherules have arranged themselves around only one centre, and ultimately become blended into one perfectly spherical figure, when the mechanical conditious necessary for molccular stasis will have become restored. The change of form which spherical particles undergo as they are in progress of coalescence into spheres of larger size being attended with a certain amount of motion of their component molecules, renders it certain that these molecules in the individual spherules were not in a state of absolute contact. In this respect these bodies are like all other hard substances; it being admitted, with the complete sanction of fact and experiment, that the atoms of all substances, however dense, are at an inappreciable distance apart. The fact of this motion is shown by the simple inspection of fig. 3 , e, which represents the sections of two calculi of equal size placerl in contact, also the section of one which would result from their union, whose proper situation and relative size is intended to be constructed in accordance with the fact of the eapacities of spheres being as the cubes of their radii. The two molecules at the point of eontact of these two spheres being between equal and opposite attracting forces, will be as if not attracted by either sphere, and therefore, boing in this way removed, each from the attractive influ- 
ence of its former splere, they are the two moleculs which remain in contact, and will be the first to take up a fixed position about the centre of the new sphere. Also, the molecules composing the adjacent sides of these two spheres, in the immediate ricinity of this central point, being circumstanced similarly to the first two molecules, in respect to the amount of effective force attracting them towards the centres of their respective spheres, will be but feebly retained in their old position, and therefore ready to leave it, and join those molecules which by their apposition formed the central part of the sphere now in progress of formation. For the same reason, the next and all the circumjacent molecules contained in these hemispheres, are less forcibly attracted towards their respective spheres, just in proportion to their proximity to their point of contact; and hence these molecules, being in a condition to admit easily of displacement by those of the remote hemispheres, whose attraction will have been less weakened, will readily give way under the pressure of the latter, which will be drawn towards one another en masse. The directions taken by these molecules will be understood in a general way by inspecting diagram e, fig. 3. All those situater in the parts of the component spheres cxtermal to the circular area of the resultant one will have to move inwards towards its centre, whilst all those contained in the parts of the component spheres nearer to the unocripied portions of area of the resultant spheres will be carried outwards from its centre; and thus these particles will continue to move until the area of the large circle is filled up. Now, as the forces urging these particles in these two directions act upon them simultaneously, each particle in passing from its condition of rest in the component sphere to one of rest in the resultant sphere, will 
describe a curve, whose elements might probably ie determined by a due consideration of the condition of its motion. As the principal olyject of this paper is ply iological, this is a task which it would be foreign to ny purpose to attempt. It will now be olsrious, from what has been stated respecting the change of position of the molecules of tro spheres in the course of their conlesecnce into one, that, in a calculus marle up of a conglomeration of spherules, the molecules of each spherule, having l:sen previously aryanged in referenee to its own eentre, will have to leare their former positions, and pass orer a certain space before they san gain their final positions in the sphere of which they are to form a part. IInee, prior to the complete coalesecnee of any number of splucieal particles into one sphere, each particle or splicrule unust underovo a process of disintegration (or be talien to pieces). and after that, the moleenles of the disintegrated spliernles must be put together asain under the same static conditions as they were before. These processes are not of course performed at seprarate periods, so that after one is completed the other begins; but they may both be going on at the same time in different parts of the same sphere. Now, the question may lye raised whether these processes are so thoromghly motenlum as is here inferred; that is, whether they extend to the actual separatiou and re-arrangment of utinute molecules or atoms, or whether it is not anficient inat the component siberales should be reduect only to extremely small pioses, and these pucked elusoly together in the resultant sulderes? As, aceording to this smpur ition, the sclid wlich rould result firem the cerelesenere of these imaginary small pieces would le a polyen, with a more or less regular coutour, sut as the ctices of grverity upor 
particles of matter exposed to its full influence is to brine them into the smallest possible space, that is, to arranece them in such a solid form as presents 2 maximum of eapacity with a minimum of supcrifies (which is the spherical form and that only). Gravity acting by itself, and under circumstances where it can exert its full force, camot consistently with its own laws produce such a figure as the one above supposed, and therefore this supposition is wholly untenable. The first effect of gravity in the formation of the minutest spherules was exerted upon the atoms or molecules of which they are formed, aud no sub)sequent operation of this force can he complete, until erery such molecule entering into any one calculus, of whaterer size it may be, has taken mp a definite and assigned position. It may be remarked, howerer, that although this observation is strictly true, the form allucled to is not geometrically splecrical, but after all but a polywon of a number of sides comesponding to that of the molecules or atoms composing its most superficial lamina.

Haring made such observations as apply generally to the sulject of the coalesecnce of artificially formed calculi, and having shown that this process which, howerer often repeated, atfects all the inolecules of these bodics, requiring in each sucessive roalcaence their readjustment to new centres, must be, therefore, strictly moleculir; I shall now consider some particular forms of coalescing splicrules.

Fig. 2 presents aecurate delineations of ne or more small globules in difierent itages of molecular coalesecnere, trom the dumb-bell figure to the perfoet suliere; ("if) show: ilio small spherical particles just bronest into contact hy tibe mutual attraction of one for the other: h) fwo other which have conleseed suflicientiy to alegume the firm of a

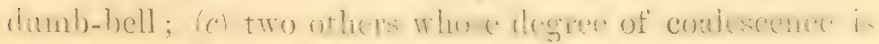


sufficiently adraneed to give them the elliptical form. Besicles these there are others representing intermediate stages. On examining specimens similar to the one of which this is a drawing, a difference of structure between the central and peripheral part in such globules $(b)$, especially on the side where they are in apposition, is distinctly visible by polarized light, under which these parts appear of different colours. Aud, during their further coalescence, the central portions appear to join before the peripheral ones; and, at a stage still more advanced, the central portions of the two spherules will be seen to have coaleseed sufficiently to circumscribe a perfectly elliptical area, whilst the peripheral parts, retaining more of their spherical form, present a depression all around their line of contact; or, in other words, the dumbbell figure is retained longer by the outer than by the inner portions. This want of correspondence in shape of these two parts proves that the central elliptical portion camnot have acted as the nucleus upon which the circumferential one was moulded. (See fig. $2 b$ and $b^{\prime}$.) It will not be difficult to account for this fact on the supposition of its being a necessary effect of attraction. Indeed, it seems to me that the fact will do as much towards proving the reality of the principles adduced to account for it as any application of these principles can do towards showing the nature and cause of the fact; or, in other words, the fact explains itself. A few observations, howerer, may make the subject more clear. For it will be evident, on the mere inspection of the particles $\left(b, b^{\prime}\right)$, and the illustrative diagram A, B, C, D, fig. 2, that as the molecules oceupying the outer portions of the remote hemispheres prescrve their spherical form not pereeptibly altered, they have the same arrangement in respect to the centres of the coalescing 
spherules as before contact, and therefore will exhibit nearly the same appearance under the microseope as if these spherules were apart. Whilst, on the contrary, the molecules contained in the inner hemespheres, coming within the attractive influcnce of both spherules, and being simultaneonsiy drawn in the direction of their centres by two variable forces, whose sum is always a constant quantity, will be brought under the mechanical conditions required to give them an elliptical form, as shown in diagram fig. 2 , whose axis major is the line $A, B$, and axis minor $c, \mathrm{D}$, and whose foci are the points $c, c^{\prime}$, the centres of the coalescing spherules and the coordinates of the curve are the lines $c, p$, and $c^{\prime}, p$. And hence the dumbbell-shaped particle made up of these several molecules will refract the rays of light passing through the peripheral portion as a sphere would, and those passing through its central elliptical portion as an ellipse would. Hence these rays, being transmitted differently, will render these parts distinguishable one from the other by the microscope, each according to its peculiar laws of transmission of light. As the coalescence of two such spherules as those just described progresses, the dumb-bell shape will gradually disappear, the spherical form of the remote hemespheres becoming changed into that of an ellipse, so that now, the exterior outline haring become also elliptical, there results a form presenting two ellipses, one situated within the other. (See fig. 2, c.) The still further coalescence of these once spherical particles is attended only with a gradual diminution of the eccentricity of these ellipses, until, their foci coinciling, one perfectly spherical calculus results. When, as was before observed, the molecules will all become quiesecnt, being now balanced between equal and opposite attractive forces, and 
the ultimate effect of gravity achicred. As there were, before the figure had attained the spherical form. two ellipses, so now there will be two spheres, one contained within the other. (See fig. 2, c.)

The complete coalescence of two such spherules as that last described would result in the production of one spherule with more than two concentric zones. IIence the careful inspection of specimens exhibiting these different stages of coalescence brings to view numerous examples of calculi with concentric lamina (as shown in figs. 2 and 3 ). Such specimens can easily be prepared, and they oceur abundantly as organic products, showing that the existence of rings or concentric lamine in organic boclies is not necessarily the effect of successive depositions on its surface as believed by physiologists and patholngists. (See Kölliker's 'Mamual of Mistology', p. 4.58.)

Now as these calculi are composed of only one material, it is inexplicable on known general principles that in such a body as the one just described, consisting of an elliptical portion contained within an irregularly spherical one, both without doubt in accurate apposition, the one should be so casily distinguished by the microscope from the other. For if this particle had been everywhere of the same density, and if every part of it had possessed the same index of refraction, that is, if it had been like two pieces of any homogeneous substance, as glass, with these forms accurately joined by Canada balsam, one part could not have been thus easily distinguished from the other. But this difficulty, on the further investigation of this subject, will he removed, when it is demonstrated that the different parts of these globules, formed as they have been shown to be under the influence of gravity, vary in their density according to the degree of attraction exerted upon their 
particles, -an attraction which is as their distance from the centre. So that, this force being least at the centre, and greatest at the surface, these differently shaped parts will possess a density rarying according to their distance from the centre and with it also will vary their refractive power. The eflect of the dimimution of refractive power being in these calculi as the distance from the surface is well seen on comparing them with the lenses of very small fishes. The lattor, being made densest at the centre and least so at the surface, for the purpose of preventing spherical aberration, present, uuder the microscope, when examined by transmitted light, a spherical figure, and can be seen to possess the property of a true lens, by one part magnifying the other, so that the markings on the remote surface of such a leus always appear, when seen through its entire thickness, considerably larger than those on the near one, and if its transparency be not much impaired, they can be secu very distinctly. Whilst, on the contrary, an artificially formed calculus of about the same size, being exactly the reverse in respect to the relative density of its different parts, causes such an amount of spherical aberration that its form, though it may be perfectly spherical, appears under the microseope, when viewed by transmitted light, to be flat, and any marking on its surface furthest from the microscrope cammot be secn at all magnified by looking through it, as was observed in the crystalline lens of the fish. This subject will be further discussed when treating of the derelopment of the crystalline lens generally. But, even so far as it has been considered, it remores the difficulty which at first presented itself, and furnishes incidental cridence in favour of the prineiples and accuracy of the reasoning which have been all along resorted to. 
The form of laminae just described is the effect only of one cause of lamination; the concentric divisions thus produced oceur chiefly in the smaller splicrules, where they are gencrally more distinct and complete than those which I am about to describe. The calculi in which the nature of the process of lamiuation now to be considered can be best shown, are those which are formed by the coalescence of sereral small globules of nearly the same size. The first stage in the formation of such calculi is a spherical conglomeration of these globules producing a mulberry-like appearance, (Sce fig. $4, b, c, d$, ) and a form closely resembling that of the corpuscle called by pathologists a glomerulus, although that is composed of particles of oil. The next is the disintegration of these spherical particles which takes place first in the peripleral ones. In this process erery vestige of their original form and structure is destroyed, and they become reduced to an amorphous granular mass. Next, the molecules nearest to the surface coalescing, form a clear ring completely surrounding the amorphous matter occupying its interior. (See fig. 4, b.) The further progress of the processes of disintegration and subsequent coalescence is marked by the increase in width of the circumferential bright ring, just as the central amorphous part diminishes, showing that the one is formed at the expense of the other, (See fig. $t, d$, ) until all the latter has disappeared, and is replaced by a succession of bright concentric laminze. These calculi, when dried and examined by reflected light, have very much the appearance of small pearls, especially the brightest of them; but after being immersed in Canada balsam, and examined in the same manner, they appear to cousist of a glassy case, filled with a whitish amorphous material. The relative propor- 
tions of these two parts vary according to the adrancement of the process of coalescence, which in rery larese calculi is rarely so complete, as not to leave some remains of the amorphous matter in the form of a central opacity, presenting in many of these bodies the appearance of a muclens; in some bodics it appears to be single, but in other's to be in process of division; or, if the cause of the appearance were not known, it might be considered as indicative of fissiparous multiplication. I may observe that this latter idea has instantly occurred to those to whom the artificial products have been shown when ignorant of their real nature. This latter appearance of the nucleus will not, however, be found in calculi formed in the mammer now described, but only in those which are formed by the coalesence of two large ones. The central portions of each, being the last to undergo disentegration and subsequent coalescence, will be recognisable by the aid of the polariscope after all the other parts have become thoroughly incorporated. Now, as respects the agency of gravity (that is, the mutual attraction of the particles of matter according to known laws), in the formation of these calculi, it will not be doubted but that the first stage of the formation-the collecting together of the floating particles into spherical masses-is due to its influence.

Next, as might have been anticipated, the peripheral layer of these calculi is that in which the disintegration and subsequent coalescence commence and are firstcompleted, as indicated by the circumferential bright ring before noticed -a fact which is in perfect accordance with the relative force which gravity is proved to exert upon the particles of natter arrauged in spherical masses. For this foree exerting its maximum influence on the spherical particles 
composing the sirperficies, and diminishing in the ratio of the distance from the ecntre, its cflects would of necessity be apparent, first at the surface of the calculus, and last at the centre. Hence, according to this application of the laws of gravity, the most external layer will be the one first formed. Nor, with respect to the subsequent layers it may be observed, that, as the ultimate effect of gravity upon the molecules of matter is so to arrange them that they shall ocenpy the least possible space, and as the exterior molccules have been slown to be thus arranged whilst the interior remain in their amorplous ronclition, it must follow, that when the former have undergone their final arrangement, that is, are brought into the smallest compass, the latter will be insuffi. sient completely to fill up the space enclosed by the outermost lamina, and therefore an interval will exist between them. But the microscopic examination of such calculi during their coalescence and lamiuation shows that this process is not divided into two separate and distinct stages, as might be inferred from this explanation (which has only been made to present this idea to show more clearly the facts), but that it takes place at sereral successive periods, and consequently as many layers, as there are periorls of formation, are produced, one layer being within the other. Now, as the inductive reasoning demonstrative of the existence of a space between the molecules, when complete coalescence has been twice effected, will apply equally if this coalescence be effected at any number of separate times, it must follow that, as the first layer is larger than necessary to contain the second, this in the same way will be too large for the third, and so on for the rest; and henee, that there will result intervals or spaces between the lamine, whaterer may be 
their number. Now, it may loe observed, that althongh this is without doulut tine, the reasoning being fully bome out by facts, still it does not necessarily follow that there should be appreciable interlaminar spaces, but only that there should be intervals where the molecules are less closely agoregated than in the laminse, the difference being only suffieicut to affect the transmission of light, both ordinary and polarized, and so to produce the appearance of lamine in the one case and that of coloured rings in the other. This, however, is not to be considered as the cause of lamination, but only a circumstance which disposes to the production of lamine upon the application of the enuse. The direct cause of lamination must be looked for in some influence which interferes with the rontinuons operation of gravity. Now, inertia is exactly such an influence, co-operating at one time with all such obstacles as oppose the first communication of motion to the coaleseing molecules, and at another urging them to go beyond the limits assigned by gravity. It is impossible that their motions, under such circunstances, can be otherwise than irregular and interrupted. And the degree of this irregularity depending also upon all other obstacles which act upon these molecules in conjunction with incrtia, the number, size, and completeness of the lamina in all those calculi must be, to a greater or less extent, accidental. These observations are not iutended so much as an explanation of the process of lamination, as to show that the fact of its taking place under such cireumstances is more in accordance with than opposed to the inference that the formation of these bodies is entirely due to the operation of gravity, and that the three stages of their formation, namely, the collecting of the spherical particles into globular masses, the disintegration of these 
particles, and the final arrangement of their molecules in an obscurely laminar form, are all the effects of the operation of the same cause-miversal attraction or gravity.

Before concluding the suljject of lamination, the coincidence and blending of the laminse of large calculi, sinilarly laminated and of about the same size, requires notice. (See Fig. 3, a, b.) When such calculi as there represented coalesee, their laminx will be seen so to coincide, that, after their union is perfected, the lamina of the resultant calculus will have the same relative position as those of the components, so that those molecules which were in the superficial layers of the latter will also compose the same layels in the former. But, although any given layer of the resultant splere may contain no other molecules than those which had existed in the corresponding laycrs of the component spheres, yet such is the relation between the eapacity and superficial dimensions of spheres, that all the molecules of the latter cammot be received into the former. As, for instance, the molecules at and near to the points of contact of the two spheres cannot become circumferential. The mere inspection of Fig. 3, diagram $e$, will show that, as in the progress of the supposed coalesecnce of the two lateral spheres into the central one, the molecules occupying the outer parts of their surface will, from this position, be the last to reach the line indicating the superficies of the agreregate sphere, where they must remain; and that, as those on the parts of their surface contained within the area of the circle intended to represent the section of the same sphere will be the first to be carried by the motion of the inmer molecules forwards to the same circle, beyond which, according to the hypothesis, they camnot go, and consequently where they must remain also, it must follow, that when the 
coalescence is complete and all the molecules of the lateral spheres have become collected into the central one, its superficies will be made up entirely of molecules which had before been contained in the superficies of the component spheres. And as the sanne reasoning will apply to the next and all the subsequent lamine, it is obrious that the greater part of the molecules which had oceupied any given position relatively to the centre of each of the component calculi, will be sinilarly placed with respect to the centre of the agenregate calculus. If the two component splierical calculi be similarly laminated, as represented in Fig. $3, a$ and $b$, it will be apparent, on inspection of these figures, that at the contiguous extremities of any two laminx similarly situated in the two coalescing spheres the molecules of each lamina will be under the same mechanical conditions; that is, the attractive forces, acting upon the two apposed molecules in the directions of the centres of both spheres, will, as these molecules shift their place, be always exerted with the same intensity upon the one as upon the other. So that when the coalescence of the spheres is completed, and there is consequently only one centre, these two molecules will lie side by side, equi-distant from it, both being in an are of the same circle. In the same nanner all the other lamina will become united, and the two spheres so completely incorporated as to leave no restige apparent of their former individuality. If one of the coalescing globules is rery much smaller than the other, so that their laminse rammot coincide, they will still become blended together, but their molecules about the parts of junction will for some time at least hare no definite arrangement.

Besides the arrangement of the molecules of these calculi into lamine, as abore sleseribed, there is also in 
arrangement of the same molecules in fine lines, of an imperfectly crystalline structure, cxtending as radii from the centre of each ealculus to its circunference. 'These radiating lines are not equally distinct in all calculi of the same composition. They are, for the most part, best secn in those of the laresest size, especially when brolicu into fragments, which, in consequence of these calculi splitting up from the ecntre to the cireunference, are wedge-shaped. These fragments require polarized ligit for their examination. This singular trausformation of a condition of carbonate of lime, which, when in small pieces, was perfectly globular and appeared to be completely homoyenous, into an imperfectly crystalline structure after these same particles had become ineorporated into large splecical masses, will require now to be considered, and the cause of the change from the slobular into the erystalline form explained. Now, as these changes are due to the same arrangement of the molecules of earbonate of lime as talies place in the production of true crystals, they cammot be explained intellisibly until the canses producing the ordinary crystalline forms are fully considered; hence the further consideration of the structure of splierieal calculi must of neecsity be interrupted by some observatious upon the nature and cause of ordinary crystallization. As crystalline forms occur in a great many organized structures, the explanation of the canses leading to their prodnction matst le ennsidered ats belonging to the physiologry of tiwater, and therefore as demanding the same ronsideration an the other con-titurnt forms of these tissucs. Any lant, to be stuclied meguly, must be comsidered in its totaligy amet not in referemese to par-

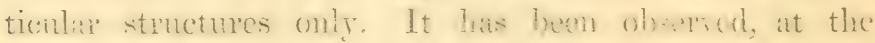

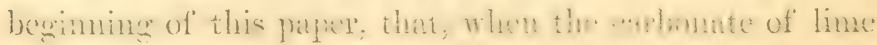


is formed in pure or common water, its first form is crystalline; but when formed in the same manncr in water containing a viscid sulustance in solution, its form is globulax. In the former casc the molecules of carbonate of lime are uncombined, and therefore, in its crystalline state, it may be regarded as: pure; in the latter, the carbonate of lime is combined with the riscid substance, as ean be show by chemical analysis, and therefore in its globular form it is obviously an impure carbonate - a compound of this substance and gum, or albumen. The facts lepuiring cxplanation are these: that, when the molecules of pure carbonate of lime, that is, carlonate uncombined with a viscirl substance, come into existence, they immediately commence arranging themselves in straight lines, and chlus, when collected together, form rectilincar figures or crystals; but mhen the impure carlonate, that is, carbon.. ate combined with a viscid substance, comes into existence moler similar circumstances, ite molccules assume a curvilinear disposition, and henee become collected into yloinles. Now, as these forms of armangenent are cxactly the reverse of one another, and as the curvilincar fom has been shomn to be the effest of attraction, the rectilinear arrangennent might have been inferred to be the effect of repulsion, or at least of some foree causing the separation of the clementary molesules of the pure curbonate. Hence it alpwars, that when the gum or allumen is intinately comblined with the ultimate particles on molecules of carbonate of hme, it eonfers upon them it property capal)le of neutralizing this infored ropulsion: and thus, making the molereukes of this componmel indir-

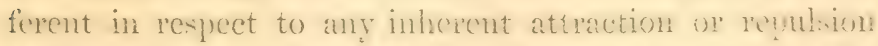

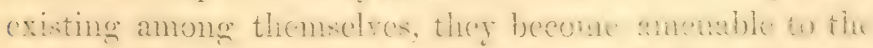

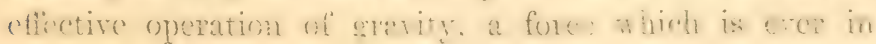


action, either effectively or ineffectively, upon the molecules of all bodies. It may now be asked what the property couferred by the viscid substance upon the carbonate is, and in what way it acts in producing such an effect as that inferred. In answer I may observe, that it is not only gum arabic and albumen which act in this manner upon the carbonate of lime; glyecrine los the same effect, and probably all other viscid substances, if only they are capable of combining intimately with the nascent carbonate. Hence this eflect of riscidity may depend upon some property of animal or regetable matter, which is no other than a form of attraction peculiar to organic products, dificring from chemical attraction in producing its effects, independently of any chemical change in the substances acted upon; as, for instance, when two recently exposed surfaces of elastic gum are brought together, they unite without any sensible development of ehemical action, differing from the attraction of gravitation in taking place only at inscnsible distances, and, lastly, differing from that force which acts indiscriminately upon all substances, organic and inorganic, called cohesion, in possessing in connexion with a certain amount of adhesiveness, a degree of elasticity, the two making up together the property called viscidity or tenacity, a property occurring only, with the exception of certain compounds of silica, in substances of animal or vegerable origin. Now, as to its action, it may be observed that if this power of attraction still continues to be exerted between the ultimate molecules of this class of substances, after their union with the carbonate of lime, as was exerted by visible portions or large masses of these substances when uncombined, it is perfectly conceivatble that such a wion would affect the repulsive or separating 
force exerted between the molecules of the pure carbonate, so as to render the molecules compounded of both sul)stances neither atfractive nor repulsive, and therefore susceptible to the effective operation of gravity; and certainly the fact of the ready and intimate union of these compound molecules, as abundantly manifested in the operation of coalescence, shows that this supposition has a weight of evidence in its favour which amounts to proof or demonstration that the point first supposed is in reality a fact; and hence, considering all the circumstances of the case, the attraction of tenacity inherent in the gum, the repulsion or some such influence existing between the nascent particles of the pure carbonate of lime in the act of erystallization, and the universal operation of gravity, it is difficult to see how the effect could have been otherwise than experiment has shown it to be, at least in kind. But in its amount or degree it may vary, producing all the results intermediate between the production of imperfect crystals and perfect globules, according to the relative amount of the forces in operation.

Of the three forces mentioned in the preceding explanation of the manner in which the rectilinear arrangement of the molecules of the carbonate of lime is changed into a curvilinear arrangement by the action of viscid substances, the cxistence of two is universally admitted by philosophers, namely, gravity and tenacity, though the latter, if not considered a distinct foree, is at least regarded as a form of rohesive attraction; consequently, there remains only one force, which, having been so far only vagucly indicated as repulsire, or capable of causing the nascent molecules of pure carbonate of lime to assume the rectilinear or crystalline arrangement, demands further consideration. As the demonstration of the nature and operation of this force, as 
displayed in the act of crystallization, rests partl: upon experimental and partly upon rational evidence, and as the former will supply data for the latter, it will he necessary to describe first some facts comnected with the cliauge of the crystalline into the globular form, as well as some facts directly connected with the production of crystalsfacts which have not been before mentioned in this paper, but which have formed a part of a communication contained in the 'Transactions of the Microscopical Socicty,' published in the 'Quarterly Journal of Microscopical Science,' for January, 1858. It has been already observed that there is in gum arabic, besides malate of lime, triple or ammoniaco-magnesian phosphate. Althongh this latter compound has not to my knowledge been given as a constituent of this substance, yet the elementary constituents entering into its composition are given in the analysis of gum by several chemists. (See 'Tumer's 'Chemistry,' 1). 855.) When the two solutions, of the density and composition prescribed in the formula for making the artificial calculi, are brought together in the mamner there directed, a malate of potash and carbouate of lime will result; and if the quantity of alkali had been only just sufficient to neutralize the vegetable acid in combination with the lime, the globular carbonate of lime would have been the only compound formed and deposited, while the triple phosphate would remain in solution. But an cxcess of earbonate of potash is ordered to be put into the denser solution, so that, after one portion of alkali has precipitated the carbonate, the other may set free the triple phosphate, and these combining form the largest linds of artificial calculi. Now, as the carbonate is formed first, it will of necessity occupy a position in the mixing fhuids above that occupied by the triple phosphate, 
but if the density of the two solutions be properly adjusted (and it is upon this circumstance that the success of the experiment mainly depends), the principal part of the globular carhonate and triple phosphate will be produced at about the same altitudes; and thus, their particles being borne up by the nearly equal density of the fluid medium in which they are contained and kept in motion by the diffusion of the unequally dense fluids, will be placed under mechanical conditions in all respects farorable to the mutual attraction of a great quantity of floating particles, and to their final coalescence. If the density of the alkaline solution exeeed much the degree mentioned in the formula, aud if that of the simple solution of gum is not equal to the degree there specified, the alkali diffusing itself through the simple solution of gum more rapidly than the gum contained in the lower solution, a larger quantity of carbonate will be formed than there will be gum to combine with it in the proportion necessary to form the globular carhonate, and, consequently, the carbonate of lime formed in the upper part of the bottle will be defieient in gum, and therefore it will be crystalline and not globular. Now, as the forms of the deposit oli one of the slides employed in this experiment will be the same as that in the fluid in contact with the lower side of it, the position of these slides being such that no particles in descending perpendicularly can fall upon their lower surface, the examination of the particles of carbonate attached to this surface will show the form of the deposit in the corresponding regions or altitudes of the fluid contained in the bottle, and consequently the result of the conditions stated in this experiment will be best seen by examining the carbonate adherent to the lower side of one of these slides. IIence, in the ease just 
specified, the uppermost part of the deposit will exhibit perfect crystals, that immediately beneath it crystals begimmo to have their angles rounded off, and the examination thus continued successively upon still lower portions, will show the gradual passage of imperfectly rectilincar figures into forms perfectly spherical. If, on the contrary, the density of the lower or alkaline solution be not sufficient, the smaller globular particles will fall to the bottom of the bottle before they have had time to coalesce in sufficient quantities to form the larger calculi. But when the densities of the two solutions are properly proportioned, as in the formula before given, no erystalline carbonate will be found adherent to the upper part of the slide, lut ouly globular carbonate of lime; lower down there will be the latter compound, triple phosphate, and a mixture of the two. This mixture will be in the globular form, and presenting different appearauces according to the relative proportions of the two component ingredients; if there be an excess of triple phospliate, the surface of the calculi will be studded with minute bright crystals, but if an excess of the carbonate no such appearance is jresent, but their surface will be smooth, and their interior more or less fincly laminated. At some distance below these nothing but crystals of triple phosphate will be seen. Now, the examination of these crystals in reference to the gradual change their form midergoes is rery remarkable. Begimning with the lowest and proceeding upwards, these crystals will be seen to be at first bcautifully perfect, presenting angles and edges sharply defined and perfectly rectilinear. Next, as they are examined higher on the slide, where they begin to mix with the corbonate of lime, they will be observed gradually to lose their rectilinear and angular form, and to becone irregu- 
larly oral, and lastly, as before observed, they become perfectly spherical. The transition from the erystalline into the globular form takes place according to the increase in the quantity of carbonate mixed with the triple phosphate, until the quantity of the former is sufficient for perfect globules. The incipient stage of this transition is frequently indicated by a slight molecular change in the middle of the crystals, producing a circular nebulous area, rescmbling an obscure mucleus. All these appearances can generally be seen on the slicles prepared in the manner before directed (at p. 5 to $\tilde{7}$ ), especially if examined by polarized light. As I believe no facts of a similar kind have ever been noticed, at least in any artificial products, though something similar is sufficiently commou in natural ones (but these have generally been attributed to a vital cause), I will give a short explanation of what appears to me to be the manner in which they are produced. But first I may notice a circumstance commected with this subject which may appear singular, namely, that the triple phosphate, produced as it is in the same solution of gum as the carbonate, should not, like it, be globular, that is, that the tenacity of the gum should not oppose the rectilinear arrangement of the molecules of the triple phosphate, as well as the molecules of the carbonate of lime. Probably this circumstance admits of no other explanation than the one commonly employed in chemical reasoning, and which may be inferred from the fact that the carbouate of lime, having a tendeney to combine with the gum, or an affinity for it, which the triple phosphate has mot, enters into a minute state of combination with it, whilst it does not combine in the same way, that is to say chemically, with the triple phosphate. A similar difference has been before observed with respect to the action of gum on the 
four alkaline earths, where it is stated that the carbonate of magnesia is the only one which does not become globullar in a solution of gum. (See p. 7.) In this respect, there is a resemblance between the ammoniaco-magnesian phosphate and the simple carbonate of magnesia. There is also another fact connected with the same property of the carbonate of lime that may be mentioned, which is its property of combining with hard substances. This is best shown by its action on the glass of the slide upon which it is deposited. The particles of this substance which are attracted by a slide and detained for some weeks in contact with it, become so intimately blended with its substance that, after the surface is washed with hydrochloric acid, impressions are left on the slide of the form of the part of the globule attached sufficiently deep to admit of being received on a film of collodion, on which they can be seen by the microscope. Hence the slides which have been employed in making the artificial calculi never recover their transparency, but remain more or less dull according to the time they had been in the solution of gum. The form of these calculi becomes also affected. The dumb-bell-shaped ones are made longer than those which had been formed whilst floating in a fluid medium. The elliptical particles, in the place of having a regular elliptical contour, as when formed whilst suspended in fluid, are lengthened, by the attraction of the glass opposing resistance to the apposition of their constituent spherules. They are also shaded off at one of their poles, that which had been most forcibly attracted by and blended with the surface of the slide; and the calculi of the largest size are flattened where they were in contact with the glass. Also, if the surface of the slide had been scratched, the calculi becoming attached to these parts in greatest quantities 
will be arranged in lines, the seratches generally passing through their centres. Now, from these facts it can casily be conceired that, when the globules of carbonate of lime and the erystals of triple phosphate, hoth floating together in the same fluid medium, are brought into contact by their mutual attraction one for the other, the carbonate of lime will enter into intimate union or combination with the triple phosphate, as it had been before shown to do with the glass, and form a compound of the two substances, in which the molecules of the triple phosphate would be brought within the sphere of the attraction of tenacity of the gum contained in the globular carbonate of lime. When therepulsive or impulsire force before operating upon the molecules of the triple phosphate, and causing them to be arranged in straight lines, would be neutralized by the force of attraction of tenacity in the gum of the globular carbonate, and the moleculcs compounded of the two substances being nearly indifferent in respect to any specific attraction or repulsion now residing in their own molccules, would he amenable to the effect of universal attraction, and thus undergo the same processes, first of disintegration, and then of conversion into spherules, as if all the molecules had consisted of simple globular carbonate of lime. Decisive proofs of the existence of these processes of disintegration and of coalescence can be seen on examining slides containing crystals of triple phosphate passing, as they become mixed with the particles of globular carbonate, from the crystaline to the globular state, already observed. Now, as in such combinations the attraction of tenacity may be inferred to get weaker just in proportion as the globular carbonate combines with increasing quantities of triple phosphate, the attracting constitucut in this instance being diffused through a larger 
portion of material not possessing the property of tenacity. Hence such relative proportions of globular carbonate and triple phosphate may be conceived to exist together in the same calculus as to render the attraction of tenacity acting upon its molecules very feeble, or wholly inoperative. In which case a compound would result, whosc particles in themselves are neither attractive nor repulsive; and therefore, when brought together into a globular form, would owe that form entirely to the attraction of gravitation. This is an important conclusion, as such a calculus would admit of being disintegrated, by reversing the direction in which gravity, during its formation, acted upon its molecules, provided only the attractire force in the reversed direction is greater than that which keeps the molecules together" and thus it would be the means of adding analytical to the synthetical evidence alrearly adranced on the subject of molecular coalescence. Now, I may observe that such calculi as the above can be prepared, and after that disintegrated, on the principle abore mentioned; but the further consideration of this subject, with an account of the experiments required to illustrate it, will be given in a separate article on 'Complete or funal Molecular Disintegration.' (See p. J.t). And as this subject throws no light on errstallization, its introduction here would be inconvenient, and therefore I will proceed to consider another fact, also showing the feeble condition of the force which preserves the molecules of the calculi composed of the globular carbonate and triple phospliate in their spherical form, and the near approach that there is in these calculi to an extinction of the attraction of tenacity. The experiment showing this fact consists in exposing a slide prepared according to the formula, and having upon it all the rarieties of calculi already described, 
to a temperature of $212^{\circ}$, cither by simply heating it, or immersing it in boiling distilled water, or in oil, turpentine, or Camada balsam raised to that heat, when the ealculi containing the triple phospliate, as well as the erystals of the same substance, will instantly become changed into masses of rhomboidal crystals of various sizes, whilst the calculi composed only of globular carbonate of lime will not be seusibly altered. Now, it must be observed, that though the attraction of teuacity may, in the above instance, have assisted in preserving the integrity of the calculi containing the largest proportion of the tenacious matter, yet if this attractive force cxeeed a certain limit, it will prevent the act of coalescence by effectually opposing the action of gravity in the preliminary stage of disintegration. Hence all the phenomena of coalescence must take place between this limit and the total extinction of the attraction of tenacity, and it is the result of experiment which alone can prove whether the conditions proper for coalescence are included or not within these two limits. The production of crystals, as observed in this experiment, is different to that under which crystallization ordinarily takes place. There is no indication of a prior state of solution, or igneus fusion, but the molecules of triple phosphate appear to pass directly and instantaneously from one form of arrangement to a different one, and, in the spherical particles, from a curvilinear to a rectilinear arrangement. As this takes place about the boiling point of water, it might have been thought, especially in the case of the crystals, to be produced by the solution of the triple phosphate in some combined or interstitial water raised to $212^{\circ}$, on the cooling of which it had again crystallized, though in a different form. If this effect had followed only the im- 
mersion of the slides in boiling turpentine, Canada balsam, \&c., this obscrvation might have been true; but occurring exactly in the same mamner in water, it cammot be so, as the crystals must, under such a supposition, have been sufficiently soluble in boiling water to have been entirely dissolved off the slide, which is contrary to the fact; bence some other explanation must be sought for. This sudden formation of crystals in one of these compounds, by a cause which does not sensibly affect the other, seems to me to admit of explanation in different ways, and on different hypotheses. It may be supposed, that the separating foree to which the rectilinear arrangement observable in crystals is due, is a form of repulsion, and, that in the compound of globular carbonate and triple phosphate, the attractive and repulsive forees acting upon their molecules are nearer the condition of equilibrium than in the simple globular carbobonate, so that when these two forces are weakened equally in both substances by the temperature of $212^{\circ}$, a preponderance of the repulsive over the attractive force, indicated by a change of the curvilinear into the rectilinear arrangement of the molecules, takes place in the compound of globular carbonate and triple phosphate, but does not sensibly affect the molecular condition of the simple globular carbonate, the attraction of tenacity still holding them together. Or, if the repulsive force were equally augmented in both substances by the same eleration of temperature, the effect would be the same upon the two compounds as that just mentioned. Hence the application of heat in this experiment may have produced the effect of sudden crystallization in two ways-either by weakening the unitiug force without affecting the separating one, or by augmenting the separating force without affecting the uniting one. 
It now remains to consider to which of these forces-the attracting or the separating one - the production of crystals as shown in this experiment, is due. Before proceeding further, I may observe, that the evidence, both rational and experimental, is altogether in favour of the latter. It was noticed in the last experiment that rhomboidal crystals, formed in the crystals of triple phosphate, rescmbled in every respect those formed in the globules composed of triple phosphate and carbonate of lime. Hence, in the case of these crystals, where the only force acting upon their molecules is repulsive, as shown by the fact of their form being crystalline, the mere change in the arrangement of their molecules from one rectilinear figure to another, presents nothing indicative of attraction, but quite the contrary ; and therefore, in this instance, a repulsire force must be inferred to be the sole agent concerned in their production. Now, it must be particularly noticed, that this observation applies only to the primary act of giving to the molecules their first form, that is, to the production of the first or primative crystals; for afterwards these forms are joined together, and so made into crystals of different sizes by the action of gravity. There is a circumstance connected with this experiment requiring especial notice, as calculated to throw some light upon the nature of this and the repulsive or separating force. The circumstance to which I refer is the sudden and instautaneous manner in which perfect crystals are formed, differing in this respect so much from the slow and gradual mamner in which the globules are produced. The latter ean be seen to be produced by the coalescence of particles of all sizes, but of no exact geometrical figure, though all curvilinear, and to increase in their dimensions by successive coalescences or stages, one stage imper- 
ceptibly blending with another, so that if these gloluules be broken up, no definite form can be detected which can be taken as a primary one, but everything gires indications of their formation being due to the operation of a continuous forec. The larger crystals, on the contrary, are formed instantancously, and built up of particles of the same form, and doubtless of the same size, showing that the force which was employed in their production had been divided into separate impulses, each impulse beginning and ending with one of these primary forms, which in some degree may be taken as a measure of the amount and an indication of the mode of operation of the force employed; so that there is every appearance that the formation of these crystals was the result of a succession of separate though similar impulses. Hence, the force producing rectilinear molecular arrangement may be inferred from this experiment to be impulsive, and thus crystals may be considered as the result of separate impulses acting upon the molecules of those substances which assume the crystalline form. This inference is particularly strengthened by the fact, that there exists in nature no known force, or combination of forces, which acting continuously and in conjunction with gravity, is in any way arlapted to produce a sustained rectilinear motion. It has been suggested that the electric and magnetic forces (the one always intersecting the plane of the other's action at right angles) are conducive to this result; but it must be rememberer, that even if the primitive particles of matter were inpelled in straight lines by a rectilinear current thus produced, it wonld not dispose them rectilinearly, unless they were solely under its influence-a supposition which would exclude the action of gravity, which has been shown by the facts of 
molecular coalescence to act continually upon the smallest particles of matter. Hence, if the action of such a current were a fact, all the nascent molecules of a crystallizable sulstance would be simultmincously acted upon by two very dissimilar forees, and also in no fixed or definite direction, the direction depending upon the position of the attracting particles in reference to the direction of the rectilinear current, which might at one instant oppose, at another coincide with, at other instants be inclined at rarying angles to, the direction of this supposed current; and thus these molecules would either have their motion only retarded or only aceelerated, or, if neither of these effects were produced, they would be disposed in eurves depending upon the relative intensities and directions of the motor forees, but they would never be disposed in straight lines, as in perfectly rectilinear erystals. A question will now arise as to the nature of the agency employed in the communication of the impulsive motion to the nasecnt molecules of the crystallizing substance, and its adequacy to accomnt for all the phenomena of crystallization. In the preceding course of experiments erystallization is shown to take place under two sets of conditions, differing altogether the one set from the other. The one is where the formation of crystals is the result of chemical action; the other, where crystals are produced on the application of heat to a body as yet not at all crystalline, or only very imperfectly so. Now, both these are well known to belong to a class of cases attended with an evolution of clectricity; so that, in the first case, the molecules of carbonate of lime, the instant they come into existence, may be inferred to be in a state of electrical excitation, and as the composition of every molecule is the same, and as the conditions under 
which they are all placed are alike, the electricity of every one will doubtless be the same, and hence they will repel one another. The second case is a mere instance of thermo-clectricity, in which electrical excitation is produced by the unequal conduction of heat. Hence there is no extravagancy in the inference that in both these cases the crystallizing particles, being under the infiuence of like electricities, should be self repulsire, or rather, as this state is acquired in an instant, and as instantaneons!y brought into operation, self-propulsive. Indeed, the bare fact of these particles luecoming rectilinearly disposed under such circumstances is an experimental proof of the existence of an agency capable of exciting upon them a repulsive power. And as there is no other known power eapable of producing, under the same ciremmstances, a like effect, exeepting electricity, it may fairly be considered as the power in question. As to the adequacy of simple electricity to account for this fact and the ordinary phenomena of crystallization, it may he observed that the impulsive power of large discharges of this agent are too well known to leave any doulst upon this head. It is certain that, in the last experiment, the sudden production of perfectly erystalline forms in such hard globular hodies must have required a considerable amount of mechanical forec, considering that the molecules of these bodies could not have taken up a new position without in some degree displacing the particles contiguous to them; and so disturbing, more or less, the coliesions of the entire calculus. But what other known foree is there in nature which could have achicved this besides electricity? Caloric, acting in different ways and through different means, might have broken these bodies into pieces, but it could not lave put them together again in regular geometrical forms. To 
demonstrate exactly in what manner the electrical forec must act upon the molecules of these calculi, as well as upon those of other crystallizable substances in the act of crystallization, so as to give them that crystalline arrangement which they have been shown suddenly to acquire, it will be necessary to divide, mentally, this process into different parts, and to inrestigate these separately, and afterwards to consider them as they would act together. First, then, let the molecules about to take on the crystalline form be supposed to be in isolated groups, one group being incapable of influencing the other; and suppose that in an instant all these molecules become endowed with the power of repelling one another, and it will be obvious that the molecules of each group will suddenly become dirergent and tend to arrange themselves in a splherical form, of which the central molecule of the group, retaining still its position, will be the centre, wlilst all those around it will be thrown into diverging lines or radii going from that centre. Next, suppose two such Eroups of equal size, placed side by side, to be acted upon in the same manner as the above, and it will be at once apparent that, as their adjacent molecules are impelled in directions which intersect one another, their motion bevond the point of intersection would be retarded and the force communicated to them diminished, the

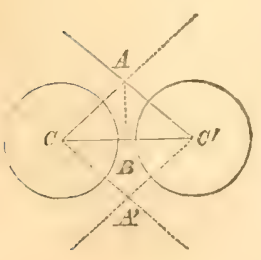
degree of diminution being as the sine of the angle A, C, B (see the accompanying diagram). Hence, at the point $\mathrm{A}$ the line $\mathrm{A}, \mathrm{B}$ will denote the amount of the attraction of gravitation necessary to balance the force of impulsion acting on the molecules at $\mathrm{A}$, and so to bring them into the condition of rest. 
And as the same reasoning would apply to the molecules on the other side of the line $\mathbf{c}, \mathbf{c}^{\prime}$, a quadrilateral area would be enclosed corresponding to the superficies of a mrimitive erystal. And extending this reasoning to similar groups situated on all sides of the one first supposed, a solid quadrilateral form would result corresponding to that of a primitive crystal. Though all crystals thus formed would be quadrilateral, yet their exact shape will vary according to the size of the angle $\Lambda, \mathrm{c}, \mathrm{B}$. If this angle be less than $45^{\circ}$, then, as the three angles of every triangle are equal to two right angles, c,. , c' will be greater than a right angle, and the form of the crystal represented by a c, A' $\mathrm{c}^{\prime}$, will be rhomboidal or lozengeshaped. But if the angle $A, C, B$ be exactly $45^{\circ}$, then the angle $C, A, B$ will be a right angle, and all the angles of the figure $\mathrm{A} \mathrm{C}, \mathrm{A}^{\prime} \mathrm{C}$ ' will be right angles, and therefore the crystal represented by this figure will be rectangular. Now the molecules at the point $\mathrm{B}$, being impelled in opposite directions and with an equal force, will be kept in their place without the aid of gravity, and therefore here, where the sine of the angle $\mathrm{A}, \mathrm{C}, \mathrm{B}$ ranishes, the attraction acting upon the molecules will be at zero. But as the force of attraction required to balance that of repulsion cstimated from the point $\mathrm{B}$ increases as the sine of the angle $A, C, B$, the density of these crystals, being as the attractive foree holding their molecules together, will be least at the centre and greatest at the surface. This inferenee agrees with several recorded facts commected with the polarization of light by erystals. As, during the formation of the primitive erystals of different crystallizable substances, or during the formation of those of the same substance under different circumstances, difierent quantities or intensitics of electricity would doubtless be crolved, 
whilst, under the same circumstances, and where the chemical action had the same amount of activity, these would always be the same, there ought to be a corresponding difference in the shapes and the sizes of different primitive crystals, agrecing with the uniformity, or want of uniformity, of the conditions under which these crystals are formed. After these first crystals are thus produced, they will become grouped together and built up by the action of gravity into other forms depending upon the order and manner in which they are packed together. But, as this belongs exclusively to the subject of crystallography, I shall not enter systematically into it. There is, howerer, room for another observation connected with this part of the sulject. It may be asked by what the primitive atoms or molecules are prevented from coming into absolute contact after the cessation of the chemical action, and the consequent crolution of fresh portions of electricity. It is not improbable or inconsistent with the facts of electrical isolation, that these molecules should be sufficiently isolated to retain their state of electricity, and therefore continue, after the subsidence of the chemical action, to repel one another. Ilowerer this may be, it is certain that there is one agent of universal existence as a repelling force, namely, caloric, which will prevent in these instances the absolute contact of molecules. But how far caloric is rightly to be regarded as a distinet force, or only as one of the sensible efficets of the same agency as clectricity, it is not necessary licre to consider, as it is only the fact of its separating or repulsive power which is insisted on. I may observe that the simple rectilinear forms shown in diagran, page 47 , into which the molecules of adjacent groups are supposed to be throw by the impulsive forces acting according to the 
hypothesis, are exactly like those of the smallest crystals on the heated slides, before mentiomed. And also it may be observed, that in examining good specimens of these crystals the larerer can be seen to be marle up of erystals of a variety of sizes, and therefore to be divisible into smaller ones, and these again into erystats still more minute, though of the same form, and so on, until the size becomes so diminutive that the true figure is inappreciable by the highest magnifying powers. (I have slides containing distinct rhomboidal crystals of ${ }_{\text {a }}^{1}$ " th of an inch in length, and containing other erystals not more than zovouth or ₹0 $\frac{1}{60}$ th of an inch long.) IIence it may fairly be inferred that this same form, being the simplest and most natural, and of all rectilinear figures most casily produced, would continue diminishing in size until a crystal would be arrived at whose further division would separate it into its constituent molecules, that is, into those portions of matter which, their inertia being overeome, ase the first to be put in motion under the combined iufuence of impulsion and gravity. Now, applying the reasoning employed at pages 17 and 48 to the formation of just such a crystal, it will be seen that one of the molecules, thus impelled, which is to form a part of this crystal, would instantly encounter another molceule jut in motion at the same time and under the same mechanical conditions, and the two being as instantly arrested by the predominant action of gravity, would become fixed in their position. Aud by the same process of reasoninger the other molecules could be shown to be added, mutil the formation of the erystal is completed, all the molecules which composed it being put in motion and brought into the condition of rest by the simultancous operation of the same forees, namely electricity, the arent generating the impulsive 
force, active inertia, and gravity. Now, if it be admitted that the size of this first crystal is such, that is, that its component molecules are so close together that they are all put in motion and afterwards brought into a state of rest by ouly one impulse; or, what is the same, that the impulse given to any one molecule could not for want of space be repeated, then no part of a curve could possibly cnter into its contour, since this contour would on this supposition be made up only of the first material points of the curves which each of these molecules would describe scparately, if it continued in motion under the conjoined effect of an impulsive and attractive force. Is this explanation perfectly agrees with the earliest appreciable forms and appearances presented by crystallizable substances in the act of crystallizing, and as I believe it is the only explanation which in principle can account for the rectilinear form of crystals, produced as they are under circunstances all tending to cause curvilinear arrangement, it may be inferred to be the correct one. It goes also to furnish conclusive evidence that the principle upon which this explanation is based, and the premises from which it has been deduced are real; and moreorer it goes to show that several of the points which have only been assumed in the course of the discussion, or imperfectly demonstrated, are themselres facts. Now, after a primitive or first crystal has been thus formed, it can easily be conceived that, as a multitude of such crystals are all formed together at the same instant, they will be brought by the attraction of gravitation into apposition, and the juxtaposition of their flat surfaces being farorable for extensive contact, they will be forcibly drawn together, and retained in the rectilinear form by the action of gravity, and thus larger rectilinear crystals will result, 
which, being packed together in different wayss, will produce all the varied forms peculiar to the several classes of crystals. Now, as the molecules or atoms composing the primitive crystals are finite magnitudes, the same observation will apply to the apparently smooth crystals as was applied to the apparently spherical calculi; namely, that as the latter were only polygons of a number of sides corresponding to that of the molecules contained in the most superficial lamina, so the former, however sharp their angles or smooth their surfaces may appear, neither their corners are geometrically angular nor their surfaces and erlges mathematically plane, but both will present inequalities of the same shape and size as their ultimate molecules. This explanation of the process of erystallization is not at all inconsistent with the fact of the expansion of water prior to and at the instant of congelation, as it is not improbable that, after a certain degree of approximation of the molecules of water, electricity is evolved, causing at first expansion, the obvious result of molccular repulsion, and afterwards rectilinear molecular arrangement, the consequence of impulsion, this latter taking place suddenly. The force of expansion is well known to be very great, its total effect being probably equal to the sum of the impulses of all the molecules of the freczing liquid. It is very probable that this might easily be determined by experiment. I may observe that I comsider this obscrvation as altogether meomected with what has been before adranecl, and merely regard it as at sugrestion quite as likely to be true as any other explanation which may have been given of this remarkable fact.

Ifaving now discussed fully the subject of crystallization, I shall proceed to apply the facts elicited by the diseussion to the explanation of the cause of the radiated 
structure of the larger globular calculi as noticed at page 30 ; where, as well as in other parts, it has been observed that the globular carbonate of lime, when in small quantities, exists in the form of bright, homogeneous spherules, looking very much like globules of oil or bubbles of air, but that, after being incorporated into large spherical masses, these forms cntirely ranish, and are replaced by concentric laminse and fine lines radiating from the centre to the circumference. The formation of the lamina has been explained; it now remains to consider that of the radiating lines. Now, as the explanation of all the appearances presented by these calculi has so far been shown to be the result of attraction, it is only a fair inference that these lines also are due to the effect of the same force. But in the last article attraction has been shown to be the direct antagonist of rectilinear molecular arrangement; therefore an apparent incongruity arises, which I will now explain. In perfect spheres, constructed on the principle of universal attraction, all the molecules, being attracted in directions parallel with their circumference by cqual and opposite forces, are as if not attracted at all by any force acting upon them laterally; and therefore the scusible effect of gravity upon these molecules can only be excrted in one direction, that is to say, it can only act in straight lines extending from the circumference to the centre. Hence, such being the action of gravity in spheres, it is clear that so far as the rectilinear arrangement of their molecules is concerned, the effect of grarity, and that of impulsion upon them is the same. But attraction thus operating upon these molecules does not produce perfect erystals, nor does impulsion acting on similar molecules produce lines like these. These lines, though presenting an im- 
perfectly crystalline appearance, are deficient in other characters belonging to true erystals. They are adherent on all sides to the contiguous lines, and therefore they have no definite form. These lines, though without doubt present in the smaller globules, are not apparent, partly from their minuteness, aud partly from the great convexity of such globules and the high refractive power consequent thereon rendering their detection difficult or impossible. Hence the cause of these mechanical conditions under which the molecules are placed in splierical calculi, which render it impossible that their arrangement could be otherwise than rectilinear, being now shown, and the differences between these liues and true crystals pointed out, the seeming incongruity before mentioned ranishes, and this circumstance itself furnishes a certain amount of evidence in proof of the correctuess of what has been before advanced on both subjects-the formation of spheres by molecular attraction, and of crystals by molecular impulsion.

It was observed at page 40 , that a separate consideration would be given to a process of complete or final molecular disintegration, there merely alluded to, and that some experiments demonstrative of this process would be described. I will therefore now proceed to consider this subject, which I may observe is in no respects inferior in importance to those already treated of, and perhaps in some respects more remarkable.

\section{ON COMPLETE MOLECULAR DISINTEGRATION.}

In the explanation of the process of coalescence of two globules of carbonate of lime into one, it was observed that, before these globules could become incorporated, 
their molecules must be displaced from the position which they had oceupied in relation to the centres of these two spheres, and be disposed around the eentre of one sphere, containing all the molecules, which, before coalesence, were contained in the two. This part of the process of coalescence was ealled molccular disintegration. Now, there is another ease in which exactly the same physical process takes place, but under different circumstances, and is therefore attended with difierent results. This I shall call final or complete molccular disintegration. It would secm, on examining specinens showng this proeess, to consist in the complete separation and dispersion of the molecules of certain compound calculi, learling to their total disappearance. But the fact is, that their molecules, in the place of becoming, after disintegration, collected into one large calculus, as in the disintegration before noticed, join together to form numerous small ones of different shapes, becoming dumb-bell ellipses or spherules, some of such extreme minuteness as only to be just visible by the mirroscope. The process by which this is effecter, and the physical conditions under which it takes place, will form the subject of the present article. It will be seen, on referring to page 10 , that the spherical figure of the calculi, composed of a mixture of carbonate of lime and triple phosphate, is referred to two kinds of attraction, namely, universal attraction or gravity, and that attraction which exists in a greater or less degree in all animal and regetable finids, called tenacity or viscidity, which, for convenience sake, I have ealled the attraction of tenacity. The former of these forees, acting at sensible distances, brings the particles of these calculi into contact, that is, within the range of the attraction of tenacity, which, acting only at insensible distances, must have been 
inoperative but for the previous action of gravity. So that in this way the attraction of tenacity mantains a position intermediate between an miversal influence strictly physical, and a condition of matter which secms to comect inorganic with organic forms of existence. The condition which I mean is that of sphericity or rotundity of contour, a character which has gencrally been regarded as one of the characteristic distinctions between inorganic and organic bodies. It is also observed in the same page, that the relative intensity of these two forces is in proportion to the quantities of the triple phosphate and the globular carbonate present. And, for reasons there given, it is further stated, that the more there is of triple phosphate combined with the globular carbonate in these ealculi, the less will be the attraction of tenacity; so that such proportions of these substances may be associated in these bodies as to neutralize the force of tenacity, in which case their molecules would be held together only by the attraction of gravitation. It is in calculi of this description that the disintegration in question can be best displayed. And the experiments by which this is effected will furnish additional evidence in proof of the principles which have been adrerted to in explaining the facts of molecular coalescence, and of their perfect applicability to the explanation which has been given of this process.

The following is one of the experiments which, for the convenience of those who may wish to repeat it, I will give in detail. Three bottles are to be chared with the two solutions mentioned at page 6 , and provided each with two glass slides exactly according to the directions there given. Then one of these bottles is to be tied orer with oiled silk, to prerent craporation of its contents, eare being taken not to disturb the solutions. The other two are to remain 
meorered for three wecks, when sufficient of the fluid in one of them is to be put into the other entirely to fill it, none of the solid material being introduced with it. These two bottles may now stand for six weeks or two months, the one bottle being kept full by the occasional addition of fluid from the other. Now, at the expiration of the time mentioned, it will be obvious that the density of the fluid in the bottle which had been tied over, and from which, therefore, all evaporation had been prevented, wiil be much less than that which had been kept full by the addition of the fluid from the third bottle; and hence the globules on the slides in these two bottles will lave becu for some time under different mechanical circumstances, one set of globules having been kept in contact with a fluid less dense than that in contact with the other globules, whilst the chemical composition of these two will be as much alike as can be under such circumstances. Any difference then which may be found in the globules of the two slides can only be attributable to a mechanical cause. All the solid matter must be removed from the upper surface of these slides, and that on the lower, after being well washed, may be examined either in Canada balsam or in glyeerine, all the slides being treated exactly in the same manner. It will be found, on comparing the specimens, that the globules on the slides taken from the fluid which had not beeu allowed to eraporate will be clear, with a sharp outline, and either laminated or not, according to the quantity of carbonate in their composition. Indeed, all the globules on these slides will answer to the description given at page 36. The globules on the other slides will be altered in their structure, the amount of difference depending upon the relative densities of the fiuids in the difterent bottles, and 
npon the time the slides harl been kept in the dense solution. The full cflect of this mole of experimenting cannot be obtained without varying the experiment above deseribed, especially with respect to the time allowed for the ghobules to be acted upon by the dense solution. But, as there giren, it will suffice to show some of the effects of complete disintegration on the globules composed oi triple phosphate and globular carbonate. Those composed entircly of the latter component, which are situated higher on the slide, are not in the least affected, however long they may have been kept in the dense solution. This

Fig 4 A.
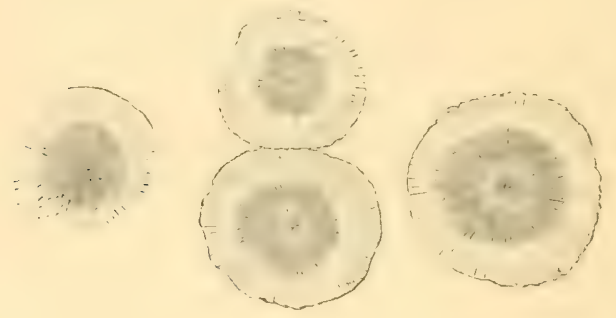

process of disintegration in the former is first indieated by the radiating lines becoming more distinct, especially near the margin of the slobules. Afterwards separations oceur between these lines, so that the circumference of a globule, in the place of being one sharp line is made up of their projecting ends, giving the appearance of a ciliated fibrous zone, whose brearlth depends upon the degree of disintegration. As this process progresses, this zone disappears in ecrtain parts, leaving the periphery meven, and afterwards it disappears altogether, when the globule becomes redueed in size according to the width of the dis- 
integrated zonc. And thus the disintegration procecds until the entire calculus is removed. (See fig. 1, 1), which accurately represents some of these globules. The disintegrated molecules, deprived of the whole or a great part of their triple phosphate, are dispersed through the solution, where some again coalesce, but into much smaller globular and oval particles, exhibiting all the stages of molecular coalescence deseribed at the begimning of this paper, while others reassume a crystalline form. Now, in explaining the cause of this fact, I may repeat the observation, that no kind of disintegration takes place in the globules of simple carbonate of lime on the same slide, that is, in those globules, whose molecules are kept together in the spherical form by two attractive forces, namely, gravity and the attraction of tenacity, but only in those globules in which the attraction of tenacity is neutralized by the combination of triple phosphate with the globular carbonate; and, therefore, it can only be with the former of these forees, namely, gravity, that the disintegrating cause has to contend; and as the conditions of the experiment are such as to exclude the action of all other forces upon these calculi, excepting that of gravitation, it must follow, of necessity, that gravity is the disintegrating agent. And, moreover, as it was shown that these calculi are formed by the foree of gravitation drawing their molecules towards their centres, so it must be inferred, that the same force, in producing a directly opposite effect on these calculi-their disintegration or destruction-will draw their molecules from their centres. In this experiment it is evident that the surrounding dense medium would act in this mamner, attracting the molecules of these bodies with a force exceding that by which they are attracted by the bodies themselves. 
IIence we arrive at a most important physical fact, namely, that spherical bodics, formed on the principle of universal attraction in a medium of given density, become, in one of greater density, gradually disintegrated, and their molecules, at first completely separated, afterwards rearrange themselves in fresh forms.

The experiments next to be described, showing the facts of molecular disintegration, have been given already, in the 'Transactions of the Microsopical Society,' published in the Jamuary number of 1858 of the 'Quarterly Journal of Microseopical Seience.' These facts can be demonstrated in a description of artificial calculi presenting characters different in some respects from those already described. They may be prepared by dissolving one pound of gum arabic in two pints of water, and straining the mucilage through a fine hair-sieve, and then putting one pint of the solution, with two ounces of carbonate of potash well mixed together, into a quart bottle, after twenty-four hours adding, by means of a syphon, the other pint of mucilage, and after that leaving the bottle at rest for six weeks or two months, when the calculi will be found adherent to its sides, or in the fluid at the surface. Besides these calculi of differeut degrees of solubility, erystals are formed in these solutions; some consist of bicarbonate of lime, formed by the free acetic acid in the mucilage combining with a portion of the potash, and setting free carbonic acid, which, uniting with some of the carbonate of lime, forms a bicarbonate. These crystals, being sparingly soluble, remain in the solutions, and chiefly on the surfice. I may obscrre, that in a solution of gum all erystals produced by double decomposition, which do not combine ehemically with it, are large and well-formed. IIence such a jrocess may be 
taken advantage of to crystallize salts, otherrise difficult of crystallization. The calculi formed according to this process are very large, being $\frac{1}{80}$ th or $\frac{1}{60}$ th of an inch in diameter, and spherical, execpting when they adhere to the side of the bottle, in which ease they are flattened on the side attached. They are very regularly and beautifully laminated, and coalesce in the same manner as those above described. When treated with weak acetic or muriatic acid they effervesce, and leave a residue of amorphous matter. When dried they retain their globular figure, but show a tendeney to split into segments; their surface is white, and generally smooth, but they do not present that glassy or pearly appearance which is remarkable in those prepared by the other process. Under polarized light they present a distinct cross, and appear somewhat coloured; but do not exhibit the prismatic colours distinctly, like the other calculi. The most remarkable property of these calculi is the facility with which they undergo cither partial or complete disintegration. So that they cannot be put up as transparent objects permanently, in any watery fluid. In glycerine they disappear after a few week̀s, leaving sometimes a residue having the form of a thin membranous capsule. If heated a little, and then put into hot oil, they first become covered with a feathery coating and afterwards fall into large fragments. This coating secms to me to be produced by their separating the oleine from the stearine, absorbing the one and leaving the other on the surface. But their most singular property is the partial disintegration which they undergo when removed from the bottle in which they were formed, and put up in a ecll filled with the solution taken from the same bottle, and so sccured from the aceess of air that no alteration in its density or chemical composition can take place. 
In this case all the carbouate separates from the regetal)le basis, and becomes collected into small globular particles of diflerent sizes, mixed with erystals of carbonate of lime. These are scattered about the regetal)le residue, which retains the place, figure, and lammated appearance of the original calculus, but when cximiued by polarized light exhibits no trace of eartly carbonate; excepting in the centre of each circular portion of residuum, there are two imperfectly-formed crystals joined together, and presenting somewhat the appearance of nuclei in process of division. I have specimens of such calculi, which have been in solution of grum for about nime months. It may not be irrelerant to state that these experiments and cxaminations have not been hastily made, or made only on scanty materials, but liave been repeated orer and over again with dne care and attention to everything at all likely to affect the results. In considering the cause of disintegration as displayed in these calculi, it may be observed, first, that their structure is less dense, as shown by the absence of transparency observable in the other calculi; and, secondly, that insoluble vegetabic matter enters largely into their composition. A part of this matter may have been suspended in the solution of gum, which had not stood sufficiently long to allow of its complete subsidence; but I belicre the principal part of it is set free during the decomposition of the salt of lime contained in the gum, which, being then placed under circumstances particularly well fitted for the production of large calculi (the experiment being performed on a large seale), combines mole'mlarly with a small portion only of the carbonate of lime, to form the ealculi in question. The other portion of the carljonate of line, combining with the gum, forms the same description of caleuli as those formed of carbonate of 
lime by the first process. Hence it is evident that calculi thus composed of very dissimilar substances, held together, as is clear from their structure, by only a feeble attractire foree, must owe their spherical figure ehiefly to gravity. Consequently, when remored from the bottle in which they were formed-where all the molecules entering into the structure of each calculus would have been exactly balanced between the mutual attractions of the molecules themselves and that exerted upon them by the various parts of the bottle-to a small cell of glass, where they will be brought into much closer contiguity with surrounding oljects, this balance will of necessity be destroyed, and the molecules being now attracted by the surrounded substances more forcibly than by one another, their scparation will ensue. The vegetable component molecularly united with the carbonate of lime being exquisitely delicate, and consequently rery light, as experiment shows, retains its form in consequence of its attraction of tenacity (which, howcrer, is only very fecble), being greater than the attraction of gravitation cxerted upon it by surrounding objects, which attraction, considering the extreme tenuity of this residuum, can only be very feeble. And the earthy particles composing these calculi, being attracted by one another more forcibly than by the molecules of the regetalble residum, become separated from it, and coalesce into globules. Now, as this explanation is perfectly in accordanec with the liaws of gravity and the attraction of tenacity, and as the conditions under which they act are within the rearh of experiment and the results determinable by microseopic examination, it may be affirmed with certainty that these forces would act as here shown. Ilenee there only remains one point to be determined, and that is the anderuacy of these furees, under the present conditions 
to produce the effects attributed to them. Now it may be observed that, as in this ease there are no other known causes capable of producing such effects, unless it can be supposed that vitality has produced them, the simple fact itself of their being produced under such circumstances is the best proof of their adequacy to produce them. I have dwelt longest upon the results of this experiment, as probably they will be considered the most remarkable of all that have been described, although I must say that there is nothing wonderful in the facts here stated respecting these calculi, or in the explanation of them just advaneed. It is only what might have been anticipated under such circumstances, being only the necessary consequence of an ordinary and universal cause.

There is yet one more case of final molecular disintegration, which differs in some respects from those just described. The experiment required for its demonstration simply consists in taling two slides from a bottle in which they had been kept for three weeks, according to the formula and directions giren at page 6 ; and then, after remoring the carbonate deposited on their upper surfaces, and washing the lower ones with distilled water, without removing any of the carbonate, introducing these slides, with the coated surfaces inclining downwards, into another bottle containing solutions the same in quantity and density as the first, and treated in the same manner, so as to have a second deposit on their lower surfaces. After a month or six weels these slides are to be remored from the bottle, the earbonate removed from the ipper surfaces, and the lower ones washed with distilled water, and then examined in glycerine or Canada balsam. The shobules adherent to the lower surfaces of these slictes will be of various kinds. A few formed from the last solution will 
have the ordinary characters, but those formed of particles from both solutions will differ considerably. Some will retain the form which they had on removal from the first bottle, but their transparency will be impaired, partly by the addition of fresh particles, partly by their former molecules haring become confused and made to present a dusty appearance; some will appear distinctly laminated, the laminis being separated by dark amorphous lines; a third set appear to be globular instead of flat, and to be filled with air and amorphous molecular matter. Sereral of each kind will be seen in different stages and degrees of disintegration, mouldering away as it were; and of a few merely circular circular traces will be left on the glass, almost invisible under ordinary illumination, but by polarized light distinct, exhibiting cross, but no colour, excepting a very faint blue. In this case the disintegration is not confined to the calculi composed of a mixture of triple phosphate and globular carbonate, but it affects equally those composed of the latter compound, whether large or small. Now, on considering the conditions of this experiment, and comparing them with those of the preceding ones on molecular disintegration, it will be obrious that these effects can only have been produced by one cause, and therefore admit only of explanation on one principle. Difference in density of the solutions in which the perfectly formed giobules were immersed, as in the first experiment, can have had no share in producing it, any peculiarity in the composition of these globules, as in the second expcriment, can have had nothing to do with it. And as the solutions were, in both stages of the process, exactly of the same composition, these changes in the structure of the globules after the second immersion are not the effects of 
chemical action. Ifence they can only be attributed to the molecular disturbance of the previously arranged and balaneer molecules by the sudden addition and contact of fresh ones. This is no more than mirht have been expected ; indeed, it could not have been otherwise, if the cause on which the globular form of these bodies depends be the force of gravitation, and if the explanation giren at the begiming of this paper be correct. One result of this experiment, the dusty appearance in the interior of many of these globules, arising from the disturbance and loss of balance of their molecules, shows that light is only perfectly transmitted by these splierical hodies when their molecules are arranged and adjusted on phrsical principles, and, therefore, that the forces by which their perfect balance is maintained are in some way comnected with the propagation of the etherial undulations upon which light is supposed to depend, molecular confusion and opacity being the effects of the same cause. This fact is apparent in the form of disintegration preceding coalescence, as shown by the central opacity of incompletely formed globules, but it is much more strikingly displayed in the globules formed in this experiment. Also another fact is made by this experiment particularly prominent, which is the necessity of time in the operation both of coalescence and disintegration. In the formation of globules according to the ordinily process of coalescence, everything takes place gradually; the decomposition, and consequently the formation, of the globular carbonate being slowly effected, and the globules being slowly attracted towards one another, as can be slown by the microscope; so that sometimes three globules lying near together ean in some specimens be secn to have changed their shape before they are actually brought into contact. 
In this second process, on the contrary, a large quantity of globules and globular particles are brought suddenly into contact with those already perfectly formed. The balance and with it the condition of stasis of their molecules is destroyed, and the globules thus circumstanced ceasing to be attracted to one centre, go into fresh globular forms, much smaller and less regular than those produced in the first stage of this experiment, and thus for a time nothing but molecular confusion results.

Ultimate molecules or atoms being frequently mentioned in the course of these obscrvations, these researches will not be complete without some some notice being taken of the probable form which matter had when it first came into being, or which it now has when it comes into existence in a new state of combination. As such existences are invisible under the highest magnifying powers, all observations on their size and shape must be speculative. 'Two opinions, however', have prevailed with respect to their form. IIaüy and others have adopted the notion that they are all angular, while Hooke, Wollaston, and other more recent writers, have assumed that they are of a rounded form. Now, as respects my own view upon this point, I may obscrve that it has been shown-I think I may say demonstrated-that matter, immediately it comes into existence in some new state of combination, assumes one or other of two forms, according to the predominant force acting upon its ultimate molecules. If that force be attraction, the first forms are curvilinear; if impulsion, they are rectilinear. But $I$ am aware that these first forms, being made up of alteruate particles, are not themsclves atoms or ultimate molecules. Now, in order that the first portions of matter may lave a definite form, they must 
either come into existence in separate places or at separate times, that is, they must not be within the sphere of each other's attraction or impulsion, for they would then be formed into globules or crystals before they had time to acquire their specific form. Now, as no experimental or natural process can be conceived by which a molecule is formed alone, this condition seems to be impossible. Hence, so far evidence is opposed to the riews of both these classes of philosophers, and the probability secms more in favour of an amorphous condition of matter prior to its arrangement into globules or crystals. But, furthermore, if attraction and impulsion are the forces to which all the known and appreciable forms of matter are due (and the correctness of this supposition, especially as respects attraction, no one doubts), then, if the component molecules making up these forms have themselves a definite form, whether angular or spherical, or some modification of these, some unknown force or forces must have excrted a prior influence upon them, affecting each molecule separately-something in the same way as gravity and impulsion have been shown to affect them collectivelyor these molecules must have in themselves the power of giving themselves a form. Now, as there is no evidence of any such force or of such an inherent power in matter, the idea of a definite form of the nascent particles of matter is unsupported by any kind of proof, and therefore is entirely untenable; and the only inference is, that when matter first comes into existence in some fresh state of combination, as, for instance, carbonate of lime combined with a riscid substance, it has no definite form until gravity has given it one. As respects the size of atoms, it may be observed, that as the attraction of gravitation is exerted upon matter directly in the ratio of the quantity, 
and as this force cannot act effectively upon it until its vis inertice is first orercome, it is perfectly conceivable that the quantity of matter, when coming into existence, may be so small as to be affected more by inertia than by gravity or impulsion, and may thus remain for an instant undetached from the surrounding material substances, until the quantity becoming augmented sufficiently to cause its removal by the action of the predominant physical force, it becomes detached as a part of a crystal, or a part of a sphere, according to the nature of that force, whether it be attractive $\mathrm{Or}^{\circ} \mathrm{impulsive;}$ and hence the size of this particle may easily be imagined to rary, that depending partly upon the intensity of the physical force and partly upon the nature of the matter acted upon; but its form, not being necessarily either spherical or rectilinear, must, for the reasons just given, be uncertain ; consequently, it may be inferred that all molecules are amorphous, and that, if there ever was a period when matter existed unacted upon by attraction or impulsion, it must have been in a chaotic or amorphous state-a something "without form, and void." 


\section{PHYSIOLOGICAL PAR'T.}

Havixg in the preceding pages considered, somewhat at length, the mode of formation and the structure of calculi artificially prepared, the subject of crystalization, and the process of final molecular disintegration, I shal now proceed to apply the facts clicited in the course of these inquiries to the explanation of the analogous forms of carbonate of lime, as they are found in organized bodies.

I shall first consider the perfect similarity as to structure which exists between the artificial and natural products; and then consider the identity of the laws under which both classes of substances are produced; after which I shall show, that the same physical laws of formation extend to other natural structures, both animal and vegetable. But as my time will not permit of more than a limited application of these laws to organized structures, I shall chiefly confine my observations to the structure and formation of shells and bone, the mode of formation of pigment and some other cells, and the structure and development of the crystalline lens. It may be observed that, as the natural products will be shown in the following pages to have been formed upon precisely the same physical principles as the artificial ones, and as it is in the latter only that their mode of formation admits of being 
investigated experimentally, and the physical principles concerned in their formation clearly and rigidly demonstrated, it will be necessary, for the full comprehension of the physiologieal division of this paper, that the physical part should have been carefully considered, and generally understood. As in the physical part of this paper I have described minutely the different processes for making artificial calculi, and the mode of performing all the necessary experiments, in order that those who wish to prepare their own specimens may be able to judge for themselves of the truth and accuracy of the varions statements contained in these accounts, so in the physiological part I shall also adopt a parallel course of proeedure, by describing the mole of cxamining the natural structures, and pointing out the parts best adapted for displaring the various stages of their derelopment. This lias been especially neglected in the examination of calcareons tissues, thin sections being too exclusively employed for that purpose, which, although they display well the number and arrangement of the lamine of perfectly formed parts, and so far are indispensable, yet shows little or nothing of the earliest forms of the earthy deposit, especially as this is all removed by the sulsequent grinding, unless care be taken to prevent it. Nothing can be more dissimilar in appearance than the different forms assumed by the globular carbonate of lime in the various parts of the same shell, and it is only by examining the passage of the one form into the other that their identity can be determined. This observation strikingly applies to the analagous forms of the artificially prepared compound of the same composition, in which, as in the natural products, there are the molecular, globular, and laminated forms, resembling one another in no respect excepting in their composition. 
The first of the natural products which I shall consider are the minute calculi found in the urine of the horse. As these structures are well known to microscopists, it will not be necessary to describe them. It may suffice merely to say that calculi of a similar composition can be formed artificially, so exactly resembling these as not to be distinguished from them by the most careful microscopic examination. Those artificial calculi, the most like the calculi found in the urine, are the calculi reposited in the bottle, and not those adherent to the lower surface of the glass slide. (See the account of the process for making artificial calculi.) These natural calculi also, if examined in a good specimen containing calculi of various forms and sizes, will be scen to present appearances indicative of coalescence, in all respects the same as those of the analogous forms of the artificial calculi. These urinary calculi, existing in a fluid excreted from the blood by a living organ, are considered by physiologists to be vital products. It is observed in a review of Professor Quekett's 'Lectures on Histology,' that " henceforth a calculus will not be regarded as mercly a mass of earthy or crystalline matter, collected by simple attraction of aggregation; but it shows evidence of the existence of cell-formation." Professor Quekett also observes, concerning these calculi, that they are not mere sediments, but are passed from the kidneys, being either made up of small calculi, or of concentric lamine; being in fact urinary calculi in miniature, the secreting cells remaining after the calcarcous element has been dissolved, as in the larger calculi; and that a calculus found in comexion with the body is not a simple mass of inorganic substance, containing organic matter as an accidental constituent, but that a calculus, when in contact with 
living tissues, may, like shell, have life, and with it the power of growth or development; the secretion serving as the blastema or pabulum from which the cellcontents are derired. Professor Quekett addis, that he would not assert positively that such is the case, but when the subject is carefully considered, "it has the appearance of truth on its side." I may olsserve that by this allusion to Mr. Quekett's lecture, I do not necessarily refer to him as the originator of these views, whether they be true or false, but I have merely quoted this lecture as showing his opinion upon this subject, an opinion which, from Mr. Quekett's high position anid very extensive knowledge of histology, I consider to be the one most generally entertained, at least in this country, where the cytollast theory of Schwann is carried to its greatest extent. Now it may be observed, that as these calculi are formed, as Mr. Quekett has noticed, in comnexion with the body, or at any rate they are found in a fluid which has proceeded directly from the blood, it is impossible to prove that they are not of vital origin. The cell theory is altogether in favour of this vicw ; for nothing can appear more probable than that a cell-germ, having escaped from the blood into the pelvis of the kidney, should afterwards be carried with the urine into the bladder, where, increasing and multiplying by the excrcise of its own inherent vitality, it should grow, at the expense of the secretion containing it - this serving as its blastema-into a calculus; hence this question, like most other pathologieal and physiological ones, ean only be decided by the comparison of evidence adduced on both sides. As in the discussion of this and other questions I shall frequently be obliged to refer to the cell-germ theory, I think my observations will be better understood if $\mathrm{I}$ at once 
avow my opinion upon this point; and, therefore, I may bricfy notice, that although I partially admit many of the facts connected with the gencral structure of cells, such as an exterior investment, or, as it is called, a cell-membrane, cell-contents, and very frequently a central part, differing from the rest, called the cell-mucleus, I am not of opinion that these parts are endowed with a distinct and separate vital jower, by which one cell can act independentl; of another and of the surrounding parts, and grow and multiply by the excreise of its own individual rital endowments. I wish particularly to notice also, that my object in bringing these rescarches before the public is not to attack the cell theory, but that it is to explain certain facts which have come under my notice, and that I wish to deal only with facts, and such deductions from them as the facts themselves will be shown to justify. Notwithstanding, as it must sometimes occur, that the decision of a doubtful question will depend upon a comparison of evidence, it will be impossible to aroid making allusions to the opinions and views of others. But to return to the subject of the formation of these urimary calculi, I may notice that, if the cell-development theory be tenable in any case of the formation of adrentitious structure, it is so in this. It is true that, in this instance, the commexion between the living structures and the adrentitious products is not so clear as in many others, but still it may be assumed that it did once exist, but that now it has ceased; howerer, that there still exists sufficient connexion between them, through the medium of the urine acting as a blastema or pabulum, to furnish the cells with the requisite supply of material for their indiriclual growth and multiplication. Such, in substance, is the explanation 
which has been given of the formation of these bodies, and nothing can be more plausible and apparently correct, if only the foundation upon which it rests is solid. The question on the other side is, can any other explanation of the same class of facts, equally plausible, be given. 'To this question it may be replied, that no other explanation which suits so completely all the circumstances of the case can be advaneed, without removing entirely the foumdation upon which this one is built. The following explanation of the manner in which these calculi are formed, uncomected altogether with the hypothesis of cell-growth, and in accordance with facts as shown by experiment, is deduced from the comparison of the results of the artificial process for making ealculi with those of the natural process. As there can be no doubt but that the urine of the horse, when reccutly secreted, contains in solution some compound of lime, albuminous matter, and some salt of urea, easy of decomposition, and when decomposed, furnishing carbonate of ammonia ; it is obvious that, as soon as this decomposition of the urea or its salts commences, all the conditions necessary for the formation of the globular carbonate of lime specified in the artificial process are brought into existence. The carbonic acid set free by the decomposition of the carbonate of ammonia would combine with the lime, displacing the acid before combined with it, to form a carbonate of lime, which, meeting in its nascent state with the albumen, would form with it the globular or coalescing compound in question, the particles of which, being suspended in a fluid medium, holding animal matter in solution, would coalesce to form globules of various sizes and degrees of perfectness, accordingly as all the other conditions prescribed in the artificial process were more or less farorable for the process of 
coalescence. Now, as in this case there appears to be no reason for assuming the alssenec of any one of these conditions, and as it is certain that, if all the physical and chemical means employed in the production of artificial calculi are the same in this-the natural process-as in the artificial one, the result will be the same also. There seems to be no reason why this explanation of the formation of these urinary calculi should not be regarded as the correct one. Vitality has not been named as having had any share in the formation of these natural products. Nor, as it has been demonstrated that bodies in all respects analogous to these calculi can be formed without any possible vital interference, does there appear to be any necessity to attribute any part of the formation of these urinary deposits to the influence of "vital forees," or to cell-development. At any rate it is certain, that if vitality does contribute anything to their production, the fact of the perfect resemblance between these calculi and the artificially formed products proves that this contribution is so small that it might have been altogether dispensed with. There is one fact connected with this subject, which has been regarded by physiologists and histologists as furnishing conclusive evidence in proof of the vital origin of these and similar natural products, which is that of a soft material_- "animal basis"-being left after the decalcification of these products by the action of hydrochloric acid, of the same form, and with marlings similar to those which these products had before being thus treated; but as exactly the same effect is produced by a like treatment of artificial calculi formed in a solution of albumen in the place of gum, this can no louger be considered as an infallible test of an organic formation. This residuum in the case of the natural products is regarded 
as the secreting cell deprived of its ealcarcous element. These calculi can be made by mixing with one portion of Thite of egg a very small quantity of muriate of lime, and with another portion of the same a little sub-carbonate of potash or solla, and then putting them together, without mixing them, into a bottle, into which two glass slides had been previously introduced, as in the process with the grum, and then keeping the bottle at rest for two or three weeks. This experiment must be made in cold weather, as the albumen rapidly decomposes. In examining these calculi for the purpose of seeing the albuminous residue, corresponding to the "animal basis" before mentioned, they should be examined on a microscopic slide, with a piece of thin glass over them at the time the acid is in action, which ought to be very weak, so that in the partially decalcified globules the perfect parts and the decalcified ones may be seen at the same time, and compared one with the other. The polariscope will be necessary in this examination. After all the calcareous matter has been removed, the residue will be seen to be of the same size and with the same appearance of laminatiou as the original globule; but these will of course be fainter and invisible under perfectly polarized light, showing that during the formation of calculi of this kind the albumen becomes solidified and molecularly blended with the earbonate of lime. This fact proves also, so far as it goes, that soft matter is as much under the influence of physical agency as hard matter, provided only the mechanical conditions under which both are placed when acted upon are the sarne. I may obscrve, in conchuding the remarks upon these calculi, that my conviction of the correctness and truth of the explanation here given of their origin and mode of formation, as opposed to the 
physiological explanation, is so strong; that I camnot help believing that, if only it had been earlier linown that borlies exactly like these calculi could be preprared artificially, and also all the conditions known under which the process is conducted, the opinion that they are organized structures would never liave been started; and therefore, if my riew is the correct one, as I have no doubt it is, I claim no credit on that accomnt, or attribute any want of penetration to those who have entertained a different one, secing that I commeneed the investigation of this subject under advantage which they had not.

The next subject which I shall investigate will be the structure and development of the shells of animals. I shall make choice for cxamination of those which are most common, and therefore can be most easily obtained. I shall begin with the external skeleton, or, as it is commonly called, the shell of crustaceans, and, first, shall consider those membranous parts which are comected with or which make up part of the shell, but only so far as the process of calcification or the development of shelltissue is concerned. I shall then examine more particularly the arrangement of the different structures, as they are found in the different parts of the completely formed shells of this class of animals.

All the parts of the ordinary crustaceans, as, for instance, the lobster, which contain a large quantity of carthy matter in their composition, cammot be considered as pertaining to the slicleton, the carapax and some other parts being more analogous to integument in the office which they have to fill, and the parts called apodemata, affording attachment to muscular filmes, y)erform the function of bone, whilst others similarly related to muscle correspond to the osseons tendons of birds. 
I shall cousider all these parts scparately, in the order I have named them. And first, the tegumentary part of the shell, which is made up of alternate layers of hard and soft tissue, very closely comected together, especially in the more superficial regions of the shell. The intimacy of the commexion of these layers differs in different crustaceans, and in different parts of the same shell. In some they are so blended together as not to admit of the slightest separation, exeepting on the surface next to the animal. The first or deepest layer consists entirely of branched pigment-corpuscles. This is alssent in the shells of many crustaceans, and therefore is not an essential part of shell-tissuc. The next layer is a thin and almost transparent membranous layer, of a glassy appearance, and of rather a dense structure; conneeted on its deep surface with the pigment-layer, and by its superficial one with a layer of similar structure, sometimes sereral such layers may be found connected together. It is between these layers that the calcareous matter is deposited; begiming on that surface of the derpest of these layers which is furthest from the branched pigment-corpuscles. The carbonate of lime here deposited is in extremely small particles, presenting when out of focus the appearance of minute points or perforations, dispersed more o? less thickly over the membranc, though sometimes collected in groups, and at others arranged in lines. This deposit I have never found on the deep surface of the first laver, and somctimes two or three membramous layers intervene between the earthy deposit and the pigmentmembrane. The particles of carbonate of lime as thus deposited, are sometimes too minute sensibly to polarize light ; and in this ease their composition can only be determined by the action of weak hydrochloric acid upon 
them whilst they are under examination by the microscope, the escape of gas, as seen passing from them, indieating the presence of one of their componentscarbonic acid. After thus acted upon, as was noticed of the artificial analogous form of carbonate, they leave a residue of soft material_-" animal basis" - of the same shape and appearance, but much less distinct. On the membranous layer next to this, and on those still nearer to the surface, these particles can be scen in erery stage of coalescence, presenting so exactly the appearance of those on the slide'employed in the artificial process, as not to admit of being distinguished from them. The resemblance between these and the artificial products is, in some respects, more complete than between the latter and the urinary calculi of the horse. In the shell all the different forms and stages of coalescence are better marked, and therefore more distinct than in the calculi from the horse's urine; and in those of the shell, which are not so well marked as the artificial ones, it will be evident that the process of coalescence has been interfered with by the mechanical causes, and that just in proportion as in their formation they cau be seen to have been exposed to mechanical interference from the contiguous structures, so do they sufier distortion and become less like those prepared artificially. Consequently, the smaller these globules are, the more exact is their resemblance to the artificial ones of the same size. By rarying the artificial process also, the less perfect forms of the matural products can be accurately imitated. See fig. 5, which is an accurate representation of a portion of the innermost layer of the shell of a very young lobster, about four inches in leugth, in which globular particles, of various sizes and in all stages of coalescence, are shomn. In the shells of 
the smaller crustaceans, as in the shrimp and the prawn, especially the latter, (if only at a proper season) in which there being a larger proportion of the softer constituents, and where consequently the process of coalescence is less interfered with, the globular form of the carbonate of lime can be seen very satisfactorily. In these animals, mixed with the spherules, there are sometimes circular dises, containing in the centre smaller globular particles, and a

Fig. 5.

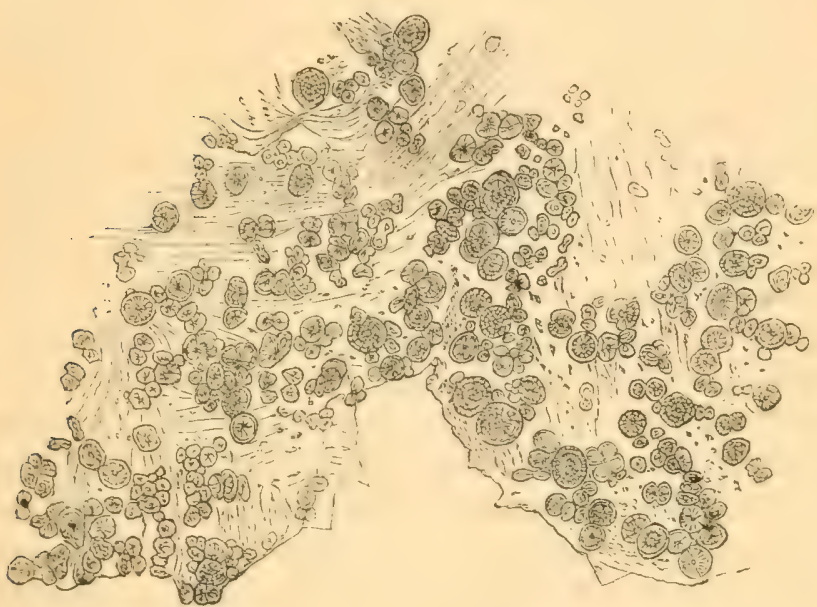

the circumference larger ones joined together, so as to present a bright crenate border. There are also patches of these bright globular particles arranged in a stellate form, assuming more of a crystalline character than in the discs. All these appearances can be best observed by merely cleansing the shells in water, and examining them in glycerine. Grinding is unnecessary and injurious. 
Polarized light is indispensable in the examination of these objects, for in some instances, as in the young liemit erab, at the part where the calcareous and membranous portions of the shell are continuous, the circular forms of globular carbonate are so delicate that no evidence whatever of its presence can be detected under the most powerful lenses, and with the best illumination, but, with polarized light it is brought ont most distinctly. The relative position of the molecular, globular, and laminated forms of this substance, can be well seen in vertical sections of the shell of the ordinary sized crab and lobster. In the crab the part of the shell which supports the nippers, and in the lobster the claws, answer very well for this purpose. But in grinding these parts great care must be taken not to remove the deep layer, which being the softest is generally the first which is ground off. In the sections which I have examined, where this caution was not attended to, all the globular layer has been removed. On examining with the nalied ere the internal surface of the portion of the shell of the crab just mentioned, two parts are to be noticed, a smooth and a rough one. In the former the globular carbonate is seen in the thin rertical sections, chiefly in one deep layer of nearly the same thickness. In the latter, portions of globular carbonate pass at certain points through the entire thickness of the shell, from the deep to the superficial surface. Sections should be marle of both of these, and ground down with the precaution aloove mentioned, and afterwards put up in olyecrine or Canada balsam. There are in all shells whose thickness is considerable irregular passages, extending from the decpest menbranous layer to the free surface of the shell. These passages are best secu in rertical sections of decaleified shells, in eonsequence of being olsseured in the 
perfect shell by the globular carbonate of lime by which they are more or less surrounded. In the claw of the lolster the globular and laminated forms of the carbonate of lime are much less regularly disposed than in the crab but in good specimens of both the deepest layer contains very good examples of globules of carbonate in their several states of coalescence. I have in my possession specimens of vertical sections of lobster-shell, showing globular particles of various kinds, resembling, in all respects, the artificial globules, and not distinguishable from them eren by the aid of the microscope and polarized light. Thin rertical and horizontal sections of the claw of a craw-fish, about three or four inches in length, or of a very small crab, examined in glycerine, are well adapted for displaying the process of development of shell. External to the membrane lining the cavity in the claw of such a crustacean, the particles of carloouate of lime coaleseed into globules of different sizes may be secn to be collected together in one layer. The globules composing this layer being joined together only by their contiguous sides, present, by their unattached portions, undulating borders, partaking of the general form of the claw; one border being parallel with its carity, from which it is separated by the deepest layer of membrane, and the other being parallel with the surface of the clarr. I may obscre that this is the general form and disposition of the coalescing globules, but it may be rariously encroached upon in different parts of the sulsstance of the shell by small circular groups of coalescing globules, which hare no connexion with the cavity of the claw, the convexity of these groups being turned towards this cavity, so that the radiating fibres of which the incliviclual globules are made up being all directed towards its concavity, that is, from 
the cavity of the claw, could have no communication with this cavity analogous to that of the fibres of dentiue with the cavity of a tooth. As the development progresses, the globules loose their bright and structureless character, and begin to present laminxe and radiating lines, just as the artificial calculi do. The lines, as stated of disintegrating globules, being most distinct when the globules are suffering disintegration, will be seen best in the layers remote from the cavity of the claw, that is, nearer to the surface, where the softer component of shell is in excess. These lines are the radii first of small circles, then, after the smaller globules have coalesced, they become so arranged in respect to the globule resulting from this coalescence as to be the radii direrging from its centre; and so they continue, as the coalescence advances, to become progressirely the radii of larger and larger circles, until at length, when this process is completed, they remain as the radii of a circle, whose centre is that of the part around which all the now completely coalesced portions of globular carbonite are situated. This, through the tendency of these lines, will be interfered with in a variety of ways and by a diversity of mechanical causes, so as to prevent the figure in any part of a shell from ever becoming perfectly circular; hence these lines will remain as the radii of a complex curvilinear form, whose elements are too complicated ever to admit of being mathematically determined. See fig. 5. 1 , which represents a vertical section of calcefying crab-shell. The lines in these shells, as in the case of those of the laminated artificial calculi, are generally continued uninterruptedly from one layer to another, so that they can be traced from the superficial surface of the claw to the decp one; but it must be observed that their distinctness diminishes towards its 
carity, where they degencrate into mere dots; and, furthermore, that their course is sometimes undulating, or, where the lamina join, interrupted, this depending upon the completeness of the coalescences of the earbonate of lime in the part of the shell examined. Fig. $5 \mathrm{~A}$ is a representation somewhat diagrammatical of a thin section of shell, in which the lamellis and

Fig. 5 A.

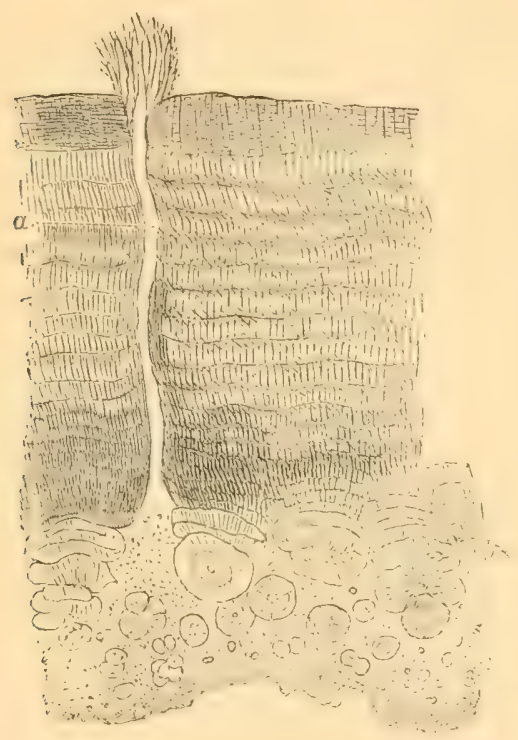

radiating fibres appear as two sets of undulating lines, one set, ealled by the physiologists lines of growth, corresponding to the lamellic of the artificial globules ruming more or less parallel with the surface, the other set corresponding to the radiating lines of the artificial globules, passing from one surface of the shell to 
the other. These lines exist in all parts of the shell of crustaceans, if only of sufficient thickness; as, for instance, in those embedded in muscular fibres, in which they can have no communication with any carity, so as to make them analogous to the fibres of dentine; but they are mercly, as in the artificial products, indications of the rirections in which attraction is exerted, with variable effect, upon the rows of molecules, producing alteruate lines of strong attraction and fceble attraction, or of strong cohesion and wcak coliesion; and thus this kind of arrangement of the molecules of carbonate of lime is altogether uncomnceted with any particular or specific function performed by the shell, as shown by its existence in all parts of it-the horny, as well as the calcareousand where the shell answers altogether different purposes, as, for instance, where it scrves for a covering and where it answers the purpose of bone; but these lines are merely the nccessary consequence of the manner in which shell is formed, and, under such circumstances, could not have been otherwise. Dr. Carpenter observes, that "the calcareous layer of the crab-shell is composed of a substance exactly analogous to irory, being very transparent, and apparently homogeneous, when cut into very thin slices, and being perforated by an immense number of minute sinuous tubuli, which run nearly parallel to one another, from one surface of the shell to the other. This arrangement may be secu by making a thin scetion of any part of the shell; but it may be shown particularly well in the end of the claw, which is thicker and of denser texture than the rest. A transverse section of this shows the tubes radiating from the entral cavity towards the external surface, and would, I feel assured, be regarded by the most experienced observer as the section of a tooth, if 
he were not informed of its real nature." The resemblance between dentine and crab-shell, as observed by Dr. Carpenter, is in most respects correct, and sufficiently striking to justify the inference that they are formed in a similar manner. This, I believe, is the general opinion of physiologists. The globular particles of carbonate of lime in shell are doubtless analogous to the globular dentine in tecth, and the apparent spaces between the radiating lines in the former correspond in a great measure to the so-called dentinal tubes in the latter. But respecting the fict of these being in either case tubes, the results of my expericuce and investigations are opposed to this riew. It is erident to me from the Plate $\mathrm{XV}$, fig. 11, in the descriptive catalogue of the Royal College of Surgeous, that if the tubes there represented are intended to show a form of structure analogous to dentinal canals, as they are gencrally termed, the author has made a great mistake. I may obscrve, that in the end of the crab's claw, as seen by the mieroscope, there are, as in other parts, the two different kinds of structure just described, one consisting of altemate dark and light, generally sinuous, lines, extending from the superficial towards the deep surface of the shell generally considered to be tubular. These lines exist in every part of the shell sufficiently thick to present them, and, in certain positions, as in the end of the claws, their course gires them very much the appearance of dentine. Ilowever, I may repeat the observation, that, in the claw, especially of the rery young animal, they de generate into mere dots before they arrive at the earity of the claw, and present nothing in their appearance of a tubular character. 'I'he cause of this arrangement of the particles of the shell has been explained, and there can be little doubt but that this same explanation applies to 
the spaces existing between the longitudinal portions of dentine. These latter spaces are in principle analogous to the canaliculi of bone, which will be fully explained in the article on bone. Hence, in one form of bone, the cementum or crusta petrosa canaliculi and dentinal canals sometimes exist together. The dentinal canals are merely spaces of feeble or imperfect cohesion, continued from the interglobular spaces, where such exist, between longitudinal portions of coalesced dentine to the pulp-carity. These passages, becoming a little widened from the contraction of the part in drying, and containing air, seem to have, under the microscope, especially if appearances depending upon distance are not sufficiently allowed for, the appearance of tubes. It is, however, incompatible with the function of tubes, as they exist in other parts, that a system of such organs, intended for the conreyance of scereted fluids, should be simple prolongations of the interstices of the body, as are the spaces between globular portions of dentine and the pulp-cavity of a tooth, this latter, notwithstanding its size, being only a cellular interval. The other structure is distinctly tubular. It does not exist, excepting in the tegumentary part of the shell, and it is this which is most unquestionably represented in the plate before referred to. These tubes pass from the external surface of the shell, through its substance, to its deep one. They have distinct parietes; and their peripheral extremities in different parts of the same shell present very different forms. All along the convex border of the claw each of these tubes projects beyond the surface, where it becomes free, presenting gencrally a feathery extremity, or sometimes it seems split up into small fibres like a brush. (See fig. 5 A, a.) Just at the point, and all along the biting edge, these tubes are rather smaller and 
more numerous; but, as might have been expected, they have not the feathery appendage. Notwithstanding, their ends are free and prominent. In the tubes represented in the plate alluded to no projecting ends are shown, these having been most probably ground off in making the preparation, but, in other respects, they perfectly agree with those I am describing, but in no respects with the flexuous lines before described. I have thin sections of crab's claw which had not been boiled, showing these tubes, but they are troublesome to make. They can be most easily shown in the very young crab, but the best way to see them is in the decalcified shell. Now, I can easily imagine that tubes thus constructed, with one of their extremities expanded, and thus rendered farorable for the operation of extensive endosmose or exosmose, and with the other extremity close to the part of the shell where the globular carbonate of lime is chicfly found, would serve admirably to convey the water in contact with the surface of the animal, containing salts of lime, to the membrane lining the shell, where a quantity of subcarbonate of soda is almays present-(this circumstance will be treated of more fully hereafter) - and thus to bring into operation all the conditions required to form the globular carbonate which occurs in this situation. But, on the contrary, in the ivory of the tooth, circumstanced altogether different to the claw of the crab, such tubes could be of no use, especially as they would be covered with a layer of enamel, and in some animals with a layer also of cementum, Now, as it is extremcly probable that, with organs so decidedly tubular, there would not exist another set of tubes to perform the same function. An additional reason is here afforded in farour of the opinion of the strueture of these alternating dark and light lines, 
being as before describer. It may be observed, further, that interstices of preciscly the same character as those existing between the particles of dentine are found also between the analowous portions of enamel, which are also considered by some anatomists as distinct tubes. The part of the shell of this class of animals next requining notice is that which is situated between the muscles, giving attachment by each of their surfaces to muscular fil)res, and therefore, both in situation and function, being analogous to bone. I allude to the parts called by anatomists "apodemata." These parts are made up of layers of calcified membrane rather loosely comected together, haring the appearance when dricel of pieces of white paper stuck together. The membranous layers of these parts, when just beginning to calcify, exhilitit all the stages of calcification very distinctly. In no part are the facts showing molecular coalescence better seen, from the minutest particles up to perfect globules, with lamine and radiating lines, and, if the part be sufficiently thick, the coalesence of these globules to form layers made up of the horizontal molulating lines, called lines of growth, and the perpendicular sinnous lines, or the so-called tubules of plyysiologists can be well seen. These parts require no other preparation than that of drying the shell, and then splitting off the thimnest possible pieces, which may be examined either in glycerine or turpentine. It is scarecly necessary to state, that these parts, in all shells, are not equally favorable for cxhibiting these appearances; scrcral, therefore, ought, if necessary, to be examined for that purpose. Of course the regular tubes, mentioned as existing in the tegumentary part of the shell, passing from its decp to its superficial surface, are absent in these parts; but, in other respects, their structure is similar. The last part of the shells of 
crustaceans to be mentioned is that which eorresponds to the osscous tendons of birds. It is to be found most dereloped where it is attached to the claws ealled the nippers. There is one attached to all the extreme claws. This part, like the preceding, is buried between muscular fibres. It consists of fibrous layers partially calcified, applied, together. Its structure is like that of the last part. 'Thin transverse sections through the thickest part exhibit the lines and lanelle, as described in the tegumentary portion. Frequent reference haring been made to the resemblance between the form of the carbonate of lime in these shells and that in the artificial products, I would wish it to be particularly observed, that in comparing these productsthe artificial with the natural-the parts compared must be in the same molceular condition, that is, the molecular, the globular, and the laminated of the one, must be sererally compared with the corresponding forms of the other, as there is but little resemblance in the appearance of the different forms of this compound, whether artificial or natural, when in different states of molecular arrangement; but the natural products do not differ in this respect more from the artificial than the rarious forms of the latter, in their dissimilar molecular conditions, differ among themselves; for nothing can be more unlike in appearance than the clear spherules, as they exist separately, and the globular bodies which they form by their coalescence, when their molecules have undergone their final arrangement into lamine and radiating imperfectly crystalline fibres, the closest inspection of the one could never suggest the idea of their being made up of the other. Such being the resemblance of the rarious parts of the shell in this class of animals, with the corresponding forms obtained by the artificial process, it now remains to cx- 
amine the chemical conditions under which the natural products are formed, and to compare them with those of the artificial process. It will be remembered that, for the production of the artificial calculi, two separate solutions are necessary, one containing subcarbonate of potash or soda with a glutimous material, the other a salt of lime, and that these solutions are to be gradually mixed with each other. Now, as it will be easy to show that these conditions exist as perfectly in the shells of crustaccans as they were described to exist in the artificial process, exactly the same results may naturally be expected in both cases. In the first place, I may observe, that an alkaline solution containing subcarbonate of soda and allumen, can easily be demonstrated on that surface of these animals which is covered with a calcareous shell. In the fluid taken from this part in the cral) or lobster albumen is thrown down by boiling, and subcarbonate of soda can be detected by the proper tests, and where the quantity of this fluid is insufficient to admit of the application of the ordinary reactives, the surface in contact with the shell can always be shown to be alkaline by simply holding a piece of reddened litmus paper for a short time in contact with it. I may observe, also, that this fact applies equally to molluses and other animals which I have examined, whose surface is corered with a shell of carbonate of lime. The production of an alkaline carbonate in these instances may then be looked upon as the effect of a natural process, and results, without doubt, from the decomposition of some of the salts of potash or soda contained in the medium in which these animals live, or with which their surface is frequently brought into contact. Under what agency this decomposition is immediately effected is not apparent, but it will probably be classed with rital pheno- 
mena, until a more advanced state of physiological and physical science reveals the chemical, or more probably the galvanic, apparatus by which it is produced. But at present the fact is all that is necessary to be considered in this investigation. And in the second place, that as these animals live very much in a fluid containing various salts of lime in solution, and as their shells are in all parts porous, and in some traversed by passages extending from the deep to the superficial surface, it secms impossible, under such physical and chemical conditions, that these two solutions, one containing salts of lime, the other alkaline, carlonate, and animal matter, should not first ponetrate, agrecably to the law of endosmose, the tissue of the shell, and then diffuse themselves, in consequenee of their unequal densities, through its substance, aud lastly, mecting together, undergo the same chemical decompositions with the same results as in the artificial process. If, under such physical and chemical conditions, these effects are not produeed, then laws, which under similar circumstances are invariably operative, must here be suspended. But in the present instance exactly the same form of carbonate of lime is produced as by the artificial process, which is the best evidence possible in farour of the process in the two cases being also the same. Now, with this fact, and considering that the same conditions, both physical and ehemical, have been shown to exist in the shell-process as in the artificial one, the evidence in farour of the identity of the two processes-the natural and artificial-is conclusive. But, notwithstanding all that has been said, it is possible that this explanation may be oljected to by some as being too mechanical to be true. The eellgerm hypothesis recuiring that all this should be regarded an the operation of the vital principle; that the globular 
portions of carbonate of lime of different sizes should be looked upon as cell-nuclei and "cells having an organic basis essentially cellular, within the cells of which inor.wanic matter is secreted and deposited ;" that their emrilinear contour should be regarded as the effect of a vital force, and the coalescence of two globules into one as eridence of cell multiplication by division. Now, in meeting this objection, I may observe, that if the globular portions of carbonate of lime occurring in these shells, so much like the artificial globules as to be deficient in no point denoting identity of structure, are the effect of a rital force, I see no reason for questioning the identity of the vital and physical forecs, since, in this case at least, their eflects upon matter appear in all respects the same. Furthermore, as it has been shown that these shells are jorous and partly memloranous, and that the globules of carbonate exist in various parts of their substance, and that there is also an alkaline solution in contact with the deep surface of the shell-indeed, that there exist, either within its tissue or contiguous to it, all the conditions necessary for cudosmose, diffusion, aud chemical decomposition, it must follow, as a matural consequence, that, if these globules are not formed on plysical principles, but by the vital foree, the first act of this force will be to put a check upon all these physical agencies. To prevent chemical action, the exterual surface of the shell must not be penetrated by the water containing one of the elements of the globular carbonate of lime, nor the internal or deep surface by the fluid furnished by the animal containing its other elements, notwithstanding the existence of tubes extencling from the one surface to the other has been demonstrated. And if these solutions should come into contactand with such mechanical contrivinees, apparently in 
tended for the very purpose, it seems to be unavoidablethen ritality must prevent them from acting chemically on each other; the uperation of their chemical affinities must be orerruled, and rendered inoperative. And why ali this opposition? Simply that vitality may be afforded an opportunity of doing that which it has been demonstrated can be just as well done without its aid or interference! As this is the only conclision which such a supposition learls to, there is, I think, orerwhelming evidence that the formation of the globules of carbonate of lime-the organic-cells of some authors-in the shells of crustaceans is due directly to physical and chemical ageney, and that these globules are identical in structure and in their mode of formation with the artificial globules. But, lest it should be inferred from all that has been stated that I regard the formation of the shells of crustaceans as cntirely physical, a few words of explanation, as to the limit which may be assigned to the operation of this agency in the formation of these structures, are necessary. Withont pretending to draw an exact line of demareation between what is physical and what physiological, I may observe that there is just one fact deserving notice which gocs a great way torards cfiecting this, which is, that when ritality makes use of material substances it nerer disunites them from those influences which are at all times acting upon them, but, on the contrary, it employs these influenees, maling them subscrve its omu purposes, whether the matter employed be in the simple condition of a crystal or the complex form of a regetable or an animal structure. Hence, in the formation of the shells of crustaceans, vitality derises the means by which the materials composing them are brought together, adjusts their proportions, and regulates the conditions 
under which they are acted upon by the plyysical forees during the different stages of their elaboration into perfectly formed shells; just as, in the artificial process, vitality displayed in an act of the will first brings together the material substances necessary to form the globules of carbonate of lime, then proportions them, and, lastly, arranges the conditions under which these materials are required to be acted upon by the physical forces. There is, however, probably this difference, that the latter is the result of distinct and separate mental acts, whilst the former is all comprised in one act, which embraces also all the operations of nature.

The preceding observations, in reference to the chemical conditions under which the globules of carbonate of lime are formed, apply entirely to the dermic portion of the sheils of crustaceans, and especially to those parts where the globules are formed entirely out of the reach of the blood, as close to their external surface, or around the passages extending from this surface to the pigment membrane. But there are other parts of these shells, as the septa (apodemata) between the cavities containing the muscles aud those parts of the shell corresponding to the osseous tendons of birds, where these conditions cannot be demonstrated. In these situations, the shell being imbedded in the substance of the muscles, and giving attachment to their fibres, corresponds in function more to the endo-skeleton or bone than to the exo-skeleton. Now in these parts of the shell the globules of carbonate of lime are formed exactly as in the other parts, and as in the artificial process. Nomhere can all the stages of molecular coplescence, from the minutest particles up to the most perfectly formed globules, be better seen than in these septa; a fact indicating an undoubted identity of process 
and similarity of physical and chemical conditions. With respect to the alkaline carbonate, it can be demonstrated on the surface of the parts connected with these septa; hence this chemical condition is the same as in the other parts of the shell, so that the difficulty exists only with regard to the source from which the salt of lime proceeds, and the route by which it anrives at the surface of the shell, moistened by the subcarbonate of soda. But this question admits at once of simplification and the removal of the first part of the difficulty, there being but one source by which the salt of lime can be furnished, which is the water taken into the system of the animal through the instrumentality of its digestive apparatus. Now, as to the route, this can only be the vascular system, which, being that through whose medium the elementary constituents of all the other structures are conveyed to their various points of destination, may be considered also to convey the soluble salts of lime to the parts where they are required. Now, it can be shown, by the application of ehemical tests to these septa, that an allialine carbonate is formed on their surface, and, by the microscope, that minute as well as larger globules of carbonate of lime exist in the same situation; and, therefore, it may be fairly concluder that this carbonate of lime is formed in the place where it is found, and not in the interior of the adjacent blood-vessels, and, more especially, as being insoluble it rould not pass through their coats in particles of such a size. Hence, taking all these circumstances into considcration, it scems in the highest degree probable that all the conditions, both mechanical and chemical, necessary for the formation of carbonate of lime in the case of the deeply-scated shellstructure, are essentially the same as in the superficial ones. The fluid containing these substances in different states of 
combination is the blastema or nutritive fluid of physiologists advocating the cell-germ theory; and, containing all the elements of the structures in progress of formation, it may be considered also as the nutritive fluid, according to the riew now advocated. There is, howerer, this difference in the explanation of the process by which this fluid is elaborated. According to one view the vital principle is imparted to separate portions of matter, endowing them with distinct and individual powers, to be employed in accordance with ecrtain hypothetical laws; according to the other, vitality is considered to disdain all such subdivision of a general principle and such co-operations, yet still to produce the same effects on this fluid but by the employment of certain physical forces from whose operation matter cannot be dissociated. I shall next consider the structure and mode of formation of shell-tissue as it occurs in the shells of molluses. Of these I shall select such as are the most common, and in which the facts observed comnected with their structure and development admit of heing most easily verified. The shell of the mussel, aud still more that of the oyster, furnishing all that is necessary to be observed in this class of shell-tissues, I shall confine my obscrrations to them, taking it for granted that all the rest of this class of animals have their shells formed upon the same plan. The shells of the mussel and oyster are laminated like that of the erab or lobster, and grow in the same manner by the sucecssive additions of new layers to the interual surface of the layer last formed; so that each valre of a shell presents the form of a cone, whose summit is the valve or layer first formed, and whose base is the layer formed last,- - the layer in immediate contact with the surface of the mollusc. Each layer also consists of a membrane calcified, especially ou its exterual surface 
This arrangement is best demonstrated by putting the entire valve of a small mussel into hydrochloric acid, so feeble that the too sudden escape of the carbonic acid will not break the membrane into fragments, but raise it entire.

Fig. 6 .

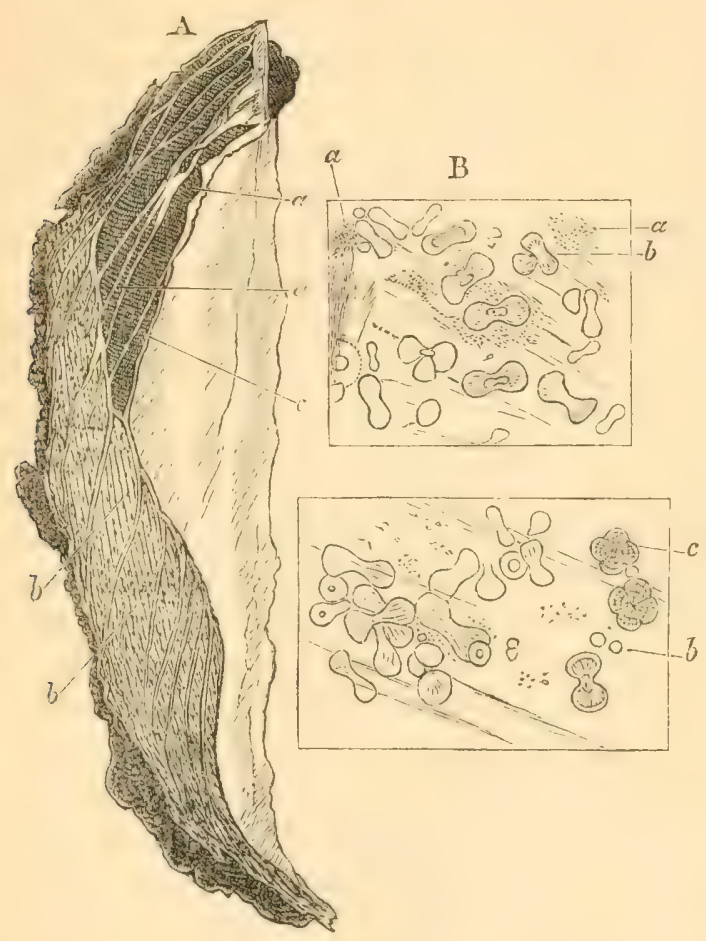

The most external membrane of the shell of this molluse rloes not become calcified, nor does it receive an addition to its entire surface, but only grows at its free border. It is of a homy structure, presenting distinct markings. But 
the internal membrane, on the contrary, as the mussel grows, receives an addition of new membrane to the whole of its inner surface. 'This membrane is perfectly homogeneous, having no markings whatever, excepting close to the elge of the valve, where it is continnous with the external horny membrane. Nearly the same arrangement exists in the lamine of the shell of the oyster, which being much less firmly connected together, are more farorably circumstanced for the examination of the process of calcification. The physical conditions farorable to the process of coalesecnee of the minute particles of carbonate of lime into a globular form are less interfered with by so close a proximity of its membranous and calcified layers as exists in the shell of the mussel. Hence I shall confine my descriptions almost entirely to the appearances showing the nature of this process, as they are found in the slecll of the oyster. I may observe that I have found those oysters which are of the largest size, and which have large carities between their laminx, as represented in fig. $6 \mathrm{~A}$, to be best adapted for displaying the development of shell-tissuc, and that the most successful examination I have made of this tissue in its earlicst state of calcification have been in the month of June. I name this circumstance since the season of the year may have a great deal to do with the development of the shells of these molluses. The common way of displaying the structure of these shells is by making vertical sections of various parts of them, and grinding: them sufficiently thin to allow of being viewed ly transmitted light. These sections are very useful, and indispensably necessary to show ecrtain facts connecied with slell-structures; but they afiord no information relative to their development. This ean only be learned from the examination of extremcly thin, partially calcificd laminx, 
sufficiently transparent to admit of being seen by transmitted light, without the necessity of any kiud of manipulation which can at all injure their structure, or alter their natural appearance. The eariier the stage of calcification, the more complete and spherical will be the forms of the carbonate of lime, and the more satisfactory the indications of molecular coalescence. If the piece of membrane examined has its surface entirely covered with calcareous matter, it will not show the earlicst stages of coalescence, and therefore will only furnish imperfect evidence of this fact. The indications of this process are best displayed on those portions of ealcifying membrane which are situated over the interlaminar cavities before alluded to, separating these spaces from the gencral cavity or hollow of the valve. In such situations the coalescing particles being placed on a membraue intervening between two spaces will be almost as little interfered with in their process of coalescence by the pressure of the adjacent parts, as if they were on the slide of glass, as in the artificial process ; and hence the globular particles formed on membranes so situated, ought to be as perfect as those produced by that process. And such is the case. I have in my possession specimens of these globules in every stage of coalescence, distinguishable from the artificial formation only by the membranous tissue which forms their bed. Partially calcified membrane, like the above, is most easily obtained by keeping oysters which have those caverns on their shells from the contact of water, until the branchire become dry, when the calcifying membrane, becoming slightly discoloured and hardened, can be both more easily distinguished and more readily separated from the contiguous parts of the shell. (These globules are not to be confounded with crystals which 
form at the same time.) Such specimens cali cither be put up in glycerine or in Canada balsam. And it is scarecly necessary to add, that they are only to be met with occasionally, and under farorable circumstances, when the development of these parts of the shell is just in the proper stage. The parts of these shells, on which the globular carbonate of lime occurs (though in an inferior degree of perfectuess of form and transparency to those just described), to be next examined, are the septa, situated between the interlaminar carities. These caritie: are always filled with saltish water containing soluble animal matter, and free carbonate of sola, so that reddened litmus paper put into this water soon becomes blue. The globular deposit is alwars on the surface of the lamina in coutact with the fluid, and therefore the lime has most probably been furmished by this fluid, after the alkaline carbonate, still in excess, had decomposed the lime-salt held by this fluid in a state of solution. Hence there is in this case very strong cvidence that the lime entering into the composition of the globular carbonate comes directly from the water in which the animal lives. The only objections to this conclusion which can be raised, are, that the water in these spaces nerer was contaminated with a salt of lime, or, if it had been, this salt was separated from it before the solution could get access to the cavity. Now, as all common water contains lime in solution, in one or other state of combination, the first objection can have no weight; as to the second objection, it may be observed, that the water contained in these spaces has lost a substance which it had before held in solution, but that it now contains an excess of the very compound which always precipitates this substance, a sufficient reason for its absence. But, besides, there is animal matter in 
this solution, and the other conditions necessary to form a globular compound of the absent substance. And this compoumd, too, actually exists on the side of the cavities containing the fluid in which these chemical changes are taking place, shoming that this compound is not only furnished in part directly from the water, but also that the principle of its formation is analogous to that of the artificial process for obtaining the same form of carbonate of lime. Hence, weighing all these circumstances and deductions together, it will appear next to certain that both inferences are correct, and that therefore the fluid contained in these spaces camnot have been deprived of its salt of lime before it arrives there. The thimmest septa between these carities consist of several laycrs of an exquisitely fine and perfectly homogencous membrane, coated more or less thickly with calcareous matter. If the larer bound immediately the cavity, the surface of it in contact with the fluid is, as was before observed, studded with particles of carbonate of a globular form; if the layer is not so situated, but connected with another layer, the calcareous matter is in thin scales, which can be demonstrated to result from the flattening out of the globules. This membrane can always be shown by examining a fragment of one of these septa with the microscope, while it is acted upon by very diluted hydrochloric acid; but very frequently it can be found only partially or very slightly covered with coalescing particles of carbonate of lime. And this is the most favorable condition under which it can be examined. Dr. Carpenter says, that he has ascertained that the nacreous lustre is due to the plication, or folding of a single layer of this membrane in such a mode that the folds shall lie over one another in an imbricated manner. Although Dr. Carpenter's evi- 
dence upon this point appears very clear and circumstantial, it does not agree at all with the facts which occurred to me in examining the same parts, and therefore I am obliged to differ from him. I have never seen in this membrane, when completely separated from the calcareous matter, any trace of this nacreous lustre, and consequently believe it to be due entirely to the carbonate of lime, and not to the membrane on which it is deposited. In my experiments I have always employed the polariscope, which furnishes the best means of deciding this point. Moreover, the nacreous lustre of a piece of shell is not in the least impaired by boiling it for any length of time in liquor potassa; and but little so by heating it to redness, which must have been the ease if the lustre were produced by the delicate folds of what Dr. Carpenter has called the nacre-membrane. Now, from what has been stated con. cerning the chemical part of the process by which the carbonate of lime in a globular form is produced in the shells of crustaceans, but little remains to be added to what has been already noticed of the formation of this compound on the septa between the interlaminar carities. A few words will finish this part of the subject. In animals of this class, all that surface which comes in contact with the shell is moistened with a solution of carbonate of soda and animal matter, which ean be casily demonstrated, as before observed, by the proper tests. I may just notice, however, that a piece of reddened litmus paper, kept in contact with the surface of a mussel or oyster for a minute or two, never fails to show the presence of an alkali. I cannot say that this is the case only with the part connected with the shell, as I have not tried it on all parts of these animals; but that does not at all affect this question. Besides this secretion of alkali, a membrane is formed on 
the surface of the oyster, to receive the carbonate of lime precipitated from the water, which has fice access to the surface of this membrane next the shell. In consequence of this membrane, with the calcareous matter formed upon it, beginning to adhere, first to the middle part of the previously formed layer of shell, and last to the circumferential parts, the water in which the oyster is placed can easily pass under those parts of this layer which are being calcified. And also in this way the water is gradually shut out from the parts of this layer as their calcification becomes completed. As the form of the growing oyster becomes less convex, its surface does not keep parallel with that of the shell; hence, the membrane formed on this surface bridges orer the most concave part of the shell, and a space is left, at first between the shell and this membrane, but afterwards, when the membrane is calcificl, this space is of course between the last two layers of shell. It is thus that these interlaminar cavities are formed. These are the portions of membrane, which, when only partially calcificd, have been already noticed as displaying the most perfect forms of the globular car. bonate of lime. (See fig. 6, A, which is a representation of the shell of one of the largest kinds of oysters; $a$, $a$, marking interlaminar spaces in which the alkaline fluid was contained; $b, b$, similarly formed spaces, but without fluid, and filled up with amorphous carbonate of lime; $c, c$, septa between the spaces containing the fluid before mentioned. $\mathrm{B}$ is a representation of portions of calcifying membrane, taken from the part where this membrane bridges over the deepest parts of the shell, as represented by $c$, fig. $\Lambda$; $a$, $a$, marking the molecular state; $b, b$, single spherules and dumb-bell-shaped particles; $c$, laminated globules, in which the cross can be seen by 
polarized light.) I may observe, that, although the primary and sceondary forms assumed by the globular carbonate of lime are perfectly alike in clustaceans and molluses, yet their ultimate forms are rery different; but, these differences depend upon mechanical causes, and admit of being imitated to a great extent by modifying the artificial process. In crustaceans, the ultimate form of the carbonate of lime is the same as that of those artificial calculi which are formed on the under surface of the glass slide, and which have the laminated structure with the radiating lines. These, during their formation, have not been so much exposed to pressure from the contact of the surrounding parts. In the shells of molluses, as the oyster, the ultimate form is that of flattened plates, closely comected together, and overlapping one another. This form can in some measure be produced in the artificial process, by allowing the globular deposit to remain at the bottom of the vessel in which it was formed, for sereral months. To produce this effect, the carbonate must not be mixed with triple phosphate. The white gum is the best in this case, and the quantity of alkali must not be sufficient to saturate the thick solution of gum. In good natural specimens of this form, globules perfectly spherical and beautifully laminated can be seen mixed with those in which the process of flattening is going on, and can be distinguished in its several stages. This is especially indicated by the laminated form becoming less and less distinct from the circumference to the centre, where it remains visible longest, afterwards disappearing altogether; and the form having become flat, that which was a globule then becomes reduced to a very thin plate, with an irregular or zigzag margin. During this transformation of the globules into plates, and after these plates 
have acquired their ultimate form, they show no tendency to coalesce, but remain intimately connected with the nembrane on which they were formed. I have several specimens showing all the appearances above described. There is a form of carbonate of lime occuring chicfly at the edge of the valves of these shells, which has been particularly noticed by Dr. Carpenter, in the Pima. It also occur's in pearls produced by the oyster, making up the principal part of their substance, where, as in other parts, it can be shown by a proper mode of examination to result from the coalescence of other smaller particles into globular bodies of varions sizes, which occupying the softer parts of the shell, do not become pressed into flat plates, as in the densest parts, but which are still so crowded together, as to be prevented from retaining the spherical figure. Besides these forms of carlonate of lime in the shell of the oyster, there is yet another form which is neither globular nor distinctly crystalline. It is the amorphous carbonate before alluded to, as occupying some of the interlaminar spaces in the place of the alkaline fluid which is contained in the other spaces. This amorphous earbonate can only result from the mixture of successive portions of water, containing in solution the compounds of lime, with the solution of alkaline carbonate formed on the surface of the animal. These two fluids finding access to these cavities, and the latter being probably deficient in animal matter, a decomposition takes place, and a carbonate is formed, not of the globular but of the amorphous character. Occasionally, in the thin plates of oyster-shell, branching dark lines are seen, resembling, in their mode of ramification, Conferrae. These, in the perfectly calcified shell, are so blended with the contignous calcareous plates, as not in such cases to admit of being 
satisfactorily examined. Howerer, in an imperfectly calcified layer, sufficiently recent, they cau be so far detached, whilst in their growing condition, from the layers of shell, as to remore all doubt as to the fact of their being true Conferre. These growths are found on the surface of the calcifying membrane, which is exposed to the contact of the salt water, this being without doubt the medium by which they are brought, in the condition of sporules, into this position. The quantity of this confervoid growth differs very much in different shells. In shell-structures the earthy matter is considered by those who have written upon the subject, to be contained in the interior of cells. Dr. Carpenter, when treating of the prismatic cellular substance of shells, observes, that "The resemblance in their structure and position between the prismatic cellular substance of shells, and the prismatic epithelium covering the mucous membrane of higher animals, leaves no room for doubt of their analogy, and we may consider this form of shell-structure in the light of a calcified epithelium, the carbonate of lime being deposited in the carities of the cells, and in general completely filling them. In most sections of Pimn a greater or less number of dark cells may be seen, which are usually disposed with some degree of regularity. These I have reason to believe to be cells incompletcly filled with carbonate of lime, the spaces remaining in which, being occupied by air only, present a dark appearance under the microscope, according to the general principle well known to obscrvers." Now, according to this view of the structure of shells, which is I believe the one generally maintained, cells are formed first, and afterwards carbonate of lime is deposited in their carities; hence, in the process of derelopment of shell-tissue, 
these pre-existing cells ought to be visible under the microseope; and the carbonate of lime afterwards deposited in their cavitics ought to be apparent when examined by the polariscope, especially as the deposition must be somewhat gradual, and the means of detecting it by this instrument are most delieate and certain. However, notwithstanding these facilities, and having the aid of all that is necessary for microscopic examination, I have not been able to see anything which gives the least comntenanec to such a ricw, or which, in any way, agrees with the appearances said to present themselves in this class of tissucs. In the first place, the membrane on which the carbonate of lime is precipitated is in most cases as devoid of marking of any kind, and as transparent, as a filn: of glass. This is expecially the case in the orstershell, and many parts of the membranous layel's of the crab-shell, where it forms septa between the carities containing the muscles, so that this membrane, in these cases, cannot be regarded as consisting of cells for the secretion and retention of the carthy matter. Sccondly, when this membrane is begimning to be calcified, and only rery partially corered with minute particles of earthy matter, nothing can be detected, either upon, or within it, so related to these particles, as to answer in any way to the description of a cell with these particles contained in its cavity. All that can be seen are minute particles joining together to form larger ones, and, these again joining to form particles still larger, until they acquire the size and form of distinct globules; but still, during the whole of this process, nothing like a membranous cell erer makes its appearance. It is true, that if these particles of carthy matter are acted upon by hydrochloric acid, an animal basis is left, the same as if a similar compound 
formed artificially were treated in like manner; but this basis being a constituent of the smallest as well as of the largest particles, and being formed simultancously, and in combination with the carbonate of lime, must be so blended with the carthy matter of the latter, as to be present in every part of their substance; hence the two materialsthe earthy matter and the animal basis-being thus incorporated in every globule large enough to be looked upon as a true cell, would in no way agree with the idea of a hollow body with a membranous exterior, and with an internal cavity either completely or incompletely filled with carbonate of lime, which, from the deseriptions given of these cells in the works of those who have written upon the shell-tissues, is evidently the idea generally entertained of these globular bodies. And what is still more remarkable, these so-called cells are believed to possess an inherent vital power of forming others exactly like them. And, thirdly, when the carbonate of lime is precipitated on a membrane which is not homogeneous, but is marked out into squares or parallelograms or other figures, still the marking has no influence on the earthy matter formed upon its surface. Sometimes, however, it scems to follow these markings, and then has the appearance of being contained in cells; yet such a circumstance is completely accidental, as any one may couvinee himself who will examine such appearances without any bias; when it will, at once, be apparent, that the earthy matter is deposited, and cxtends itself irregularly, and withont any limitation, by such markings, or without in the least corresponding to them. I may just notice here, that although the currilinear contour may not be regarded by histologists as essential to organic cells, yet, that the tendency of the vital foree is always to produce that form. Hence in the descriptive and 
illustrated eatalogue of the histological scries contained in the MIuseum of the Royal College of Surgeons, Plate XVI, fig. 14, there is a representation of perfect rhombohedral masses resembling crystals, taken from the shell of the common oyster. Such crystals are found, when treated with muriatic acid, to leave a residue of the same form as the original crystals, from which circumstance alone they are considered to be organic products, the residuum being regarded as the cell, and the carthy matter the cell-contents. The crystalline form, in these cases, is attributed to "the animal cell not having sufficiently controlled the mode of deposition of the earthy particles, they have, in consequence, assumed the crystalline form." I may observe, that, in globular calculi, containing a large proportion of triple phosphate, when in a state of molecular disintegration, in consequence of being kept in a denser medium than that in which they were formed, almost the same kind of crystals are produced. See article, 'Complete Molecular Disintegration.' The particular structure named by Dr. Carpenter, "prismatic cellular substance," found in some parts of the shell of the Pinna, and about the edge of the shell of the oyster, forms no exception in its mode of formation to that of the other parts of these shells. But, on the contrary, if examined in a sufficiently early stage of development, it will be seen to present appearances as indicative of molecular coalescence as any other shell-tissue. This substance occurring in the softer and more membranous shell-tissues, where the globular particles are not exposed to pressure on all sides, as in the hardest parts, and, therefore, flattened out into scales, is only pressed laterally by the adjacent globules, and, therefore, flattened only on the sides where they lie in contact, the parts of these globules which are free retain- 
ing their convexity. In Dr. Carpenter's plate, representing a portion of the shell of Pinna, two small spaces, situated at the conflux of several compressed globules, are represented dark. In these the calcareous matter is said to be deficicnt, and the dark appearance, as before obscrved, is attributed to the presenec of air. 'This appearance is fairly represented in Dr. Carpenter's delincation; but the cause he assigns for it is not, I am persuaded, the right one, being uncomected altogether with air. It is caused by the particles of globular carbonate of lime, in which this appearance is olsecrable, being both more dense in structure, as well as smaller than those to whirh they are contiguous, and consequently more highly refractive; hence the smaller, that is, the more convex these particles are, the darker they appear. If a single layer of these compressed globules be viewed by reflected light with the superficial or outer surface uppernost, the small particles, looking the darkest by transnitted light, will then appear to he of the densest white. The smallest, or dark particles, are situated at the conflux of several larwer ones, and generally deeper, but not always. They present, therefore, great difference in their shade and in their appearance, accordingly as, when viewed, they are superficial to or decper than the contiguous particles. Now, these particles being, from their greater density and sualler size, more highly refractive than the coutignous ones, an appearance is produced resembling that eaused by the presence of air; this appearance being increased ly the unequal refraction of the globules through which these smaller ones are secu. But, it may be olserved, that, as the appearance of air in these particles is only observable when they are seen with one of their sides next to the microseope, it camnot be occasioned by the prescnce 
of air. These small globular portions are well seen in decalcified specimens. I have such specimens showing these facts. I may obscrve, also, that the examination of the decalcified shell of pimna perfectly agrees with the fact just demonstrated, namely, that its component globules are made up of earthy mattcr, and animal basis molecularly combined, and not of cells formed first and afterwards filled with the formor material. In the shell perfectly deprived of its component carthy constituent by hydrochloric acid, the appearance is so little altered, that were it not for the cridence afforded by the polariseope, the fact of its decalcification might be doubted. The portions of animal residua perfectly retaining their convexity, and their distinction of dark and light parts, when viewed by transmitted light, show that something is left which had been in intimate mion with the carbonate; but, as a matter of course, these appearances are less marked than before. There is no appearance of distinct cell-walls in these globules, when no pressure is made upon them; howerer, when pressed together, their exterior denser layers, which owe that density, as a natural consequence, to the mechanical forces concerned in their formation, may be forced one orer another, and thus made to present the appearance of a cluster of compressed cells. As for the presence of nuclei, or the germs of cells in these residua, I may have seen something as characteristic as the granules represented in p. xrii, figs. 2 and 10, of 'The College Catalogue,' but I am not aware that I have; howerer, if I had seen such gramules, or eren some much more defined and regular in their form, I should have required eridence much more elear than has yet been andluced, before I could be convinced that each of these granules is endowed with the power of constructing a 
globule, anatomically and physiologically, like the one in which it is contained. I have frequently seen patliologists, in examining morbid products, point out cells with their cell-germs extending through several generations; but to me the matter has always appeared to be entirely speculative, and perfectly gratuitous. Lastly, if the exterior laycer of each of these globules had been a cell constructed according to the ecll-theory, for the purpose of secreting the carbonate of lime contained within it, the question might be asked how it happens that, with the microscope, aided by the polariscope, all the carbonate can be seen when perfect globules are being acted upon by acid, gradually to disappear from their interior, and to leave the part which it had before occupied demonstrable, whilst, by the same means, no deposition of carbonate into the interior of similar bodies can erer be shown? whilst if it had been deposited in previously formed eells, the fact of its deposition ought to have been as demonstrable as that of its removal. The only answer this question admits of is, that cells or globules so constructed have only a hypothetieal existence, and that there are in fact no such globules apart from their earthy constituent; but that in all stages of their development, the earthy component and animal basis are alwars found together, which being possessed of a property of coalescence, as shown by experiment, pass throngh a succession of coalescences, until they result in the formation of the globular bodies in question. The hard tisine next to be considered is bone.

\section{ON THE STRUC'TUIRE AND FORMATION OF BONE.}

Of all the tissues wheh have been dexeribed in the preeding lages, the calcified tendons in crusticcons conc 
nearest, in composition and function, to bone. These tendons agree almost in every respect with the osseous tendons of birds. Both structures give attachment to muscular fibres, and are composed of the same chemical substances, though in different proportions; the carbonate of lime preponderating in the former, the phosphate of of lime in the latter. Now, considering that these strictures present such marked points of resemblance, and differ only in the relative quantities of one of their constituents, it scems impossible, that they should be formed upon totally different principles, and according to diametrically opposite laws; that is, that the ultimate forms assumed by the particles of the one should have been determined by physical force, whilst the similar forms assumed by the particles of the other should have been determined hy a vital force; hence, it must be inferred that both are produced under the direct influence of the same agency, whether it he physical or vital. Now I consider that the efficient cause determining the mode of arrangement of the substances composing shell-tissues, has been demonstrated to be pliysical; and therefore, as a quod sequitur, the morle of armgement of the material constituents of the osscous tissue must also be physical. But as this is so important a question, and as this inference is at variance with the opinion of all physiologists, I cannot do less than make this tissue a subject of special examination. It is a rell-known fact, that in erery form of hard tissue where phosphate of lime is present, there is also mixed with it some carbonate of lime. The necessity of this combination, and the use of the carbonate of lime will be apparent from the following facts. If pure pliosphate of lime be formed and drposited, muder precisely the same conditions as those mentioned in the process for 
olstaining the globular form of the carbonate of lime, it does not, like this compound, assume that form, or lose its crystalline character, but its crystals congregate into globular masses; if, however, a small quantity of carbonate of lime be formed together with it, then the phosphate of lime, combining with this carbonate, forms a globular coalescing compound, like that of the globular carbonate of lime. This compound is not quite so homogeneous as that of the ummixed globular carbonate, but its optical and physical properties are very similar. This combination can be produced by introducing into the same bottle a small quantity of phosphate of soda, and muriate of lime, dissolved in separate portions of white of egg, and allowing them to mix gradually, when a phosphate and earbonate of lime will be formed. The carlonic acid is furnislied by the alkaline carbonate contained in the white of egg, which is quite sufficient to prevent the crystalline arrangement of a considerable quantity of the phosphate of lime. This effect of a small quantity of carbonate of lime is also beantifully secn in the change which it produces on the form of the crystals of triple phosphate, forming with that substance the largest and most perfect spherical calculi. (See page 36). Having. now determined by experiment this important fact, which, being comnected with the chemical composition of bone, stands at the head of this inquiry. I shall next give the results of a careful examination of the appearances prescuted by bone in its very earliest stage of development, as seen in the ossifying teudons of birds, and in some parts of the lower animals. The structure of the osseous tissue has been too exclusively studied by means of thin sections. These are not only useful, but for some purposes indispensable, still they give no idea whatever of the 
appearances first presented by the cartly deposit, or of the arrangement and form it assumes in a short time after its precipitation. The osscous tendons which I have found to be well adapted for this examination, are those of the dorsal muscles of any young bird. In the parts of these tendons where the ossification is just beginning, minute scattered particles can be seen taking somewhat the course of the tendinous fibres. On the same tendon, rather nearer to this muscle, these particles being more numerous, lie close together, and extend in patches, of no definite form or size, along with its fibres. In some of these patches, when examined by transmitted light, darkish, ill-defined spots can be scen, arising, I have no doubt, from a deficiency of the earthy matter at these parts, and the accumulation of it in the parts around. In others, where the earthy matter is much less in quantity, the particles can be seen to have arranged themselves in circles, more or less complete. As there can be no question but that the process of ossification in these tendons is essentially the same as in other parts, and that it is identical in all classes of animals, I shall continne the description of the appearances presented by the eartly deposit, as I have seen them in the bones of the reptile, the fish, and the human subject. There are two forms in which the ordinary process of ossification may be studied; one, where the ossifying process is confined to isolated portions of earthy deposit; another, where the bone in process of development is commected with perfectly formed bone. The former can be seen rery well in the young frog, or in a very young fish. (Fig. 7 is a representation of the appearance presented by the particles of phosphate of lime taken from a frog about one inch in length, and with no other dissection of the part than was neces- 
sary to remore it from the animal. It is preserved in glyecrine. ", is a piece of cartilage with nodulat edportions of earthy matter evidently formed upon it by the coalesecuce of previously existing particles of various sizes, but inclining to a rounded figure; $b$, these nodulated portions still furtlier coalescing to form osscous rings. These rings are, in this subject, formed upon a cartilaginous sterum, and have been exposed by mercly stripluing off the skin. They have no definite relation to the cartilage-cells bencath, nor is there any appearance of the phosplhate being deposited in their interior, or confined to

Fig. 7 .

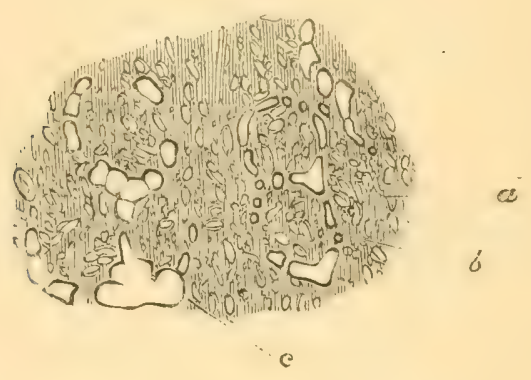

the intercellular substance around them. These rings neither correspond in number nor in form with the cartilage-cells. Their long axes may be comeirlent or at right angles. Indeed, there is nothing which agrees with the notion that the derelopment of the one is in any way comnected with that of the other. Thesc osscous particles simply coalesce upon it as they do upon tendon, or upon membrane where no such cells have erer existed. Hence the use of cartilage in this and similar situations, is without doubt simply to serve as a temporary substitute for 
bone; and all those changes of strueture thich have been so claborately described in the parts of cartilage, near to which the process of ossification is going on, are only such as are consequent on the remoral of cartilage, and not necessary for the production of bone, as is shown by the fact that bone is formed just as well without cartilage as with it. As the proecss of ossification advanees, the circular areas enclosed by the osseous rings become gradually but only partially filled up. (Fig. 8 is an accurate representation of this stage of the ossifying process from the same animal. The part here represented had not been in any way mutilated. It was in glycerine. It shows how the canaliculi are merely the result of spaces left between the coalescing granules, which converge towards, Fig. 8. and terminate in, a central unossified part, called a lacma, or what physiologists and histologists consider to be a "bone-cell.") The other form of the ossifying process, that in which the bone in progress of development is comnected with fully formed bone, rescmbles the one just described, in all points but one, which consists in the osseous granules being deposited in loops or arches, with their extremities connected with the most recently formed bone. The spaces enclosed by these osscous arches are at first large, but they become gradually but imperfectly filled up, exactly in the same manner as the circular areas in the other form, and canaliculi and lacume remain. This form can be seen, also, without mutilating the parts, in the young frog, as well as in the tendon of the bird, as before observed. I have seen it 
very beautifully in the lamina spiralis of a child, agred six years. In this case, the particles of phospliate of lime are minute, but spherical, and show decided indications of coalescence. I have in my possession a preparation showing this fact very distinctly. It is scarcely necessary to say that I have not mistaken the arches formed by the cochlear nerves for bone. But the best of all subjects for demonstrating the fact of molecular coalescence, is the very young fish, in which occasionally the globular particles, containing probably a larger proportion of carbonate of lime mixed with the phosphate than is contained in the bones of other classes of animals, exhibit, under polarized light, a dark cross, like the artificial globular particles, and like many of those found in shells. Now, I may observe, that in all these examinations of the incipient stage of ossification, as seen in the tendon of the bird, in membrane, and in cartilage, all these parts have been in as normal and unmutilated a state as possible, yet I have never been able to sce anything like the six dereloping bone-cells depicted and described by Professor Kölliker in his manual of Histology, namely, "simple bone-cells; compound ones running to a parent-cell, with two secondary cells, each arising from free cells, from rickety boue," p. 81, English translation. (It would have been better if Professor Kölliker lad selected specimens intended to illustrate the normal structure of healthy bone, from sound ratlier than from rickety bone. Are specimens of dereloping bonecells, exhibiting the appearances represented in the plate alluded to, so difficult to be obtained from an unsuspected source, that Professor Kölliker is obliged to get them from a suspected one? At any rate, this is not the simplest way of prosecuting the inquiry. By employing a tissue in an abnormal state to illustrate its normal 
structure, a new condition, or a fresh unknown quantity is introduced into the problem; and it is exceedingly doubtful whether a person prudently sceptical would not on that account object to any conclusion arrived at from such a mode of investigation, and more especially where that conclusion is to serve as a foundation upon which the superstructure of the histology of a part is to be erected. We deduce the nature of a diseased structure by comparing it with a sound one, the latter being taken as the exemplar. But Professor Kölliker reverses this mode of procedure, and builds up his tissue of bone with materials taken from the osseous tissue of a rickety subject. No wouder, then, if his histology of this structure partakes also of the abnormality of the elements of which it is composed.) All that can be seen in the very earliest stage of the ossific process are minute particles of earthy matter, which, from their number, camnot possibly be germs of cells, nor, from their size, can be regarded as perfectly formed cells; but they are, notwithstanding, particles of osseous matter; hence, it is clear that the production of bone is antecedent to, and independent of, cither secreting cells or cell-germs. And besides, these particles, by a careful and proper mode of cxamination, can be seen to produce, by their umion, lacuna; consequently the lacunx, instead of being a system of organs designed to produce bone, that is, instead of being the vital cause of the elaboration of the primary osseous particles, are only the effects of a subsequent arrangement and union of these same particles. So that the microscopic appearances presented by the earliest stage of the formation of bone in nowise agree with the cell-germ theory. A great deal of importance is attached by physiologists and pathologists, to the existence of a certain 
wranule or gramules in all kinds of corpuseles, their presence being always considered as a sure indication of the rital formative capabilities of all corpuscles possessing them; and henee, as might have becu expected, they have been diligently sought for in the lacuuce of bone. Professor Kölliker observes upon this subject, that "the contents of the lacunre, according to the later investigations of Donders, Virchow, and myself, appear very closely to resemble those of the cells of cartilages DURING LIFE; that is to say, they are a clear, probably viscid fluid, with a nucleus. If bone-cartilage be boiled in water or caustic soda for one or two minutes, these uuclei often show themselres rery distinctly; or opuque corpuscles make their appearance, which must be regarded as the contracted cell-contents, inclucling the nucleus, and analogous to the corpuscles in cartilage." See English translation, page 305. In this quotation, it is observed "that the contents of lacuma resemble those of cartilage-cells during life." Does this mean that the contents of both kinds of cells are living when compared, or that only those of the cartilage cells are? If the former is intended, the determination of this point appears to my common scuse to be entirely beyond the reach of experiment or accurate obscrvation. If the latter be intended, as I suppose from the scquel, then the incongruity is greater than that just complained of. There the observations referred only to parts sound and unsound, here the comparison is between living and dead ones. However, as it is a trauslation that I am quoting from, where it is possible that the meaning of the original may not be exactly rendered, so that this perhaps is not the precise meaning of the author. Now I may obscrve, with respect to the existence of any particular gramule or nucleus in these lacme, that I have 
myself scon nothing that struck me as giving them the appearance of nucleated cells, that is as compared with typical forms of these cells, such as the germinal resicle of the mammal, or the caudate cells occurring in the grey cerebral substance. Indecel they have always appeared to me, excepting as oceasionally represented in plates, to be most uncell-like, which from the observation just quoted ought not to be the case. For the contents of the lacunre being represented as clear, the nuclei contained therein onglit to have been distinctly visible without the severe expedients of fire and caustic. And then, after boiling the bone in caustic soda, Professor Kölliker observes, as a quod sequitur, that the opaque corpuscles which make their appearance must be regarded as the contracted eell-contents, including the nucleus. Now to me the more probable inference would be, that a nucleus, so delicate as to be before invisible or only dimly secn, would by such rough treatment have been utterly amililated; and that the granular material remaining after the coction would have been so ill-defined and irregular in its form as to allow of being considered anything which the experimenter wished. As for my own opinion upon the subject, I state positirely that if the experiment had been mine instead of Professor Kölliker's, I should have considered the result to be of no value whatever.

I know of no part in which the true nature of lacunx is so manifest as in the osscous laminæe spiralis of the human sulject. This part consists of two very thin plates, partially separated by canals containing the cochlear nerres. If a detached portion of one of these plates, where it is thimest, be examined by the microseope, it will be seen to be perforated by oval spaces of difierent sizes, eorresponding to the usscous lacune or bone-cells of the 
denser parts of this orman. The piece of lamina spiralis thus perforated has the appearance of a fragment of a foraminiferons animalenle. This form of lacuna scems to arise simply from the thickness of the plate of bone at this part being less than the transwerse diameter of an ordinary lacuna, so that organs like these, complete in all their dimensions, would have, in such situations, presented a number of bulgings on the surface of the osscous lamina, instead of rounded or oral spaces penetrating entirely through it. Now, if the function of these parts had been of vital importance, is it not more probable that they would have retained their integrity at so apparently inconsiderable a sacrifice, than that they would have been thes mutilated? Perhaps the identity of these foramina with lacunie will not be admitted ; then, as there is nothing else connected with these plates of bone which can be taken for bone-cells, the only conclusion to be arrired at would be that they were formed without the instrumentality of any such organism; and thus fresh testimony would he added to that which has been alrearly adduced, to prove that the form of osseous tissue, called by physiologists lacunæ or bone-cells, is not endowed with the rital power of forming bone, being itself a secondary and not a primary formation. Now, as the identity of these openings with true and perfect lacumx can scarcely be questioned, the last supposition is not likely to be generally maintained; and as the improbability of their function as formative organs will be shown better by considering what lacunæ are, than what they are not, I will proceed to the consideration of what appears to me to be their use; both as they exist in the form of foramina in the lamina spiralis, and as minute cavities elsewhere. Now bone, like erery other form of organized tissue, is in no part of 
its structure absolutely solid; comsequently vacuitics or interstices are an essential part of its morphology. Hence, onc purpose answered by lacune in common with Harersian cauals, medullary passages, and cavities containing medulla, is the prevention of a degree of solidity which would be incompatible with its nature as a constituent of an organized body. It is true that some of these spaces contain fat, and give passage to ressels, so that they liave a twofold use; but the others not containing these structures answer only to the one purpose here mentioned, which admits of positive and certain proof. From these considerations then, I hold it as a demonstrated fact that, at least, one use of the lacume of bone is to prevent such a degree of approximation of the particles of the earthy matter of which it is composed as would be incompatible with its rery organization. It now remains to cxamine how far this inferred fact agrees with the general and intimate structure of bone. A careful comparison of the vacuities in different parts of a bone, and in the bones of different classes of animals, will show that one description of space insensibly merges into another, and therefore that there is only one eavity in a bone whaterer may be its magnitude, and the complexity of its form, and that the Ilarcisian canals, lacuma, and canaliculi are merely its prolongations, assuming rarious shapes and sizes in different parts of a bone, according as circunstances may require. The transition of the central meclulla-canal in the shaft of a cylindrical bone into the irregular passages contained in its expanded ends; and the gradual diminution and conversion of these into the larger Haversian canals, is too obvious to need any further notice. But the transition of Haverian canals into lacune, and of these into canaliculi, will require the airl of the microscope, and the 
comparison of these parts in bones of different classes of animals. The bone of fish, presenting the greatest irregularity in structure, is well arlapted for the remonstration of this fact; and I know of no part better than the caudal fin-bone of the anchory, simply cleared of the surrounding structures, and examined in water or grlycerine. In some parts of this bone irregular spaces oceur, of a form inclining to that of an ordinary lacunx, and with canaliculi branching out from them; but they directly communicate with, and are of about the same size as, a small Haversian canal; so that, partaking equally of the character of both, it is not possible to determine whether they ought to be considered as belonging to the former or to the latter named parts. In other parts of the same bone minute spaces are scen, presenting fusiform cularecments, but prolonged at each end into a filiform structure. Some passages of a similar kind have no distinct enlargenent, but continue nearly of the sane size until they inosculate with canaliculi from other lacumse of a more characteristic form. In such instances the distinction betwcen canaliculi and lacune is so obscure that one cannot be distinguished from the other. These facts show that such spaces and interstices are of 110 vital importance, and agree with the general inference that they merely serve to give lightness to the denser parts of hone, and thus their office in the osseous tissue secms to be analogons to that of the meshes or areolie in other tissues of inferior density, such as ligaments, tendons, se. which are composcel only of fibrous material, which itscelf in a modified form enters also largely into the composition of the hardest pruts of the densest bones. The corpectucsis of this ricw is ("olroborated by the structure of the lanine spiralis, as just 
described. The foramina in the osseous plates of this part replacing the lacme as foumd in other bones, and presenting a decided form of osseous areolar tissue. It is also still more corroborated by the areolated character of the osscous tissue, erident in a rery early stage of development of the flat bones, as those of the cranium of foetal animals. In this case the recently ossified membrane has the appearance of being made up of meshes of various sizes produced by the interlacement of its fibres. The smallest meshes correspond to the lacume of perfect bone, and appear to result from the plaiting or interlacing of the individual fibres; the largest ones corresponding to Harersian canals, are of rery different sizes, and seem to be formed by a similar interlacing of fascicula of these fibres. This appearance is rery distinct in the ossifying cranial bones of a very young pigeon; also in those of the human foetus at a very carly period. The part where the ossifying process is just beginning to encroach upon the membrane, shows this fact most elearly. No preparation is necessary beyond remoring the integument, and putting the part into water or glycerine. The part of the process of ossification next to be considered relates to the chemical conditions under which the earthy matter is produced, and precipitated in a globular form. Now, as bone in most parts of the animal body is placed under the same anatomical conditions as the plates of shell, which, in the larger crustaceans, afford attachment to muscular fibres; and as the surfice of the lattcr can be proved by proper tests to be moistened witli a solution of an alkaline carbonate, and thus to be provided with one of the elements of which shell is formed; and as it is shown that the other elements are brought into contact with the former through the medium of the circulating fluid where, 
there results, after their decomposition, not only the necessary combination of lime with carlonic acid, but a compound containing also the requisite animal matter, it may be inferred that the coalescing particles of a similar composition, demonstrable on ossifying membranous tissues, are formed preciscly on the same principles, the membrane on which the phosphate and carbonate are precipitated presenting the alkaline carbonate, and the blood furnishing the eartlyy compounds. As respects the precise manner in which the alkali, demonstrable in the crustacean, is produced, there is the same difficulty in the vital theory as in the physical explanation, and for the present hoth are equally inexplicable. However, it is much more probable that the production of this alkaline carbonate should be the effect of electricity, than of the direct agency of life. Electricity is a well-known decomposing power, and electrical combinations are sufficicntly common in animal bodies. The electric power of the torpedo may be takcn as an example, but I am not aware that there is any proof that life, acting by itself, erer produced any of those phenomena which can be exhibited experimentally on inanimate matter. Now, in the process of calcification, as in that of ossification, the carbonate and phosphate of lime are always precipitated on a membranous tissue of some form or other, either presenting markings or wholly homogencons, this depending upon some particular function performed by the membrane, and not at all connected with the formation of shell or of bone. For, however disimilar these membranous structures are in different parts of the same animal, or in different animals, the deposit in its primary condition is always the same. After the first precipitation and coalescence of the carthy matter, either in the form of rings, or in that of 
arches is completed, the membrane on which this process has taken place becomes completely covered with a laver of bone; and thus is formed the outermost circle of an II aversian canal, consisting externally of a layer of membrane, and internally of one of bone. Within the latter another layer of membrane is formed, which becomes coated in the same manner by a laver of bone, and thus the process is repeated until the Harersian canal is completed. Now this arrangement of alternate layers of bone and membrane can be secu by polarized light distinctly in thin transverse sections preserved in Canada balsam or glycerine, by polarized light, the osseous portion appearing white, and the membranous, not polarizing the light, black. A difference of structure, as first pointed out by Tomes and De Morgan, can be distinguished also by the ordinary illumination, one layer presenting a more gramular appearance than the other. These lanella are scen distinctly only in the higher manmalians. They are searcely recognisable in the bones of cetaceans, and in those of birks they are absent altogether. 1 similar irregularity occurs also in respeet to the lacune, canalieuli, and Haversian canals. The lacunse and the canalieuli connected with them are subject to every possible degree of variety in different classes of animals. In the higher mammals the form of the lacune is somewhat clliptical, and the canaliculi procecling from them take chicfly two directions, namely, towards the centre, and towards the circumference of the IIarersian system to which the lacune belong. In birds, especinlly the lish Hying ones, as the conclor and alluatrose, the lacmic are generally rery small and of no particulat form, and the canaliculi, which are also very minute, diverge from them in all directions, and, communicating very 
fieely, appear to enclose in their circular meshes the romiled, osseons particles of which the bone is composed. In the bone of the palate of the Myliobatis, the lateme appear to be replaced by IIaversian camals, from which very larece canaliculi proced, so that there being ouly oue set of passages besides canalieuli, either lacume or Haversian canals must be wanting. The Haversian canals, and Haversian systems, as they are called, present great variety. Some of the most irregular and ill-defined of these canals are called Iaversian spaces. As to the Haversian system, it may be observed that in some bones they are distinct, and separated by interstitical portions of osseous tissue; but, in others, as in those of the bird, they are blended together. Besides, in the bones of fishes generally, and in some of those of the larger reptiles, as the crocodile, one part of a specimen will present Iaversian systems, whilst in other parts they are altogether absent. Lastly, as a sprecimen of bone remarkable for the irregularity of its various componcut structures, I may mention the cementum of ruminants, which often presents Ifaversian canals, lacunce, and canaliculi, all of the most irregular and apparcutly abnormal character. Indecd, thin sections of some of the densest of the sclerous regetalble tissues have, excepting the fact of the total absence in those of Havexsian canals, as much the appearance of ordinary bone as this substance. And in good specimens of the sclerous ti.sue in progress of development, the lacume and canalieuli can be seen to be formed by the partial coalesence of previously existing sclerogen particles, in the same mamer as was noticed of the osseous particles, mhen describing the lacune and canaliculi of bone. The innermost portion of the shell of the rimipe peacl-unt is well adapted for the examinaticn of this process, especially if 
the part be examined in glycerine. And, as this tissue polarizes light much better than the phosphate of lime, either in perfectly or imperfectly formed bone, the polariscope can be employed with greater adrantage in inrestigating the structure and the mode of formation of this form of regetable tissue than in bone. I have merely mentioned this regetable substance incidentally, being led to it by its resemblance to bone; but I hope to consider it more fully at some future period. I slall next proceed to consider the formation of some of the less dense kinds of tissue. Having, in the preceding pages, shown, as far as experiment and induction can show, that the molecules of what are called hard tissues, ore their curvilinear disposition to the direct operation of physical force, it may reasonably be expected that the molecules of the less dense ones owe their curvilincar arrangement to the same canse, and that the process of coalescence above described is as applicable to soft as to hard tissues, whether they be animal or regetable provided only, in both cases, these molecules are brought under eireumstances alike favorable for its operation. As it is certain that the elenentary constituents of these two classes of tissues, before they are combined to form living organs, are alike affected by gravity, it is inconceivable, that a difference in this respect should be oceasioned merely by these same dements being associated with different proportions of fluid, or that the molecules composing a spherule of globular (arbonate of lime, and thowe composing a spherical particle uf mucus, should, under similar circumstances, be brought ('xactly into the same form by the ageney of the most dissimilar forees; and more especially, as it has becur shown by the plainest anguments, that, the force of sravitation being all that is necesary to give the particles 
of matter exposed to its full influence their globular form, any assumed vital interference, would be superfluous and inconsistent. Dr. Carpenter observes, in reference to one form of shell-structure, the prismatic cellular substance, " that such is its resemblance to mucous membrane that it may be considered in the light of a calcified epithelium." With this resemblance in structure, no doubt Dr. Carpenter would iuclude the idea of identity of the forees employed in their formation. There are, however, two other struetures, one hard and the other soft, whose resemblance is more striking than that named by Dr. Carpenter, which I will briefly consider. One is the common integument of mammals; the other the dermic part of the shell of crustaceans. In both there is a deep-seated layer of membrane -basement membrane-in contact, by its superficial surface, with rounded particles of various sizes; next abore is a layer of globular bodics containing granules of different forms and magnitudes; and, lastly, a corcring of scales or laminæ, this depending upon circumstances. Now, organs with so many points of resemblance in structure, and both performing the same function, would be anomalous, if they were formed upon an entirely different plan, and under the influenee of agencies of a diametrically opposite character; that is to say, if the comporient elements of the former should owe their globular form to a vital force residing in these globnles, whilst it has been demoustrated, that the elements of the latter owe their arrangement in the same form to a force entirely physical; and the more especially so, as there is 110 other differenee in these tegunentary structures, but that oceasioncel by the presence of earbonate of lime in the onc, and its absence from the other. Howerer anomalons it may appear that two such organs as those just mentioned 
should be formed on different principles, it would appear much more so, if these two opposite principles were employed at the same time in the formation of different parts of the same integument, this could not fail to be the case in the skins of those reptiles, which, as in the toad, contain in some parts, carbonate of lime, resembling shell, whilst in other parts this sulsstance is entirely ajsent. See a paper of mine on the Skin of the Toad in the "Microscopical Journal.' I may notice here, that this explanation is intended to apply only to the histology of tissues, and not to their physiology; that is, to the manner in which they are formed, and not to the manner in which they act. To take in illustration of my meaning the three kinds of corpuscles - the common mucous corpuseles, the ciliated mucous corpuscles, and the cerebral corpuscles, I may observe that, although I consider each kind to acquire its form by the operation of the same physical force, and that this force, in all of them, acts exactly in the same manner, I do not by this intend to imply, that the function of each, whether obscure or patent, is necessarily a physical phenomenon,- - this is not a part of the subject-matter of these rescarches. However, if the cause of these phenomena is physical, it is certain that the mamer in which they are produced would require for its comprehension a knowledge of the different departments of physical science,-chemistry, electricity, and the molecular condition and capabilities of matter more refined and more exteusive than is at present possessed by philosophers. And as life, considered abstractedly, is altogether incomprehensible by our senses, it is probable that all future advances in physiological science will be little more than fresh disclosures or clearer views of physies and the sciences therewith associated, as comnected with orga- 
nized bodies. This view has certainly the sanction of experience. As respects the fact of coalescence in soft structures I may observe, that the proofs cammot be expeeted to be so demonstrable as in hard ones, in consequence of the process being in the latter sufficien tly slow aud gradual to afford ample opportunities of observing it through all its stages, whilst in the former it would take place too suddenly to admit of being observed in detail, one part of the process following so closely upon the other as to be distinguishable only as one physical act; consequently, in the case of coalescence of the softer tissues, other evidence besides that furnished by microscopical examination must be resorted to. IIence, I may observe that the words hard and soft are merely relative terms, implying different degrees of cohesion; and therefore, as it camnot be supposed that the physical forces acting upon the particles of the harder substance, and learling to their coalescence, ean be different, or can act differently upon the particles of the softer ones, leading precisely to the same result, (namely, in both cases to the like incorporation of smaller particles into larger ones,) the process of coalescence in both substances must be identical. I may notice also, in reference to the appearances presented by growing cartilage-this being a structure in which development by self-multiplication of its cells is considered to be well marked-that if an isolated piece of cartilage in this state were examined with the microscope, by the side of some coalescing globules of carbonate of lime, it would be just as difficult, in the one case as in the other, to say, from mere inspection, whether the larger rounded particles are the result of coalescence, or of cell-multiplication by division. Howerer, if the slide containing the globules of carbonate of lime be so moved that the smaller globules 
can be secn with the larger ones, then the nature of the appearance becomes obrious. Just so with the growing piece of cartilage. When it is so shifted that its growing circumferential part is brought into vicw, the corpuscles can be observed gradially to become smaller and less perfect as they approach the margin; thercfore giving in this respect the same evidence of coalesence as the globules of carbonate on the slide, on which the larger are known to be formed by the union of the smaller. Besides, if the growing circumferential part of this pice of eartilage had increased by the addition only of cells dividing each into two, and these again, after having attained a state of maturity, dividing each into two more, and so on, the margin of the cartilage ought to give much better indications of the fact than the central portion, whereas the rererse is the ease, the margin presenting nothing but small, incomplete, and irregularly shaped particles. The growth of cartilage, as here described, cau be very well seen in the extreme phalanges of the toes of a frog whilst in progress of development from the tadpole-condition. But cartilage, being made up of particles, sometimes not rery dissimilar to those of the surrounding parts, is not so well calculated to give positive evidence either in favour of one or the other view of development, as some other soft structures-as, for example, the branched pigment-corpuscles. I have chosen these corpuscles for examination, these being formed by the aggregation of opaque black particles, can be distinguished in a rery carly stage, and when their size is very small; corresponding in this respect with the calcarcous particles of shell and bone. The accompanying plate (see fig. 9) is an accurate representation of these so-ealled eells, as seen in the periosteum of the fang of a tooth taken from a foctal calf. In this 
specimen the isolated particles of pigment can be seen cither scattered about irregularly, or arranged in lines, prior to their union to form a corpusele; hence these irregular bodies furnish the same evidence of being formed by the mion and coalescence of pre-cxisting particles, as the irregular stellate carthy bodies before noticed in shells and bone do. Whilst there is nothing in their appearance which ean give the least semblance of probability to the generally received opinion that the branched and dotted lines, as represented in the figure, are offsets or shoots from a ecntral formative organ or eell-germ. I may observe that I have the specimens from which the

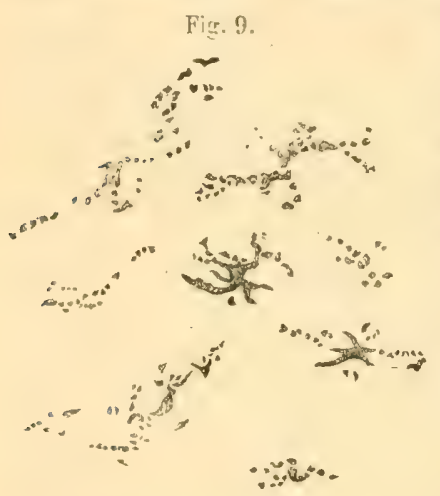
drawing was taken, and that similar ones can easily be obtained from very young animals, especially from reptiles and fish, and from the choroid coat of foetal mammals. Also examples of molecular coalescence in the softer tissues, equally striking, can be seen in the developing hooklets of the cysticercus cellulosæ as described by me in a paper' in the 'Philosophical Transactions' of 185\%. These organs being composed of a very highly refractile material, dissimilar in appearance to the adjacent structures, can easily be distimguished in very minute quantities; and these having a spherical figure, admit of being traced through all the changes of form attending the coalescence of the first visible particles, up to that of the recognisable parts of a hooklet. The following is the description of the development of these 
oreans, from the paper just referred to, written as early as i85.5, before I was aepuainted with the coalescing property of the globular carbonate of lime. "The primary condition of these hooklets is very remarkable, cousisting merely of a confused and irregular group of rery bright particles of a pale straw-colour, which are of various shapes; but still all have a conton more or less curvilinear, and the smaller ones are of a splerical figure. Their size varies from about that of the third part of a handle of a perfect hooklet, to a particle so minute as scarecly to be appreciable by the highest powers of the microscope. There are all the intermediate sizes between these extremes. Notwithstunding, howerel, these extremes of size and form, all these particles possess the same optical and physical properties, so as to be perfectly recognisable both when apart and when joined together in the perfect looklet, in which the larger pieces, formed obviously by the coaleseenec of smaller ones, can be seen fused (as it were) together, more or less completely in a nerly-formed hooklet, where frequently the joining is so incomplete as to amount to little more than mere apposition of the coalescing particles." Now, I may observe that there are only two interpretations which cau be given of these appearanecs. Either they are in reality what I have described them, or they must be looklets in a state of degeneration, that is undergoing a process of molecular disintegration. The examination by the microscope would furnish no clew to the correct decision of this question, as the microscopic appearances would, in either case, be similar. But, as it can be seen by referring to the original paper, that this appearance camnot reasonably be supposed to be due to degencration, it may be inferred in this case to be indicatire of coalescence. For, in the first place, the eysticerei 
were in a rery carly stage of derelopment, as can be seen by their size, which in the plates in the 'Philosophical 'Transactions' is giren, and the figures represent eutire auimaleules; also, by the diminutive size of the part containing the calcareous particles, called the neck, which is an infallible proof of their immaturity, being, in these specimens, scarcely at all developed; and by there being, in two of them, only a few of the hooklets, the regular number in the perfect animaleule being twenty-six; and in the second place, I may observe, that the hooklets, which are represented in the plates, were not detached, but are dramn as they were seen in their natural situation in the unmutilated animaleules. And having besides the specimens by me from which the drawings were taken, I am enabled to give satisfactory proof that neither the descriptions nor the plates are marle up partly from facts, and partly from imagination. I may also notice, that it would not have oecurred to me that these changes conld, by any one, ever have been attributed to a state of degeneration occurring, as they do, in cysticerei which had not yet got the full number of these organs, had it not been stated that such was the explanation given by some pathologists.

The next part, showing the fact of molecular coalescence, which I shall describe, will be the erystalline lens; and, in cxamining its true structure and mode of formation, I shall follow the same rule as that observed in the other tissues, namely, that of selecting such specimens as will afford the best opportunity of secing, in as natural a state as possible, the earliest stage of its derelopment, and the changes of structure dependent thereon, without the necessity of employing such chemical substances, or mechanical mutilation as cammot fail to render the appearances presenting themselres during the examination 
umnatumal; and thus more likely to gire false ideas than correct views of the structure of this organ. Of all the lenses which I have cxamined, I have met with none which answers the purpose so well as the leus of a young sticklcback, of abont three quarter of an inch or an inch long, but it should not be more. This part being of small size, admits of being seen cutire without any further dissection than that necessary to remore it from the eye of the animal, and can be cxamined perfectly fresh, which in this case is indispensable; and as these animals are everywhere to be met with, the examination is within the reach of any one disposed to make it. Besides, I may obscrve, that if it be done with sufficient care, and not in an imperfect manner, as too many microscopical examinations are, it exhibits some most interesting and beautiful physical facts. The following is the manner in which the examination may be conducted. The head must be taken off whilst the animal is alive, and an eye removed without delay, which, being torn open by a sharp scapel, the leus enclosed in its capsule will escape, and is to be put immediately into a shallow cell filled with water, then a thin glass corer being placed orer it, it must be examined at once. A lialf-inch lens at first, and afterwards a quarter-inch, are the best magnifying powers for the purpose, and it will, of course require to he seen by transmitted light. I may observe that the leus of this fish is nearly of a spherical figure, and that it is divided into an equator and two poles, the plane of the former being at right angles with that of the latter. The superficial layer of fibres, those especially recpuring notice, and proceeding from each side of the equator towards the poles, may, from this circumstance, be divided into an anterior and a posterior set, each 
covering its respective hemisplere, and converging towards its pole, near to which the fibres appear to dip into the substance of the lens, and insensibly to blend with the nucleus. Now, to obtain the best view of these fibres, and the manner in which they are formed, the lens, whilst being examined, must be placed with either its anterior or posterior surface towards the obscrver, and with its polar axis corresponding to that of the microscope. In a few seconds after the lens, still enveloped by its capsule, has been in the water, the latter will become visibly increased in size, and a space will begin to appear around the edge of the lens, between it and the inner surface of the investing eapsule. The lens itself will also become cnlarged, and continue cnlarging, so long as it is acted upon by the water, until its capsule, becoming incapable of further distension, will burst, and the lens will be either entirely or partially extruded. The time which will clapse after the contact of these parts with the water before this takes place, will depend upon the age of the fish from which the eye was taken, varying from two minutes in a very young fish, to five in an older one. It is at once obvious, that this distension of the capsule, and enlargement of the lens under these conditions, is the effect of endosmose. If the examination is made before auy distension has had time to take place, clear, more or less compressed globular particles of an oily-looking fluid, and of very various sizes, will be seen throngh the capsule lying close to its deep surface. As the distension increases, a clear space around the margin of the lens, between it and the capsule, comes into view, and the before-named oily looking particles becomes more distinct, having increased in size, and apparently in number. They still present no kind of regularity either in shape, size, 
or position, excepting that they all have a romded form, and the same clear and pale aspect. By a careful adjustment of the focus, rows of sharply defined lines placed clowe together, and at right angles with the direction of the lens-fibres, resembling the marking of very fine voluntary muscular fibre, will be visible. (See $c$, fig. 10.) These lines, howerer, are sometimes first distinguishable as long closely set strix, rumning more or less parallel with the sturface of the lens. This is not their natural appearanec, but arises from the rows being pressed together, and thus the lines of several are made to appear continuous. Such are the appearances risible beneath the capsule of the

Fig. 10.

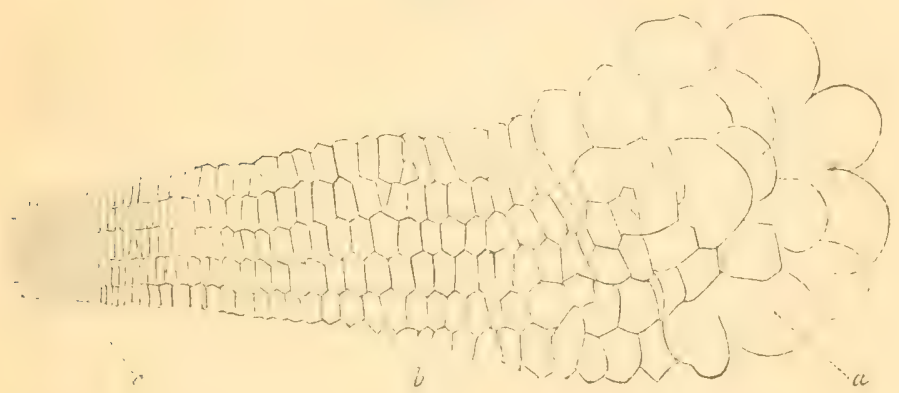

lens prior' to its becoming ruptured. "After this, all the appearances above described become much more distinct, and the causes producing them obrious. Fig. 10 is an accurate represcutation of these parts, as seen an hour or two after the bunsting of the capsule, magnified three hunded diameters, and drawn with the cancra lucida. In this stage of the examination, the oily-looking globul('s, in their turil, have become rery much enlarged, by the cudosmose still going on. These are indicated in the 
diagram by the letter $a$. Next to these are the globules still somewhat compressed, but yet rery much distended, shown by the letter $b$. Before the absorption of water by these particles they were apparently empty, and the walls of the contiguous ones being then in contact, the transverse marking, lofore described, was produced. Still, nearer the centre of the lens, the transverse lines remain; the sides of these globules having become adlerent, and consequently their eavities obliterated. (See letter c.) And, lastly, again, nearer to the centre, all appearance of lines, both transverse and longitudinal, has clisappeared, and the structure is entirely homogeneous. This part is not represented in the accompanying figure. During the further distension of these globules the transrerse lines in some of the rows can be secu gradually to disappear, and then these rows of compressed globules assume the appearance of tubes with bullous extremities. It is this appearance which probalbly led Kölliker to describe the "fibres of the lens as tubes, having thin walls, which are flexible and soft, and possessed of a considerable degree of toughmess, with clcar, viscous, albuminous contents, which, when the tubes are torn, escape from them in the form of large irregular drops." This is just the appearance presented in the figure at $a$. Now, as my own observations do not in the least agree with the opinion expressed by Professor Kölliker, concerning the origin of this albuminous fluid, and the tubular character of the fibres of the lens, and as these are points of ereat importance in respect to the mode of its formation, I camnot do less than gire my reasons for dificring from so high an anthority. Now, as this same clear, viscons oily-looking fluid, although in smaller globules, is risible thiongh the capsule of the lens, and before it has liccome 
in the least distended, and where no mechanical injury had been done to it, it may be concluded, that this is its nomal situation and natural appearanees. And, moreover, as in this case, no force could have been employed eitler in kind, or in degree, sufficient to lacerate tubes, whose walls were possessed of a "considerable degree of toughmess," and thus cause the eseape of their contents ; it is impossible that vessels from which, under such circumstances, the contents had escaped, could have possessed the property of toughuess; hence, there is an evident incongruity between the alleged fact of the toughness of these ressels, and their rupture under the cireumstances here mentioned. Moreover, it can casily be shown by examination of the lens, a short time after the rupture of its capsule, that the "large irregular drops" reforred to by Professor Kiblliker, have a dianeter many times greater than that of the fibres of the lens; and, consecpuently, if these had becu tubes, as there is no reason to suppose they are, grobules of such dimensions could never haveluecn lodged in their interior. It is, therefore, obvious, that the views of Professor Kölliker conceming the minute structure of the lens, being entirely at variance with facts, are unteuable. In concluding the account of these appearanecs, I may observe that, as the form and size of namy of the parts extruled from the capsule of lens vary according to the time the cudosmose and conscaucut distension has been in operation, the microscopical cxanination will require to be nade almost continuously. This is the only way in which a collect knowledge of these appearances (ain be obtrined, as after the cessation of the curiosmose, the globular particles become gramular, the transicrse marking indistinct, and the ecucral aspere of all the parts,

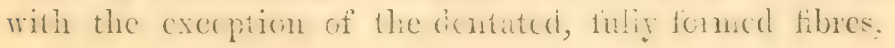


confused and ill defined. The exact form of the lens in these fishes, with the arrangement of its fibres, as given at the commencement of this description, ean be best scen in eyes which have been kept in glycerine for several months. In some specimens thus treated, the stria in that part of the converging fibres near to the equator of the lens can also be seen, but not sufficiently to gire any idea of their true structure, and nothing definite is observable of the clear viscous, albuminous particles so distinct in the perfectly recent lens, these having become granular and amorphous. I may mention, that in all the examinations I have made of the lenses of these fishes, I have never met with the layer of nucleated cells seen in the eyes of mammals close to the deep surface of the capsule; in some instances there have been regular corpuscles, but these were found only occasionally, and without any definite arrangement or situation; and I have no doubt but that they are accidental, and are only the white corpuscles of the blood which have escaped from the ressels ruptured in remoring the lens from the eye, especially as I have found the red corpuscles with them. Having now described thee parts as minutely as appears to me to be necessary, also the manner of examining the lens, both in its recent and preserved states, I will consider its development in relation to the process of molcenlar coalescence. Tow, commeted with the albuminous particles situated on the surface of the lens, between it and its capsule, the following facts require notice. First, their extremely rariable size, the smallest being too minute to adinit of accurate measurement, the largest, in the melistended condition, being about פon, th of an inch in diancter, and the rest being of all sizes intermediate between these extrenes. Secondly, the perfect resemblance of these purticles one to another 
so far as is possible, considering their difference in sizc. Thirdly, the same property possessed by all, of imbibing water and swelling out to several times their original dimensions. And, fourthly, their identity in structure and appearance with those which, after having become arranged in lines, form the first portions of the radiating fibres of which the future lens is to be composed. (See fig. 10, in which some of these forms are represented after having been acted upon by water.) The free particles of different sizes above noticed, are not, however, shown in this figure. Now, considering the appearances presented by these particles, and weighing all these circumstances together, it is impossible to question the identity of the larger detached globules with those which have become stationary, and are beginning to take the linear arrangement; and therefore only one point remains to be determined, and that is, whether the larger of the intermediate sizes of the globular particles assumed that size at the instant of their coming into existence, or whether they are the result of the coalescence of pre-cxisting minuter forms of the same composition ; that is, of smaller globular albuminous particles similar to those which are still present with them. As the kind of evidence necessary to decide the question is not in this case of the same demonstrative character as that which was adduced in answer to a similar question respecting the coalescence of small particles of carbonate of lime to form larger ones (see page 12), its decision must, in some degree, depend upon the relative value of the evidence adducible on each side. Now, on the side of coalescence there is-First, the fact before referred to, showing that there is such a process as coalescence eren of the particles of hard substances. Secondly, that the effects of this same proress admit of demonstration in the 
ealcarcous particles of organized tissues. And lastly, that there is ocular proof of the same process in softer substances, as shown in the development of the hooklets of the Cysticercus cellulose. Whilst in support of the opposite view, there is not one fact of a demonstrable character which can be adduced; hence, with the entire weight of evidence in farour of the coalescing process, its operation may be fairly considered here to be assatisfactorilyproved in reference to the formation of the crystalline lens as it has been shown to be in the other structures which have been described. But as these observations only apply to the formation of the large albuminous globules, it will be necessary to explain also the transformation of these globules into transverse strix ; then the disappearance of these strix ; after that the appearance of longitudinal zigzag lines between the converging fibres; and, lastly, the entire obliteration of all marking at the central part of the lens. The globules as thus formed appear then to be merely rounded masses of an alluminous material, with a dense and rery dilatable extcrior lamina. The greater density of this layer is the natural effect of the attractive force to which the formation of these, and all other globular hodics constructed in the same manner, and on the same principle, is due. And without doubt this is the mode of formation of the peripheral layer of all corpuscles which have received the appellation of "cells," this layer being the cell-wall, or cell-membrane, as it is frequently called. These globular particles are, in the entire eye, contained in an elastic capsule-the capsule of the lens-where, at first, they are placed without any apparent order, but afterwards they become arranged in converging lines. (See fig. 10.) Now, as in the growing condition of the lens fresh portions of solution of albumen, forming new globules, will 
be constantly added to the contents of the capsule, the globules must press one against another, and thus their grlobular form is seen to become destroyed, and to be replaced by the polyhedral form. Besides this, it can be seen by inspection of fig. 10 that they are smaller the nearer they are to the centre of the lens, and appear to have suffered compression, especially in the dircetion from without to within, and therefore they must have lost some part of their contents. Now the fact of these cells becoming so rapidly enlarged by the imbibition of water, prores that they retain the albumen in solution, and only lose the water; consequently, as their sides in their natural state are brought nearer together, the fluid within them must become more and more inspissated, until nothing remains but their dense exterior and the portion of albumen which was in solution in the original albuminous globule. This portion of albumen now blending with that which before formed the wall of the globule in which it is contained, a permanent addition is made to the radiating fibre of which the individual globules are parts. The close apposition of the walls of a multitude of such globules, with the inspissated solution of albumen in their interior, constitutes the beantiful transwerse marking represented in fig. $10 c$. And the fact of these becoming separated by the imbibition of water is an experimental demonstration, that the cause of the collapse of these cells is the reverse of the effect produced upon them by the action of the water as applied in the experiment, namely, the loss of their fluid, probably by exosmose. Whilst the transverse marking exists in the radiating fibres, no defined scrration of their edges is apparent, but as the transrerse lines disappear in consequence of the perfect blending together of the contignous particles 
with their now solid contents, these edges become sharply serrated. Lastly, in and towards the centre of the lens, where the coalescence is complete, the dentate lines which indicate the lateral extent of the radiating fibres become obliterated, showing, at this part, a thorough incorporation of the material of which they are composed, and with this the process of molecular coalescence of the lens terminates. Mr. Numneley, in a paper contained in the 'Quarterly Jourual of Microscopical Science' for April, 1858, gives a plate of the epithelial cells from the posterior part of the capsule of the lens of a sheep, showing lines of cells, concerning which he observes that "were it not that similar cells are found in Petit's canal I should feel inclined to think that they are not merely the means of nutrition to the lens, but that they are lens-fibres in progress of development." This observation seems to me to show that Mr. Nunneley would have persisted in entertaining his first impression as to the nature of these corpuscles, which I have no doubt is the right one, had he not been diverted from this view by some preconceived physiological theory concerning the nutrition of the lens. The dentate lines, corresponding doubtless to the radiating lines of feeble attraction in the artificially formed calculi, are the last to become obliterated; and this does not take place until the predominant force is the attraction of tenacity. These lines are distinctly serrated only in the fish, being merely undulating and irregular in mammals. The circumstance of irregularity in these lines, as contrasted with that of the artificial and some of the natural products, is probably to be accounted for by the difference of mechanical conditions under which in the two cases they are formed. These conditions in the former, - the artificial product-applying at the same time to the entire spherical 
mass, but in the latter-the lens-being limited only to very small portions of lens-substance. It must also be observed that the process of coalescence is accompanied by a chemical change in these albuminous globules, as is shown by boiling a leus for a considerable time in water, when the peripheral and imperfectly coalesced portion will by its opacity indicate the presence of coagulated albumen, whilst the central and adjoining parts will retain their transparency, thus sceming to partake more of the character of horn than of coagulated albumen. Now, on reviewing this account of the formation of the crystalline lens of the fish by the process of molecular coalescence, and contrasting it with the simple manner in which artificial globules of the same size, as well as the otolithes of these same fish, are formed (which can be shown to be formed by coalescence), this will appear to be a very round-about way of making a globular body, which according to the explanation of the mode of formation of artificial and other calculi, seems possible by a method so very simple and direct. And if such trausparent globules as those produced by the artificial process could have served for the purpose of vision, this objection would have been just. But these former giobules being of necessity so formed that their centre is the least dense, and their circumference most so, $-\mathbf{a}$ form of construction exactly the reverse of that of the lens,-could never have sufficed to bring the rays of light to a focus, and therefore they would be totally unfit for vision. Hence when vitality is engaged in constructing such a lens as that just described, and the principle of universal attraction has to take chief part in the process, the tendency of this attraction to form just such a lens as that which would be constructed by the artificial process will require at every iustant to be opposed. 
(Incleed gravity is not a universal influenee, if its operation is to be cxcluded from the process by which the lens of the eye is formed; and its laws are not those which mathematicians and philosophers have unanimously considered them, if a lens formed in complete obedience thereunto would not have been, in respect to rision, a useless one.) Hence the impossibility of anything short of intricacy in the mechanism of an organ constructed under circumstances where the principal force employed in the process is always working in the wrong direction, and is therefore requiring constantly to be opposed, and to be put into the right track. Now these ends scem to be attained in the case of the crystalline lens, by its being composed of globules of such a composition that they do not coalesce until the more fluid part has been removed; and thus in place of being made up at once of all the molecules entering into the composition of the globules at first collected together, as in the artificial calculi, it is formed only by the gradual coalescence of their denser portions, and especially of their outer laminx. Besides these physical peculiarities, it has been observed that the coalescence is accompanied by a chemical change in the coalesced particles, as is shown by the fact of their retaining their transparency after being boiled in water, and by their density becoming increased as the coalescence progresses, and attains its ultimate condition of completeness in the centre of the lens, an effect the opposite of that which would have been produced by the uncontrolled action of gravity. Hence in the gencral arrangement of the particles composing the crystalline lens, the two attractions mentioned at pages 32 and 55 - the attraction of tenacity, and the attraction of gravitation-mustliave acted inversely as cach other. But the latter being unirersal, 
and unceasingly in action, would require no fresh arrangement of conditions necessary for its production, whilst the former being entirely a local influcnee, and exerted for one purjose only, and with an effect varying at every instant, would require the chemical condition upon which it depends to be also constantly varying. Now, in the formation of the crab- and oyster-shell these conditions, and the manner in which they operate, are to a very great extent apparent; but in the case of the formation of the material composing the lens, the chemical process is not, at least in the present state of science, at all clear; and doubtless a most exact cliemical inrestigation, directed especially to this point, would be required to make it so. However, one question presents itself, whether, is that which has the power of bringing together these conditions, chemical and mechanical, and exactly adapting them to the necessities of the ease, resident in and exercised by the material of the lens? or, whether it is the effect of a separate and independent principle, acting upon this material, throngh the instrumentality of well-known influenees, called the properties of matter? If the affirmative is to be given to the first part of this question, then I cannot see how it is possible to deny the existence of an amount of intelligence and skill in the cells of the lens of the eye of any being, infinitely surpassing that of the individual to which it belongs. For how condl the particles composing these globules so regulate their density and curvature, that all the rays passing through them should be brought colourless to one point, without possessing a perfect linowledge of the laws of dispersion and refraction of light? or', how could the dereloping particles, oceupying similar points on opposite sides of the axis of the same lens, or points having precisely the same relatire position in the lenses of both eyes, preserve always a like 
form and density, unless these developing globules were severally acquainted with the changes of form and structure going on simultaneously in all globules similarly situated? Whereas, if the affirmative be given to the second side of this question, then the rounded form of the erystalline lens will be due to the operation of the same physical forces as that of the shells of molluses and crustaceans before described. And so with respect to rotundity of contour generally, organic will agree with inorganic bodies; the spherical figure of both when placed under circumstances where their component molecules are affected more by the mutual attraction they have one for another, than by that of remote objects being alike dependent upon gravity; and thus the analogy of nature, in regard to this fact, is complete; and the same Infinite power and wisdom which are displayed in the government of the inorganic world according to fixed laws, are also equally displayed in the arrangement of the material parts of organized beings, according to the same laws. 




$$
+d 8
$$


